Aus der Klinik für Dermatologie, Venerologie und Allergologie (Prof. Dr. med. M. P. Schön) der Medizinischen Fakultät der Universität Göttingen

\title{
Anti-entzündliche Wirkungen in vitro durch Dimethylfumarat und NF-kB-Inhibitoren
}

\author{
INAUGURAL -DISSERTATION \\ zur Erlangung des Doktorgrades \\ der Medizinischen Fakultät der \\ Georg-August-Universität zu Göttingen
}

vorgelegt von

Anna- Carina Hund

aus

Höxter

Göttingen 2018 
Dekan:

Prof. Dr. rer. nat. H. K. Kroemer

Referent:

Prof. Dr. med. M. P. Schön

Korreferent:

Prof. Dr. H. Reichardt

Drittreferent:

Prof. Dr. T. Meyer

Datum der mündlichen Prüfung: 20. September 2018 


\section{Inhaltsverzeichnis}

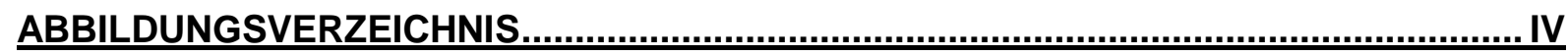

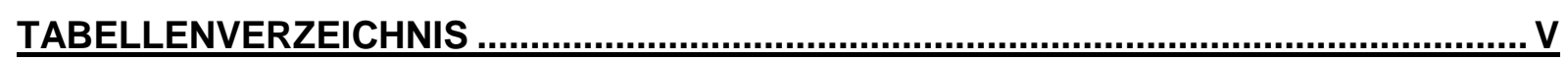

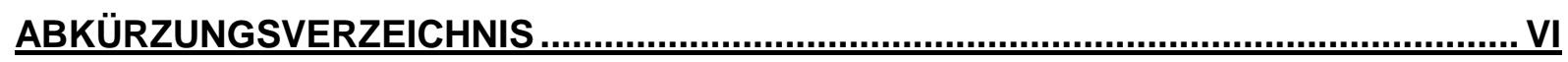

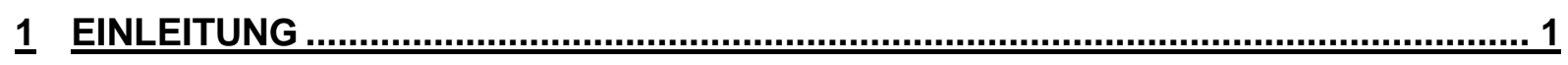

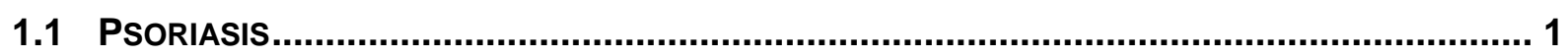

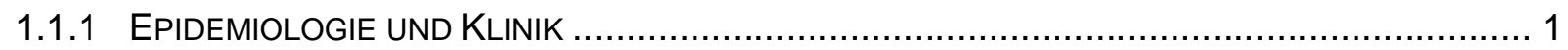

1.1.2 PATHOGENESE DER PSORIASIS ………………………………………… 2

1.1.3 ZELL-ZELL-INTERAKTION ZWISCHEN ENDOTHELZELLEN UND LYMPHOZYTEN.................... 5

1.1.4 THERAPIE DER PSORIASIS ........................................................................ 7

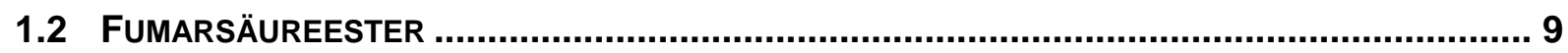

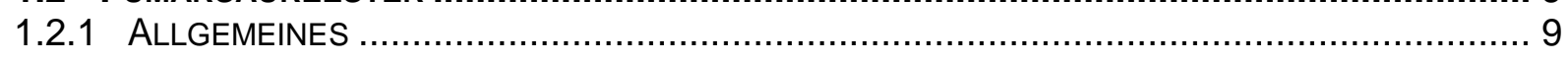

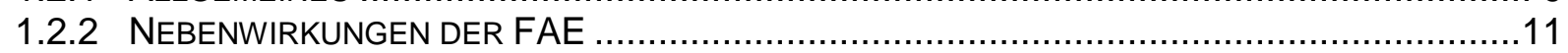

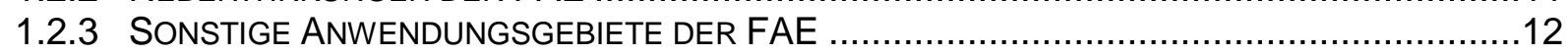

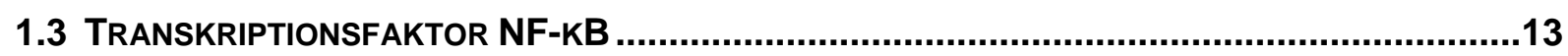

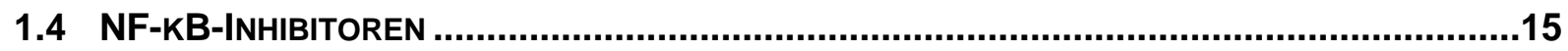

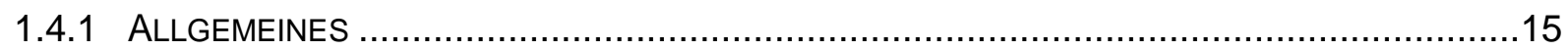

1.4.2 KINK-1 (KINASE INHIBITOR OF NUCLEAR FACTOR-KB-1) …….................................16

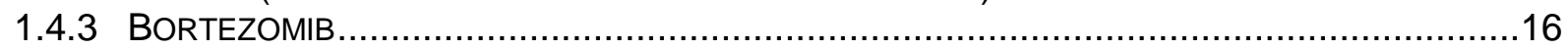

1.5 ZIELSTELLUNG DER ARBEIT ...................................................................................18

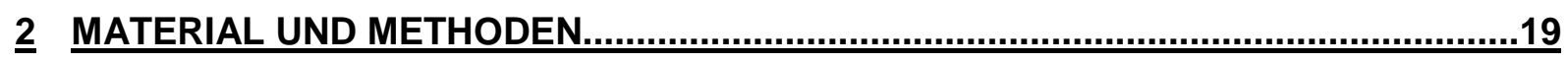

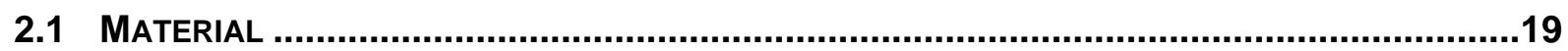

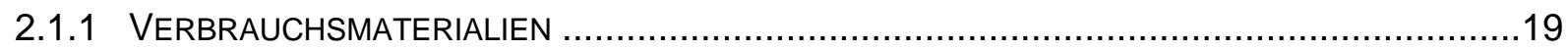

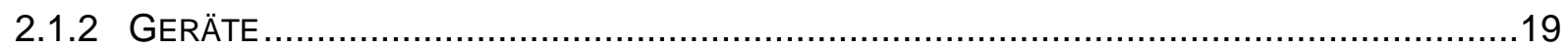

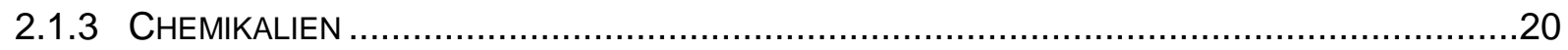

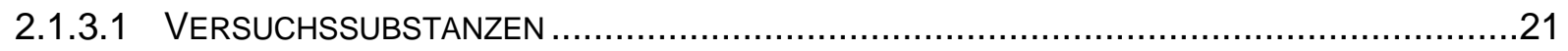

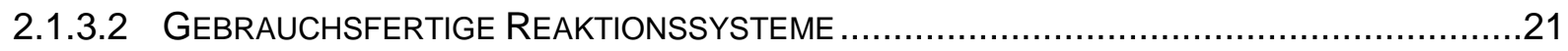

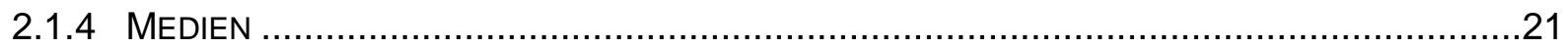

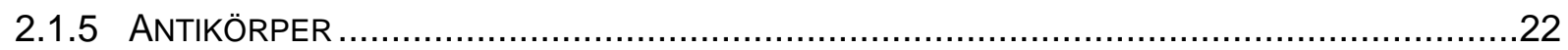

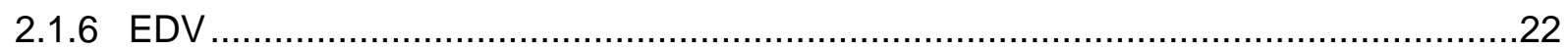

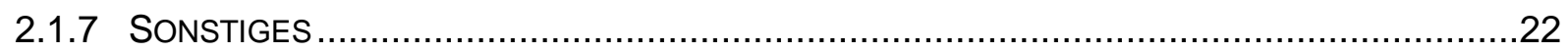

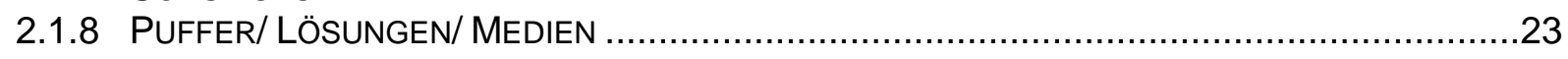

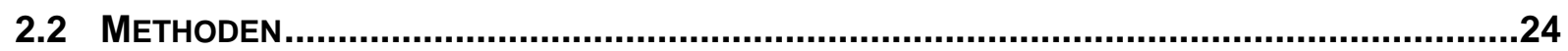

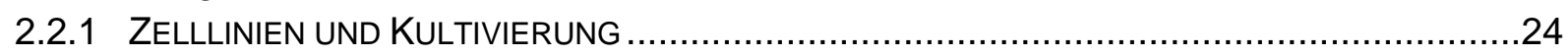




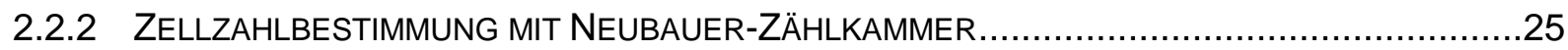

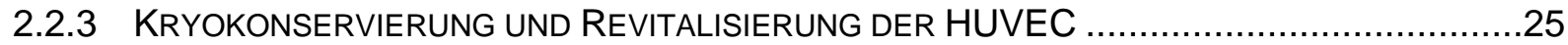

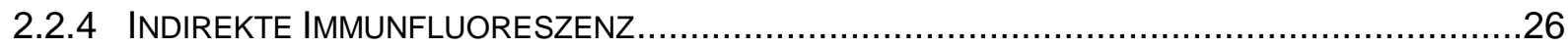

2.2.5 POLYMERASE-KETTENREAKTION (POLYMERASE CHAIN REACTION, PCR) .......................28

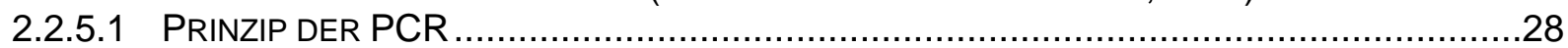

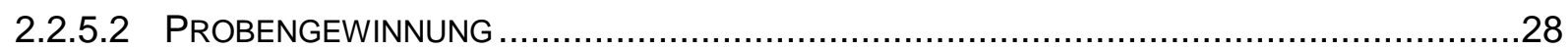

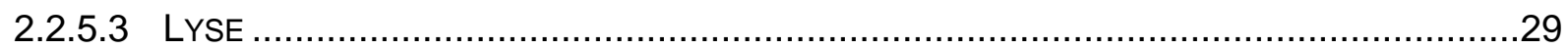

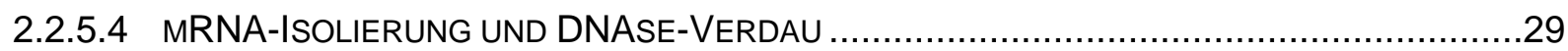

2.2.5.5 PHOTOMETRISCHE BESTIMMUNG DER MRNA-KONZENTRATION UND REVERSE

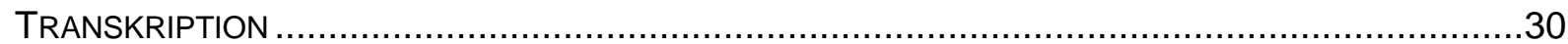

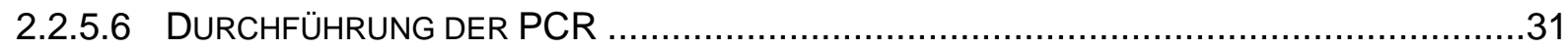

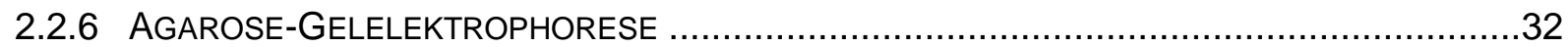

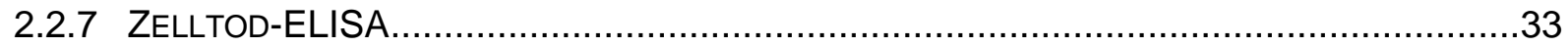

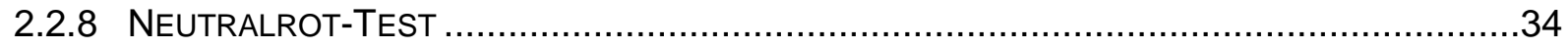

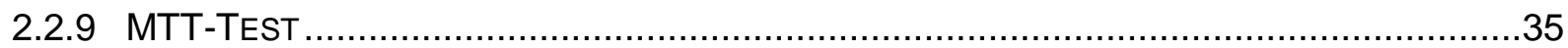

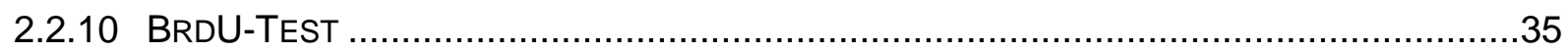

2.2.11 DURCHFLUSSZYTOMETRIE (FLUORESCENCE-ACTIVATED CELL SORTING, FACS) ............36

2.2.11.1 PRINZIP DER DURCHFLUSSZYTOMETRIE ..........................................................

2.2.11.2 DURCHFLUSSZYTOMETRISCHE MESSUNG DER ADHÄSIONSMOLEKÜLE AUF HUVEC ....36

2.2.11.3 DURCHFLUSSZYTOMETRISCHE MESSUNG DER OBERFLÄCHENMOLEKÜLE VON

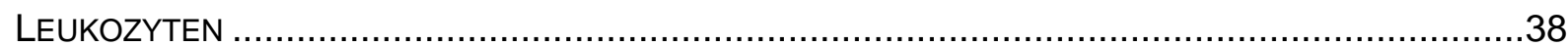

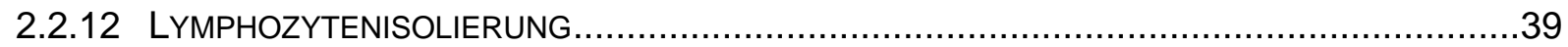

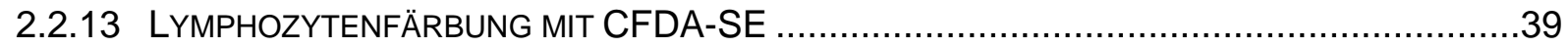

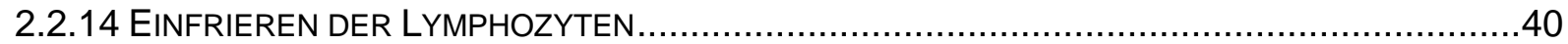

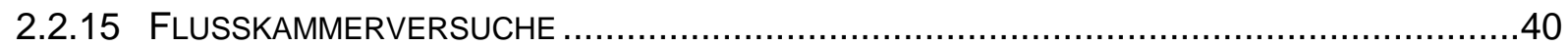

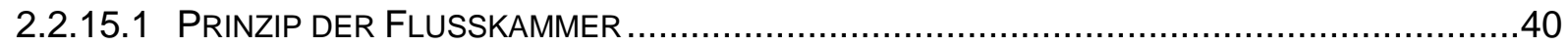

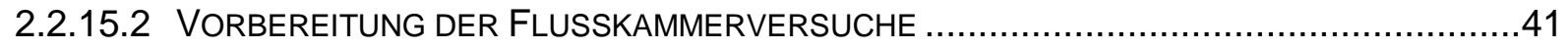

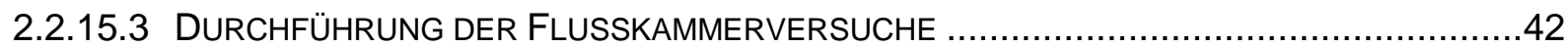

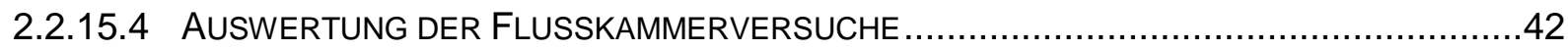

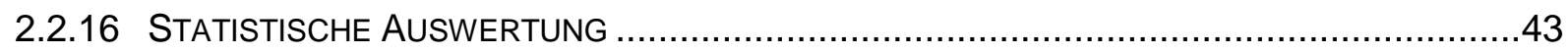

$\underline{3}$ ERGEBNISSE

3.1 AUSWIRKUNGEN DER UNTERSCHIEDLICHEN EINZELSTOFFE SOWIE IHRER KOMBINATIONEN AUF DIE TRANSLOKATION DES TRANSKRIPTIONSFAKTOR NF-KB/ P65......................................44

3.2 AUSWIRKUNGEN DER UNTERSCHIEDLICHEN EINZELSUBSTANZEN SOWIE IHRER KOMBINATIONEN AUF MRNA-EBENE.

3.2.1 WIRKUNGEN DER EINZELSUBSTANZEN AUF MRNA-EBENE ..................................46

3.2.1.1 WIRKUNG VON DMF AUF DIE TRANSKRIPTION VON ADHÄSIONSPROTEINEN, CHEMOKINEN

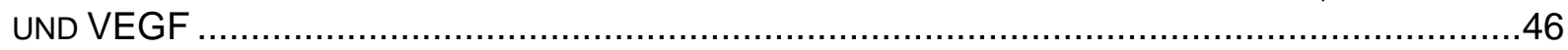
3.2.1.2 WIRKUNG VON KINK-1 UND BORTEZOMIB AUF DIE TRANSKRIPTION VON ADHÄSIONSPROTEINEN, CHEMOKINEN UND VEGF .................................................... 48 3.2.2 WIRKUNGEN DER KOMBINATIONEN VON DMF MIT NF-KB-INHIBITOREN AUF MRNA-EBENE..

3.2.2.1 WIRKUNG DER KOMBINATION VON DMF UND KINK-1 AUF DIE TRANSKRIPTION VON ADHÄSIONSPROTEINEN, CHEMOKINEN UND VEGF ...................................................... 3.2.2.2 WIRKUNG DER KOMBINATION VON DMF UND BORTEZOMIB AUF DIE TRANSKRIPTION VON ADHÄSIONSPROTEINEN, CHEMOKINEN UND VEGF .......................................................

3.3 AUSWIRKUNGEN DER UNTERSCHIEDLICHEN EINZELSTOFFE SOWIE IHRER KOMBINATIONEN

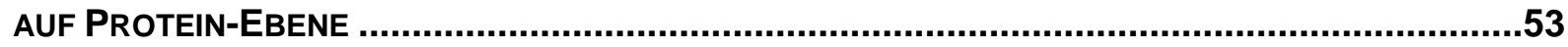

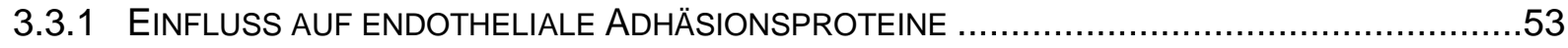

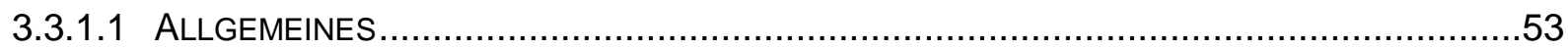


3.3.1.2.1 Einfluss der Kombination von DMF und KINK-1 auf die E-Selektin-Expression ....53

3.3.1.2.2 Einfluss der Kombination von DMF und Bortezomib auf die E-Selektin- Expression

3.3 .13 EINFLUSS AUF DIE EXPRESSION VON VCAM-1

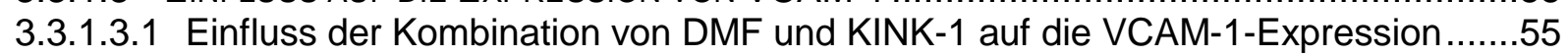

3.3.1.3.2 Einfluss der Kombination von DMF und Bortezomib auf die VCAM-1-Expression 56

3.3.1.4 EINFLUSS AUF DIE EXPRESSION VON ICAM-1 …................................................57

3.3.1.4.1 Einfluss der Kombination von DMF und KINK-1 auf die ICAM-1-Expression ........57

3.3.1.4.2 Einfluss der Kombination von DMF und Bortezomib auf die ICAM-1- Expression.59

3.3.2 EINFLUSS AUF LEUKOZYTÄRE OBERFLÄCHENMOLEKÜLE ..... .60

3.4 INDUKTION VON APOPTOSE, VIABILITÄT UND PROLIFERATION HUMANER ENDOTHELZELLEN

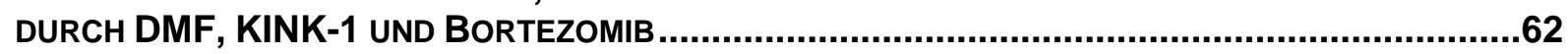

3.4.1 APOPTOSEINDUKTION/ ZYTOTOXIZITÄT VON DMF, KINK-1 UND BORTEZOMIB ................62

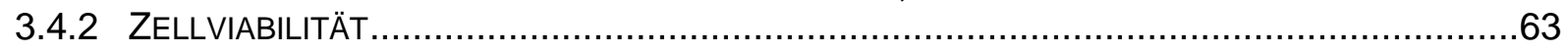

3.4.3 PROLIFERATION DER HUVEC UNTER DMF, KINK-1 UND BORTEZOMIB .........................64

3.5 WIRKUNG DER UNTERSCHIEDLICHEN EINZELSTOFFE SOWIE IHRER KOMBINATIONEN AUF DIE INTERAKTION VON ENDOTHELZELLEN UND LYMPHOZYTEN. .65

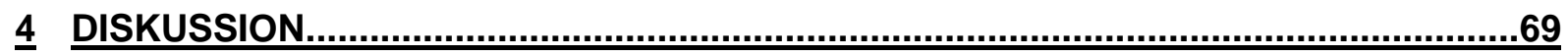

4.1 ÜBERSICHT 69

4.2 VERSTÄRKUNG DER DURCH DMF-INDUZIERTEN NF-KB-INHIBITION DURCH KOMBINATION MIT

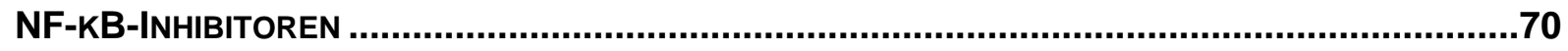

4.3 KOMBINATIONEN VON DMF UND NF-KB-INHIBITOREN ZEIGEN BEREITS BEI NIEDRIGEN KONZENTRATIONEN EINE SIGNIFIKANTE HERABREGULATION ENDOTHELIALER ADHÄSIONSMOLEKÜLE.

4.4 DMF, KINK-1 UND BORTEZOMIB REDUZIEREN DIE EXPRESSION ENDOTHELIALER, NICHT ABER LEUKOZYTÄRER ADHÄSIONSMOLEKÜLE

4.5 KOMBINATIONEN VON DMF MIT NF-KB-INHIBITOREN REDUZIEREN DIE EXPRESSION PROINFLAMMATORISCHER CHEMOKINE, ABER NICHT DIE VON VEGF.

4.6 KOMBINATIONEN VON DMF MIT NF-KB-INHIBITOREN VERSTÄRKEN NEGATIVE EFFEKTE IM VERGLEICH ZU DEN EINZELSUBSTANZEN NICHT

4.7 KOMBINATIONEN VON DMF UND NF-KB-INHIBITOREN FÜHREN ZU EINER VERMINDERTEN INTERAKTION ZWISCHEN ENDOTHELZELLEN UND LYMPHOZYTEN .............................................76

4.8 AUSBLICK AUF NEBENWIRKUNGSÄRMERE FAE-THERAPIEN .....................................77

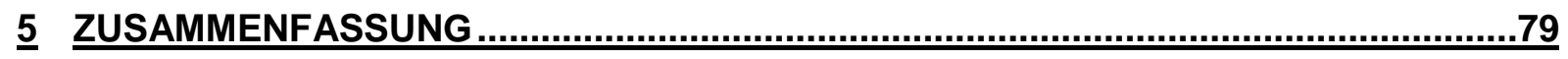

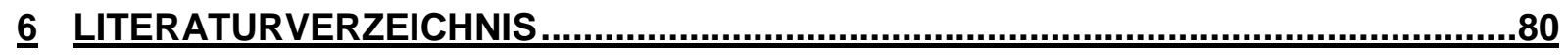




\section{Abbildungsverzeichnis}

Abbildung 1: Schematische Darstellung der Interaktion von Endothelzellen und Leukozyten

Abbildung 2: Unterschiedliche Wirkorte von KINK-1 und Bortezomib innerhalb des NF-kB-Signalweges.

Abbildung 3: Lymphozytenisolierung mittels Ficoll-Gradient .....

Abbildung 4 Flusskammer

Abbildung 5: Verteilung der Gesichtsfelder für die Aufzählung der adhärenten PBMC

Abbildung 6: Inhibition des Transkriptionsfaktors NF-kB.

Abbildung 7: Wirkung von DMF auf mRNA-Ebene

Abbildung 8: Wirkung von KINK-1 und Bortezomib auf mRNA-Ebene .... 49

Abbildung 9: Wirkung der Kombination von DMF und KINK-1 auf die Transkription in HUVEC und HDMEC.

Abbildung 10: Wirkung der Kombination von DMF und Bortezomib auf die Transkription in HUVEC und HDMEC.

Abbildung 11: Einfluss der Kombination von DMF und KINK-1 auf die Expression von ESelektin an der Zelloberfläche von HUVEC. .54

Abbildung 12: Einfluss der Kombination von DMF und Bortezomib auf die Expression von E-Selektin an der Zelloberfläche von HUVEC.

Abbildung 13: Einfluss der Kombination von DMF und KINK-1 auf die Expression von VCAM-1 an der Zelloberfläche von HUVEC

Abbildung 14: Einfluss der Kombination von DMF und Bortezomib auf die Expression von VCAM-1 an der Zelloberfläche von HUVEC

Abbildung 15: Einfluss der Kombination von DMF und KINK-1 auf die Expression von ICAM-1 an der Zelloberfläche von HUVEC

Abbildung 16: Einfluss der Kombination von DMF und Bortezomib auf die Expression von ICAM-1 an der Zelloberfläche von HUVEC

Abbildung 17: Einfluss von DMF, KINK-1 und Bortezomib auf PBMC

Abbildung 18: Apoptoseinduktion durch DMF, KINK-1 und Bortezomib.... 62 
Abbildung 19: Zytotoxizität von DMF, KINK-1 und Bortezomib in HUVEC

Abbildung 20: Viabilität der HUVEC unter DMF, KINK-1 und Bortezomib

Abbildung 21: Proliferationsfähigkeit der HUVEC unter Behandlung mit DMF, KINK-1 und Bortezomib 65

Abbildung 22: Interaktion von HUVEC und Lymphozyten unter dem Einfluss von DMF, KINK-1 und Bortezomib.

Abbildung 23: Morphologie der HUVEC unter DMF, KINK-1 und Bortezomib .68

\section{Tabellenverzeichnis}

Tabelle 1: Ausgewählte NF-kB-abhängige Genprodukte

Tabelle 2: Verbrauchsmaterialien

Tabelle 3: Geräte

Tabelle 4: Chemikalien

Tabelle 5: Versuchssubstanzen

Tabelle 6: Gebrauchsfertige Reaktionssysteme

Tabelle 7: Medien

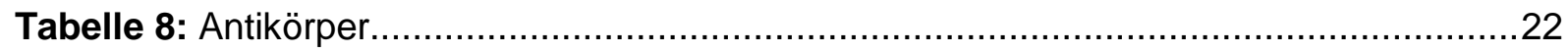

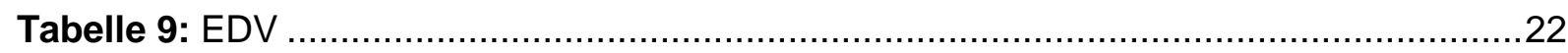

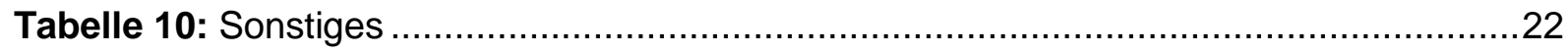

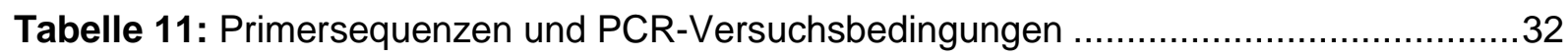




\section{Abkürzungsverzeichnis}

\begin{tabular}{|c|c|}
\hline Abb. & Abbildung \\
\hline AK & Antikörper \\
\hline bidest. & zweifach destilliertes Wasser \\
\hline $\mathrm{bp}$ & Basenpaar \\
\hline BrdU & Bromdesoxyuridin \\
\hline BSA & bovine serum albumin (dt.: Rinderserumalbumin) \\
\hline CD & cluster of differentiation \\
\hline cDNA & $\begin{array}{l}\text { complementary deoxyribonucleic acid } \\
\text { (dt.: komplementäre Desoxyribonukleinsäure) }\end{array}$ \\
\hline CFDA-SE & Carboxyfluorescein-diacetat-succinimidyl-ester \\
\hline CLA-1 & cutaneus lymphocyte-associated antigen-1 \\
\hline CXCL-1 (Gro- $\alpha)$ & growth regulated onkogen- alpha \\
\hline DAPI & 4',6-Diamidin-2-phenylindol \\
\hline DEPC & Diethylpyrocarbonat \\
\hline DMF & Dimethylfumarat \\
\hline DMSO & Dimethylsulfoxid \\
\hline DNA & desoxyribonucleic acid (dt.: Desoxyribonukleinsäure) \\
\hline dNTP & Desoxyribonukleotid-Triphosphat \\
\hline EBM & endothelial basal medium (dt.: Basalmedium) \\
\hline EGM & endothelial growth medium (dt.: Wachstumsmedium) \\
\hline ELISA & enzyme-linked immunosorbent assay \\
\hline E-Selektin & endothelial selectin (CD62E) \\
\hline FACS & $\begin{array}{l}\text { fluorescence- activated cell sorting } \\
\text { (dt.: Durchflusszytometrie) }\end{array}$ \\
\hline FAE & fumaric acid ester (dt.: Fumarsäureester) \\
\hline FCS & fetal calf serum (dt.: fetales Kälberserum) \\
\hline FITC & fluorescein isothiocyanate (dt.: Fluoresceinisothiocyanat) \\
\hline $\mathrm{g}, \mathrm{mg}, \mu \mathrm{g}, \mathrm{ng}$ & Gramm, Milligramm, Mikrogramm, Nanogramm \\
\hline GAPDH & Glycerinaldehyd-3-Phosphat-Dehydrogenase \\
\hline GSH & Glutathion \\
\hline $\mathrm{h}$ & Stunde \\
\hline HBSS & Hank`s balanced salt solution \\
\hline HDMEC & Human Dermal Microvascular Endothelial Cells \\
\hline HLA & Human Leucocyte Antigen \\
\hline HUVEC & Human Umbilical Vein Endothelial Cells \\
\hline ICAM-1 & intercellular adhesion molecule-1 (CD54) \\
\hline & Int \\
\hline
\end{tabular}


KINK-1

I, ml, $\mu \mathrm{l}$

LFA-1

L-Selektin

$\mathrm{M}, \mathrm{mM}, \mu \mathrm{M}$

MCP-1

MEF

$\mathrm{MFI}$

MHF

$\min$

MMF

MMP-9

mRNA

MTT

$\mathrm{Nm}$

NEMO

NF-KB

PASI

PBMC

PBS

PCR

PE

PI

PSORS

RNA

Rpm

RPMI

$\mathrm{RT}$

RT-PCR

sek

Tab.

TNFa

UV

VCAM

VEGF

VLA-1 kinase inhibitor of nuclear factor-кB-1

Liter, Milliliter, Mikroliter

lymphocyte function-associated antigen-1

lymphocyte selectin (CD62L)

Molar, Millimolar, Mikromolar

monocyte chemotactic protein-1(CCL2)

Monoethylfumarat

mean fluorescence intensity (dt.: mittlere

Fluoreszenzintensität)

Methylhydrogenfumarate

Minute

Monomethylfumarat

matrix metalloprotease- 9

messenger ribonucleic acid

3-(4,5-Dimethylthiazol-2yl)-2,5-diphenyltetrazoliumbromid Nanometer

$N F-K B$ essential modifier

nuclear factor 'kappa-light-chain-enhancer' of activated $B$ -

cells

Psoriasis Area and Severity Index

peripheral blood mononuclear cell

phosphate buffered saline

polymerase chain reaction (dt.: Polymerase-

Kettenreaktion)

Phycoerythrin

propidium iodine

Psoriasis Susceptibility Locus

Ribonukleinsäure

rounds per minute

Roswell Park Memorial Institute Medium 1640

Raumtemperatur

Reverse Transkriptase-Polymerasekettenreaktion

Sekunde

Tabelle

tumor necrosis factor- $\alpha$ (dt.: Tumornekrosefaktor- alpha)

ultraviolett

vascular cell adhesion molecule (CD106)

vascular endothelial growth factor

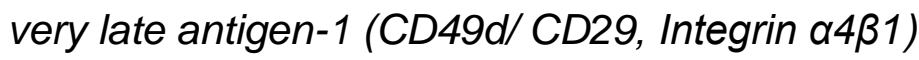




\section{$1 \quad$ Einleitung}

\subsection{Psoriasis}

\subsubsection{Epidemiologie und Klinik}

Die Psoriasis gehört zu den häufigsten chronisch entzündlichen Erkrankungen (Boehncke und Schön 2015). Bei weißen Europäern beträgt ihre Prävalenz etwa 2 bis 3\%, weniger häufig tritt sie bei Asiaten und Afrikanern auf (Christophers 2001, Lowes et al. 2007). Von der schubweise verlaufenden Erkrankung sind allein in Deutschland etwa 1,6 Millionen Menschen betroffen (Nast et al. 2012b), von denen bis zu $50 \%$ an einer mittelschweren bis schweren Verlaufsform leiden (Augustin et al. 2008). Für $56 \%$ der Betroffenen geht die gleichermaßen bei weiblichen und männlichen Patienten auftretende Erkrankung mit großen Einschränkungen einher, angefangen bei sozialen und psychologischen Problemen (Nestle et al. 2009) bis hin zu assoziierten Erkrankungen (Komorbidität), wie kardiovaskulären Leiden (Gelfand et al. 2006), chronisch-entzündlichen Darmerkrankungen (Yates et al. 1982), dem metabolischen Syndrom (Sommer et al. 2006) sowie psychischen Erkrankungen. Eine Studie belegte darüber hinaus eine im Vergleich zur Allgemeinbevölkerung erhöhte Mortalität sowie verkürzte Lebenserwartung bei Psoriasis-Patienten (Gelfand et al. 2007). Es findet sich eine Inzidenzhäufung innerhalb der 2.-3. sowie der 5.-6. Lebensdekade (Henseler und Christophers 1985). Die Erkrankung kann aber auch bereits im Kleinkindalter auftreten.

Die häufigste Form ist mit $90 \%$ aller Psoriasis-Erkrankungen die Psoriasis vulgaris (Griffiths und Barker 2007; Crow 2012). Sie ist durch scharf begrenzte erythematösquamöse Plaques, welche vor allem an den Streckseiten der Extremitäten auftreten, gekennzeichnet. Auch der Bauchnabel, die beharrte Kopfhaut sowie die Sakralregion sind Prädilektionsstellen. Weitere, aber deutlich seltenere Entitäten stellen die Psoriasis guttata, die Psoriasis inversa und die lokalisierte (palmoplantare) oder generalisierte Psoriasis pustulosa dar. Die psoriatische Erythrodermie (Befall der gesamten Körperoberfläche) ist eine lebensbedrohliche Maximalform. Etwa $50 \%$ der Psoriasis-Patienten weisen einen Nagelbefall mit „Tüpfelnägeln“ (Onycholysis punctata), Onycholyse oder "Ölflecken“ auf. 5-42\% aller Psoriasis-Patienten leiden an einer seronegativen Arthritis, welche unabhängig von 
den Hautveränderungen auftreten kann (O'Neill und Silman 1994; Christophers 2001; Gladman et al. 2005; Zachariae 2012). Genaue Aussagen über den individuellen Krankheitsverlauf können nicht getroffen werden.

Bei der Psoriasis vulgaris schuppen die betroffenen silbrig-weißen Hautareale stark, was sich auf die erhöhte Proliferationsgeschwindigkeit und verfrühte Reifung der Keratinozyten zurückführen lässt. Die Regenerationszeit der Epidermis ist bei Psoriasis-Patienten von 28 auf nur vier Tage reduziert (Weinstein et al. 1984; Schön und Boehncke 2005). Die erkrankte Haut weist ein verdicktes Stratum corneum mit noch vorhandenen Zellkernen (Parakeratose), ein fehlendes Stratum granulosum, eine Akanthose sowie verlängerte Reteleisten auf. Zudem treten Ansammlungen von Immunzellen, vor allem innerhalb der erkrankten Hautareale, auf. In der oberen Dermis sind dies vor allem CD8+-Lymphozyten, dendritische Zellen und Makrophagen, in der Epidermis in erster Linie neutrophile Granulozyten, welche die Munro-Mikroabzesse bilden (Nestle et al. 2009). Auch innerhalb gesunder Hautareale treten deutlich erhöhte Immunzellzahlen auf (Lowes et al. 2007). Außerdem findet sich eine hohe Anzahl verlängerter, stark gewundener Blutgefäße in den dermalen Papillen (Nestle et al. 2009; Micali et al. 2010), deren Dilatation das deutlich sichtbare Erythem der betroffenen Hautareale bedingt (Nograles et al. 2010). Diese Gefäße weisen große Ähnlichkeiten mit den für Lymphknoten charakteristischen hochendothelialen Venolen (HEV) auf und sind permeabler als die ursprünglichen Gefäße.

\subsubsection{Pathogenese der Psoriasis}

Bisher konnte nicht abschließend geklärt werden, ob es sich bei der Psoriasis um eine Erkrankung immunologischen oder epithelialen Ursprungs handelt, wobei die Evidenz für eine primäre Rolle des Immunsystems überwiegt (Nickoloff et al. 2000; Nestle et al. 2009; Boehncke und Schön 2015). Eine Dysregulation des angeborenen Immunsystems ist zweifelsfrei von großer Bedeutung, wobei diese nicht nur lokal, also innerhalb der betroffenen Hautabschnitte, sondern systemisch auftritt. So spricht die infektionsunabhängige Überaktivierung von B- und T-Zellen für eine organspezifische Autoimmunerkrankung (Christophers 1996; Lowes et al. 2007). Inzwischen gibt es auch konkrete Anhaltspunkte für eine T-Zell-vermittelte Autoimmunreaktion (Lande et al. 2014; Arakawa et al. 2015). Typischerweise erfolgt 
bei der Psoriasis zunächst eine Aktivierung plasmazytoider dendritischer Zellen, unter anderem durch Keratinozyten, welche wiederum myeloische dendritische Zellen durch IFN- $\alpha$ stimulieren (Nestle et al. 1994). Innerhalb der Lymphknoten differenzieren sich T-Zellen nach Aktivierung durch dendritische Zellen und IL-23 dann in Th1-, Th17- und Th22-Lymphozyten und produzieren verschiedene Mediatoren (z. B. IL-17, IL-22). Auf den T-Helfer-Zellen kommt es außerdem zu einer erhöhten Expression von CLA und VLA-1 (Di Meglio et al. 2011). Bei der Psoriasis liegt ein Ungleichgewicht zwischen Th1- und Th2-Zellen zugunsten der Th1-Zellen vor. Dieses hat eine vermehrte Produktion von TNFa, IL-2, und IFN-y zur Folge, welche zur Stimulation einer zellulären Immunantwort führt. Die dadurch ausgelöste Entzündungsreaktion induziert unter anderem die Diapedese, Keratinozytenreifung und vaskuläre Veränderungen (Lew et al. 2004). Als pathogenetisch bedeutsamste Zellpopulation werden heute die Th17-Zellen angesehen, welche durch die Produktion von IL-17 gekennzeichnet sind (Boehncke und Schön, 2015). Stimulierte Lymphozyten, Keratinozyten und Endothelzellen beginnen nun ihrerseits, Chemokine und Zytokine zu produzieren. Zu den wichtigsten zählen CCL2 (Monocyte chemotactic protein-1, MCP-1), CXCL1 (Growth regulated onkogen alpha, Gro- $\alpha$ ) und CXCL8 (Interleukin-8, IL-8) (Gillitzer et al. 1993, 1996; Schön und Ruzicka 2001; Wang et al. 2008).

Die T-Zell-Abhängigkeit der Erkrankung wird durch die Tatsache unterstrichen, dass eine Assoziation der Psoriasis mit bestimmten HLA-Allelen besteht (Harden et al. 2015) und dass nach einer Knochenmarktransplantation von einem an Psoriasis erkrankten Spender der Empfänger ebenfalls an Psoriasis erkrankte (GardembasPain et al. 1990). Hinweisend ist auch die deutlich erhöhte T-Zell-Konzentration innerhalb betroffener Hautabschnitte (Mak et al. 2009) und die gute Wirksamkeit des Calcineurin-Inhibitors Ciclosporin A auf die Erkrankung. Ciclosporin A greift unter anderem in die T-Zell-Aktivierung, Keratinozytenproliferation und Zytokinfreisetzung ein (Gottlieb et al. 1992; Borel et al. 1976; Cooper et al. 1990; Berth-Jones 2005). Schließlich können experimentell psoriasisartige Hautentzündungen in Mäusen oder Ratten ohne primäre epitheliale Veränderungen allein durch pathogene T-Zellen induziert werden (Breban et al. 1996; Schön et al. 1997; Schön 2008).

Die Psoriasis geht mit einer erhöhten Expression des Vascular Endothelial Growth Factor (VEGF) innerhalb der betroffenen Hautareale einher (Detmar et al. 1994), was zu verstärkter Angiogenese, erhöhter Permeabilität dermaler Blutgefäße sowie zur 
Stimulation der Keratinozytenproliferation führt (Elias et al. 2008). Durch die erhöhte Expression der Adhäsionsmoleküle ICAM-1 (CD54), VCAM-1 (CD106) und ESelectin (CD62E) ermöglichen die unter anderem durch VEGF aktivierten Endothelzellen den Austritt von Immunzellen in das umliegende Gewebe (Kim et al. 2001).

Psoriasis kann durch Medikamente (wie Betablocker, Lithium oder Malariatherapeutika), Streptokokken-Infektionen (Telfer et al. 1992), psychischen oder mechanischen Stress (Köbner-Effekt) sowie klimatische Bedingungen (Nograles et al. 2010) ausgelöst (provoziert) oder verschlechtert werden. Erhöhter Alkoholkonsum und Nikotinabusus werden ebenfalls als Auslöser diskutiert (Naldi et al. 1992; Naldi et al. 1999; Armstrong et al. 2011; Naldi et al. 2005; Poikolainen et al. 1994).

Für eine genetische Basis der Psoriasis spricht vor allem ihre familiäre Häufung. So besitzen Kinder mit einem erkrankten Elternteil ein 20-fach erhöhtes Erkrankungsrisiko, bei Erkrankung beider Eltern steigt das Risiko auf $75 \%$. Die Hälfte aller Patienten mit Typ-I-Psoriasis weisen einen erkrankten Elternteil auf (Henseler und Christophers 1985). Die Konkordanzrate monozygoter Zwillinge beträgt 70\% (Schön und Boehncke 2005). Mittlerweile wurden zahlreiche Genloci (bezeichnet als PSORS, psoriasis susceptibility locus) identifiziert, die mit dem Auftreten der Psoriasis assoziiert sind (Bowcock und Krueger 2005). Das häufigste mit Psoriasis assoziierte und in mehreren unabhängigen Studien bestätigte Allel ist hierbei das PSORS1, bei dem es sich um die MHC-Region auf Chromosom 6 handelt, welches für das humane Leukozytenantigen (human leucocyte antigen) (HLA)-Cw6 kodiert (Nair et al. 2006). HLA-Cw6 findet sich bei etwa 50\% der Psoriasis-Patienten (Schön und Boehncke 2005), während es nur bei $15 \%$ der gesunden Probanden auftritt. Man geht bei Allelträgern von einem 10- bis 20-fach erhöhten Erkrankungsrisiko aus (Mak et al. 2009), bei Homozygotie erhöht sich das Risiko noch einmal um das 2,5-Fache (Gudjonsson et al. 2003). PSORS1 ist vor allem mit der Typ-I-Psoriasis assoziiert (Schmitt-Egenolf et al. 1996). Vermutet wird eine Funktion des Allels bei der Antigenpräsentation und Regulation der natürlichen Killerzellen (Lowes et al. 2014). Tatsächlich scheint es direkt an kürzlich beschriebenen Autoimmunreaktionen bei Psoriasis beteiligt $\mathrm{zu}$ sein (Lande et al. 2014). Die Immun-Pathogenese unterstreichend, fielen Veränderungen in Genregionen auf, welche für spezifische inflammatorische Signalwege kodieren, wie den NF-KB-, den IL-23- oder den TNFa- 
Signalweg (Arias et al. 1996; Reich et al. 2002; Nair et al. 2009; Suárez-Fariñas et al. 2012). Überschneidungen mit einigen mit anderen Autoimmunerkrankungen assoziierten Genloci wurden ebenfalls beschrieben (Bowcock 2005; Langley et al. 2005). Eine erkrankungsspezifische Mutation konnte bisher bei Psoriasis-Patienten nicht gefunden werden (Nestle et al. 2009).

\subsubsection{Zell-Zell-Interaktion zwischen Endothelzellen und Lymphozyten}

Die Diapedese bezeichnet das Hindurchtreten von Immunzellen durch das Endothel kleiner Gefäße und spielt eine wichtige Rolle bei der Entstehung akuter und chronischer Entzündungen. Nicht-aktivierte Lymphozyten werden im Blutstrom durch die Blutgefäße bewegt, ohne an die Endothelzellen zu adhärieren. Durch verschiedene Stimuli, wie Lipide, Chemokine, Komplementfaktoren oder Bakterienpeptide, wird eine Kaskade ausgelöst, welche letztlich zum Austritt der Zellen aus den Gefäßen führt. Diese lymphozytäre Extravasation gliedert sich in folgende Schritte: lockeres Anhaften und Rollen (tethering and rolling), Aktivierung und feste Adhäsion sowie transendotheliale Migration. Maßgeblich gesteuert wird dieser Vorgang von endothelialen und leukozytären Adhäsionsmolekülen (Schön et al. 2003).

Zunächst kommt es zum Rollen und einer lockeren Adhäsion der Lymphozyten an die Gefäßwand. Dieser Schritt wird vor allem durch Selektine, wie E-Selektin (CD62E), P-Selektin und L-Selektin vermittelt (Schön et al. 2003). Hierbei handelt es sich um einkettige Membranproteine, die mit einem Teil ihrer Transmembranhelix in das Gefäßlumen ragen und dort Bindungen mit leukozytären Glykopeptiden und Glykoproteinen eingehen können. Beispielsweise binden das endotheliale E- und PSelektin an das kutane Lymphozytenantigen 1 (cutaneus lymphocyte antigen-1, CLA1) (Fuhlbrigge et al. 1997), das lymphozytäre Selektin (CD62L, L-Selektin) bindet unter anderem an P-Selectin-Glykoprotein-Ligand-1 (PSGL-1) (Tu et al. 1996; Tsang et al. 1997; Raffler et al. 2005). Entzündungsmediatoren bedingen eine Aktivierung von Leukozyten und Endothelzellen sowie eine vermehrte Expression der Adhäsionsmoleküle sowohl auf endothelialer als auch auf leukozytärer Seite. Dies ermöglicht die feste Adhäsion der Leukozyten an das Endothel. Dieser Schritt wird durch ICAM-1 und VCAM-1 vermittelt, wobei VCAM-1 vorrangig an das Integrin VLA4 (very late antigen-4, entspricht $\alpha 4 \beta 1$-Integrin, CD49d/CD29) bindet und ICAM-1 an 
das Integrin LFA-1 (lymphocyte function-associated antigen-1, entspricht aL $\beta 2$ Integrin, CD11a/CD18) bindet (Shimizu et al. 1991; Dustin und Springer 1988; Makgoba et al. 1988; Lowes et al. 2014). Durch eine Abflachung ihrer Form entziehen sich die Leukozyten nun den Scherkräften des Blutes und wandern langsam an der Gefäßwand entlang, um durch endotheliale Lücken in das umgebende Gewebe auszutreten. Im Gewebe angekommen, produzieren THelferzellen (CD4-positive Lymphozyten) und zytotoxische T-Zellen (CD8-positive Lymphozyten) weitere Zytokine, welche die Entzündung aufrechterhalten.

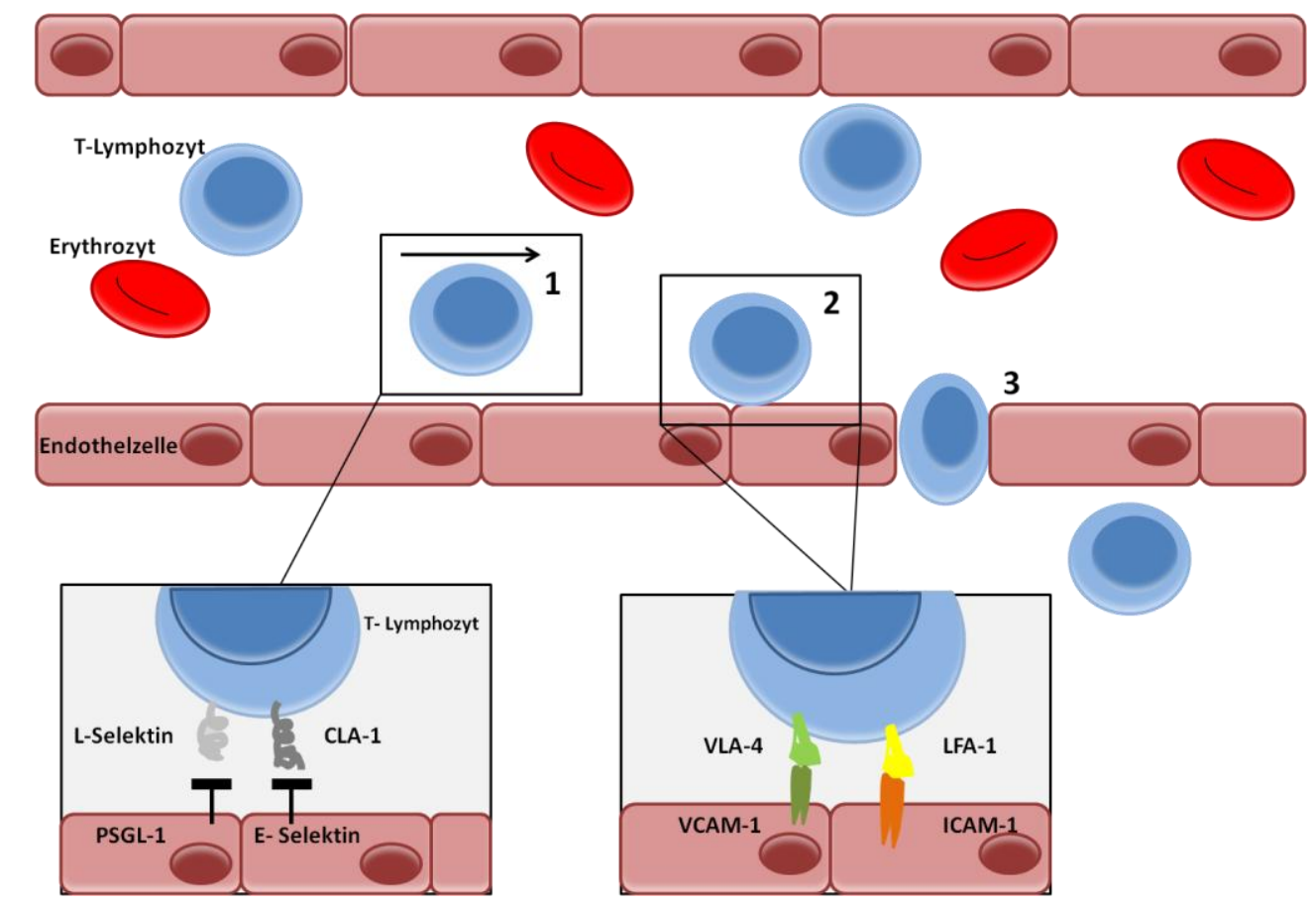

Abb. 1: Schematische Darstellung der Interaktion von Endothelzellen und Leukozyten 1) Rollen und lockere Adhäsion werden auf Seiten der Endothelzellen von E-und P-Selektin, auf leukozytärer Seite von L-Selektin und CLA-1 vermittelt 2) Die feste Adhäsion erfolgt durch die endothelialen Adhäsionsmoleküle VCAM-1 und ICAM-1 sowie durch das leukozytäre VLA-4 und LFA-1 3) transendotheliale Migration. 


\subsubsection{Therapie der Psoriasis}

Vor Beginn der Psoriasis-Therapie erfolgt die Beurteilung des Schweregrades der Erkrankung mit Hilfe klinischer Skalen wie der BSA (Body Surface Area) oder dem PASI (Psoriasis Area and Severity Index, Werte zwischen 0 und 72 möglich). Aber auch der PGA (Physician`s Global Assessment) sowie der DLQI (DermatologyRelated Life Quality Index, Werte zwischen 0 und 30 möglich) werden herangezogen. Darüber hinaus wurden spezielle Instrumente zur Beurteilung der Psoriasis in besonderen Lokalisationen wie der behaarten Kopfhaut, den Handflächen und Fußsohlen sowie der Nägel entwickelt und validiert. Bei der BSA wird der Befall der Körperoberfläche in Prozent erfasst, beim PASI werden zusätzlich das Ausmaß der Schuppung (Desquamation), Rötung (Erythem) und Infiltration beurteilt. Eine mittelschwere bis schwere Psoriasis ist durch BSA > 10\%, DLQI $>10$ Punkte und/ oder PASI > 10 Punkte definiert. Bei einer mindestens mittelschweren Psoriasis wird eine systemische Therapie dringend empfohlen. Die genannten Skalen werden ebenfalls zur Beurteilung des Therapieerfolges angewandt (Nast et al. 2012 b).

Die Basis der Psoriasis-Therapie bildet die intensive antiproliferative und antientzündliche topische Therapie beispielsweise mit Vitamin D3-Analoga (Calcitriol, Calcipotriol, Tacalcitol), Cignolin, Retinoiden (Tazarotene), Calcineurin-Inhibitoren (Tacrolimus, Pimecrolimus) oder Glukokortikosteroiden. Die Wahl des jeweiligen Wirkstoffes wird hierbei in Abhängigkeit von Schweregrad und Lokalisation der betroffenen Hautareale getroffen. Je nach Ausmaß der Hyperkeratose erfolgt initial außerdem häufig eine Keratolyse mittels Harnstoff oder Salizylsäure, um so die Wirkung der weiteren differenten topischen Therapie zu erhöhen. Zusätzlich können Lichttherapien mit UVB 311nm oder eine PUVA (UV-A-Licht + Psoralen) durchgeführt werden. Für milde Verlaufsformen und damit zur Behandlung der meisten Patienten ist die Lokaltherapie ausreichend (Altmeyer und Nüchel 1996). In schwereren Fällen, bei Therapieresistenz oder dem Auftreten einer Psoriasis-Arthritis sind allerdings Systemtherapien angezeigt. Zur konventionellen Therapie zählen hier der Folsäurantagonist Methotrexat, der Calcineurin-Inhibitor Ciclosporin A, Retinoide sowie die Fumarsäureester. Apremilast ist ein im Jahr 2015 zugelassener oral verfügbarer Antagonist der Phosphodiesterase-4. Zusätzlich können bei Versagen der konventionellen Therapie seit einigen Jahren Biologicals eingesetzt werden. Hierbei handelt es sich um monoklonale Antikörper oder andere Proteine, welche 
selektiv Zytokine oder T-Zellen inhibieren (Lowes et al. 2007). Die derzeit zugelassenen Substanzklassen umfassen TNFa-Inhibitoren (Etanercept, Adalimumab, Golimumab (nur gegen Psoriasis-Arthritis zugelassen) und Infliximab), IL-12/23-Blocker (Ustekinumab) sowie IL-17-Antagonisten (Secukinumab, Ixekizumab). Weitere Präparate, beispielsweise selektiv gegen IL-23, befinden sich in der Entwicklung.

Oft besteht aufgrund tatsächlicher Nebenwirkungen, zeitlichen Aufwandes, Angst vor Langzeitfolgen und langer Wirklatenz nur eine geringe Therapieadhärenz (Zaghloul und Goodfield 2004). Lediglich $60 \%$ der Patienten wenden die verordneten Medikamente regelmäßig und verordnungsgemäß an (Richards et al. 1999; Richards et al. 2006). Bei der Lichttherapie etwa handelt es sich um eine sehr zeitintensive Behandlungsform, die über mindestens 4 Wochen mehrmals wöchentlich durchgeführt werden muss und darüber hinaus potentiell karzinogen auf die Haut wirkt (Altmeyer und Nüchel 1996). Konventionelle systemische Therapien können mit Nebenwirkungen wie Hepato- oder Nephrotoxizität (Ciclosporin, Methotrexat), Teratogenität (Retinoide, Methotrexat), Medikamenten-Wechselwirkungen und/oder schwerwiegenden Blutbildveränderungen einhergehen (Menter und Griffiths 2007), was ihre Eignung für eine Langzeittherapie und auch die Adhärenz der Patienten einschränkt. Biologika zeigen eine gute Verträglichkeit, allerdings liegen noch nicht in allen Fällen Langzeitstudien vor. Die Therapieadhärenz ist bei Biologika oftmals besser als bei konventionellen antipsoriatischen Systemtherapeutika (Arnold et al. 2016).

Ein im Vergleich günstiges Nutzen-Risiko-Profil zeigen die im folgenden Kapitel charakterisierten Fumarsäureester. 


\subsection{Fumarsäureester}

\subsubsection{Allgemeines}

Fumarsäureester (fumaric acid esters, FAE) wurden erstmals in den späten 1950er Jahren in einem Selbstversuch erfolgreich zur Langzeittherapie der Psoriasis eingesetzt. Heute wird zunehmend auch ihre Wirkung auf andere Erkrankungen getestet. Bei Fumaderm ${ }^{\circledR}$ handelt es sich um ein oral verabreichtes Medikament aus dem Fumarsäureester Dimethylfumarat (DMF) und verschiedenen Salzen $\left(\mathrm{Ca}^{2+}\right.$, $\mathrm{Mg}^{2+}, \mathrm{Zn}^{2+}$ ) des Monoethylfumarats (MEF). Es wurde in Deutschland im Jahr 1994 zur Behandlung von Patienten mit schwerer und 2008 für Patienten mit moderater Psoriasis zugelassen (Mrowietz et al. 2009). Heute ist Fumaderm ${ }^{\circledR}$ in Deutschland das am häufigsten eingesetzte Systemtherapeutikum. Die Therapie wird einschleichend begonnen: Nach einer dreiwöchigen Behandlung mit Fumaderm initial $^{\circledR}$ (30 mg DMF) in ansteigender Dosierung (bis auf $90 \mathrm{mg} / \mathrm{d}$ in der dritten Woche) erfolgt die weitere Therapie mit Fumaderm ${ }^{\circledR}$ (120 mg DMF/Tablette) ebenfalls in ansteigender Dosierung (bis zu 6 Tabletten täglich). FAE weisen ein gutes Nutzen-Risiko-Profil auf und sind daher zur Langzeittherapie geeignet. Der Nutzen der FAE wurde in zahlreichen Studien belegt (Nugteren-Huying et al. 1990; Altmeyer et al. 1994; Hoefnagel et al. 2003). Bei 50 bis $70 \%$ der Patienten zeigte sich eine Verbesserung des PASI um bis zu 75\% nach Abschluss einer viermonatigen Behandlung (Moharregh-Khiabani et al. 2009). Außerdem bedingen FAE selten Arzneimittelwechselwirkungen, was in Anbetracht der häufigen Assoziation der Psoriasis mit schwerwiegenden systemischen Erkrankungen ein weiterer Vorteil ist.

Die Wirkmechanismen der FAE sind noch nicht vollends bekannt. DMF reduziert unter anderem die Expression proinflammatorischer Zytokine und Chemokine in humanen Keratinozyten, PBMC (Stoof et al. 2001) und Endothelzellen (Wallbrecht et al. 2011). Außerdem vermindert DMF die Expression endothelialer und leukozytärer Adhäsionsmoleküle (Rubant et al. 2008; Vandermeeren et al. 1997; Wallbrecht et al. 2011) und damit die Interaktion von Endothelzellen und Leukozyten (Wallbrecht et al. 2011). Letzteres wurde sowohl in vivo für die Interaktion muriner Endothelzellen und Lymphozyten, als auch in vitro für HUVEC und humane Lymphozyten beschrieben (Rubant et al. 2008; Wallbrecht et al. 2011). Histologische Untersuchungen belegten eine deutliche Abnahme CD4-positiver T-Helferzellen sowie ein Fehlen CD15positiver Zellen in der oberen Dermis bei Psoriasis-Patienten, die FAE einnahmen 
(Ockenfels et al. 1998). Blutuntersuchungen zeigten ebenfalls eine Reduktion peripherer CD4+- und CD8+-Lymphozyten (Höxtermann et al. 1998). Darüber hinaus inhibiert DMF die Differenzierung von Monozyten zu dendritischen Zellen (DC) (Zhu und Mrowietz 2001), wirkt der für die Pathogenese der Psoriasis wichtigen Angiogenese entgegen (Meissner et al. 2011; García-Caballero et al. 2011), entfaltet eine apoptotische Wirkung auf T-Zellen (Treumer et al. 2003) und induziert die Wiederherstellung der Zytokinbalance (de Jong et al. 1996; Ockenfels et al. 1998). Die Inhibition des Transkriptionsfaktors NF-KB wird als eine der Hauptwirkungen des DMF angesehen (Loewe et al. 2001, 2002; Vandermeeren et al. 2001; Gillard et al. 2015). Vermutet wird hier, dass DMF in das zelluläre Redoxsystem eingreift und durch eine erhöhte Konzentration an reduziertem Glutathion unter anderem zu einer Inhibition von NF-KB führt (Mrowietz und Asadullah 2005; Moharregh-Khiabani et al. 2009). Aber auch eine direkte Hemmung der Translokation von NF-KB in den Zellkern wird durch DMF bewirkt. Ebenso wäre eine Beeinflussung von Transportproteinen oder der Phosphorylierung des Transkriptionsfaktors denkbar. Eine Inhibition der DNA-NF-KB-Bindung wurde hingegen nicht beobachtet (Vandermeeren et al. 2001; Loewe et al. 2002).

In den letzten Jahren wurde vermehrt diskutiert, bei welchem der FAE es sich um die biologisch aktive Komponente des Fumaderm ${ }^{\circledR}$ handelt, die somit zum antipsoriatischen Effekt führt. Klinische sowie experimentelle Studien zeigten, dass nur DMF, nicht aber MEF oder MMF einen signifikanten Effekt ausüben (Nieboer et al. 1989, 1990; Wallbrecht et al. 2011). Allerdings konnte DMF eine Stunde nach oraler Einnahme im Blutplasma gesunder Probanden nicht nachgewiesen werden, lediglich sein Hydrolyseprodukt MMF sowie MEF wurden gefunden (Litjens et al. 2004b). Was die MMF-Konzentration anbelangt, wurden große interindividuelle Unterschiede detektiert. Für diese Beobachtung existieren verschiedene Theorien. Zum einen wird von einer Hydrolyse von DMF zu MMF im alkalischen Milieu des Dünndarms noch vor dem Durchtritt durch die Darmschleimhaut (Litjens et al. 2004a) ausgegangen, zum anderen von einer Metabolisierung und Bindung des DMF durch Blutzellen (Litjens et al. 2004a). Aber auch die Hydrolyse durch im Blutplasma befindliche Esterasen (Werdenberg et al. 2003) und eine Reaktion von DMF mit GSH werden diskutiert (Schmidt et al.2007; Rostami-Yazdi et al. 2008; Dibbert et al. 2013). Außerdem besteht die Theorie, dass DMF nur zum Teil mit GSH reagiert und das restliche DMF unverändert in den Blutzellen verbleibt, wodurch es nicht im 
Blutplasma nachgewiesen werden kann (Wollina 2011). Mittlerweile konnte die Mercaptursäure des DMF im Urin behandelter Psoriasis-Patienten nachgewiesen werden. Als Abfallprodukt der Glutathion-Bildung entsteht die Mercaptursäure höchstwahrscheinlich im Pfortaderkreislauf, nachdem DMF im Duodenum resorbiert wurde (Rostami-Yazdi et al. 2010; 2008). Weiterführende Untersuchungen zeigten jedoch, dass DMF nicht im Pfortaderblut zu finden ist (Dibbert et al. 2013).

Aufgrund der Tatsache, dass bisherige Studien eine ausschließlich durch DMFvermittelte Wirkung zeigten, wurde der Fokus auch in der vorliegenden Arbeit auf die Wirkung und mögliche Verbesserung der Therapie mit DMF gelegt.

\subsubsection{Nebenwirkungen der FAE}

In einer prospektiven multizentrischen Studie zeigten 69 von 100 mit FAE behandelten Patienten mit schwerer Psoriasis Nebenwirkungen (Mrowietz et al., 1998). 56\% der Patienten litten an gastrointestinalen Beschwerden, wie Diarrhö, Tenesmen, Meteorismus und abdominalen Schmerzen. Hinzukommend berichteten $31 \%$ der Patienten über kutane Flushes (anfallsartig auftretende Rötung von Gesicht und Dekolleté). $\mathrm{Zu}$ den selteneren Nebenwirkungen zählten Transaminasenerhöhungen, Lymphozytopenien sowie Eosinophilien. Bei $7 \%$ der behandelten Patienten musste die Therapie aufgrund der beschriebenen Nebenwirkungen abgebrochen werden (Mrowietz et al. 1998). In einer weiteren Studie zeigten $73 \%$ der Probanden Nebenwirkungen, auch hier überwogen Flushes (55\%) und gastrointestinale Symptome (12-42\%). Bei 76\% der Patienten trat zudem eine Lymphozytopenie auf (Hoefnagel et al. 2003). In seltenen Fällen kam es zu einer Erhöhung der Kreatininwerte oder zu einer Proteinurie. Gleichzeitig zeigten beide Studien aber auch die Eignung der Fumarsäureester zur Langzeittherapie, da schwerwiegende Nebenwirkungen (Infektionen, Malignome), wie sie im Zusammenhang mit anderen systemischen Therapeutika beschrieben wurden, ausblieben. Die genannten Nebenwirkungen, die vor allem innerhalb der ersten 6 Monate beobachtet werden, führen allerdings zu einer Therapielimitierung, da sie die Compliance (Therapietreue) der Patienten stark einschränken und gar zum Therapieabbruch führen. Nebenwirkungen werden vor allem bei hohen Dosen der FAE beschrieben, so dass eine Reduktion des Wirkstoffes häufig zu einer Besserung 
unerwünschter Symptome führt. Allerdings vermindert sich durch die Dosisreduktion gleichzeitig auch die therapeutische Wirksamkeit.

\subsubsection{Sonstige Anwendungsgebiete der FAE}

Seit 2013 sind FAE in Deutschland auch zur Behandlung der Multiplen Sklerose (MS; Encephalomyelitis disseminata), einer demyelinisierenden chronisch-entzündlichen Erkrankung des zentralen Nervensystems, zugelassen (Frohman et al. 2006). In einer doppelblinden placebo-kontrollierten Studie zeigte sich unter einer Hochdosistherapie mit FAE ein Rückgang zerebraler MS-Läsionen um 69\% (Kappos et al. 2008). Zur MS-Therapie wird BG-12, ein reines DMF-Präparat, genutzt. Phase III-Studien an Patienten mit schubweise verlaufender MS zeigten eine gute Wirksamkeit, aber auch die typischen Nebenwirkungen der FAE (Fox et al. 2012; Gold et al. 2012). DMF war auch in vitro neuroprotektiv wirksam (Duffy, So und Murphy 1998; Lin et al. 2011; Scannevin et al. 2012; Albrecht et al. 2012).

In aktuellen Studien werden FAE auch hinsichtlich ihrer Wirkung auf Sarkoidose, Epidermolysis bullosa acquisita, Lupus erythematodes und Alopecia areata untersucht. Bei all diesen Erkrankungen handelt es sich (vermutlich) um Autoimmunerkrankungen (Breuer et al. 2005; Venten et al. 2006; Tsianakas et al. 2014). Auch die Wirksamkeit der FAE in der Asthma-bronchiale-Therapie wird diskutiert (Seidel et al. 2009; Seidel und Roth 2013). Beobachtungen, dass FAE antinekrotisch auf Kardiomyozyten (Meili-Butz et al. 2008) und anti-tumorigen auf Prostatakarzinom- und Melanomzellen (Loewe et al. 2006; Yamazoe et al. 2009) wirken, könnten weitere Einsatzgebiete aufzeigen. Des Weiteren ist aufzuführen, dass DMF die HIV (Human Immuno-deficiency Virus)-Replikation hemmt (Cross et al. 2011; Gill und Kolson 2013). Außerdem zeigten mit DMF behandelte ChoreaHuntington-Mäuse einen geringer ausgeprägten Phänotyp als Kontrolltiere (Ellrichmann et al. 2011).

Ausgehend von der guten Wirksamkeit bei Psoriasis könnten FAE auch bei weiteren Th1-gewichteten entzündlichen Erkrankungen wirksam sein. Diese große Zahl möglicher Anwendungsgebiete belegt die klinische Relevanz und den Bedarf an einer Verbesserung der Therapie mit DMF. 


\subsection{Transkriptionsfaktor NF-kB}

Der ubiquitär im menschlichen Körper vorkommende Transkriptionsfaktor NF-kB (nuclear factor kappa-light-chain-enhancer of activated B-cells) ist ein wichtiger Regulator zahlreicher Gene und seine Fehlregulation wird mit der Pathogenese verschiedenster inflammatorischer, neoplastischer und immunologischer Erkrankungen in Verbindung gebracht (Gerondakis et al. 1999; Grossmann et al. 1999; Dolcet et al. 2005). Da die Existenz der NF-KB-Familie erstmals in Lymphozyten beschrieben wurde (Sen und Baltimore 1986), galt der Transkriptionsfaktor in erster Linie als zentraler Mediator der adaptiven Immunantwort. In nachfolgenden Studien wurde NF-KB aber auch in zahlreichen anderen Körperzellen, wie Endothelzellen und Neuronen nachgewiesen (Kaltschmidt et al. 1994; Read et al. 1994; Kaltschmidt und Kaltschmidt 2009). Außerdem gilt als erwiesen, dass NF-kB in die Apoptose-Induktion, Zell-Zell-Kommunikation, neuronale Vorgänge sowie in inflammatorische Prozesse und die zelluläre Stressantwort involviert ist. Auch in der Entwicklung und Reifung von Lymphozyten, der Steuerung des Zellzyklus sowie beim Wachstum und der Proliferation von Zellen übernimmt NFKB eine wichtige Rolle (Ghosh et al. 1998).

Bei dem geläufig als NF-KB bezeichneten Transkriptionsfaktor handelt es sich um eine Familie aus fünf strukturell miteinander verwandten Transkriptionsfaktoren, zu der die Proteine RelA (p65), RelB, c-Rel, p50/p105 (NF-kB1) und p52/ p100 (NF-kB2) gehören (Lawrence et al. 2001). Untereinander sind sie in der Lage, Homo- und Heterodimere zu bilden und jede Untereinheit verfügt über ganz eigene Funktionen (Gerondakis et al. 1999; Hoffmann et al. 2003). Inhibiert werden sie von Proteinen

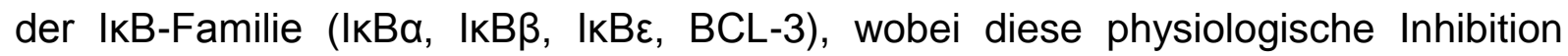
wiederum von der IKB-Kinase (IKK) aufgehoben wird, deren drei Untereinheiten (IKKa, IKK $\beta$ und NEMO) als Komplex vorliegen (Greten und Karin 2004; Hayden und Ghosh 2004). NF-kB liegt in den meisten Zellen zunächst inaktiv als p50/p65(RelA)Heterodimer, das an das inhibitorische Protein IkBa gebunden ist, im Zytoplasma vor (Baldwin 1996). Beispielsweise in Malignomen findet sich aber auch eine konstitutive NF-kB-Aktivierung (Rayet und Gélinas 1999). Durch unterschiedliche Stimuli, wie inflammatorische Mediatoren, Hormone, virale und bakterielle Pathogene oder physikalischer Stress (Baeuerle und Henkel 1994; Baldwin 1996; Piva et al. 2006), wird IKBa von der IKB-Kinase (IKKß) phosphoryliert und daraufhin ubiquitiniert 
(Karian und Ben- Neriah 2000). Während IkB nun im 26S-Proteasom abgebaut wird, kann NF-kB in den Nukleus translozieren und an die DNA binden (Gerondakis et al. 1999).

NF-kB übernimmt eine zentrale Rolle bei der Pathogenese der Psoriasis (Nair et al. 2009). So besteht eine deutlich gesteigerte Konzentration der Untereinheit p65 in den Zellkernen betroffener Haut, wohingegen in der Haut gesunder Probanden kaum p65 nachweisbar war (Lizzul et al. 2005). Außerdem korreliert die Höhe der NF-kBKonzentration in epidermalen Keratinozyten mit dem Grad der dermalen Hyperplasie sowie dem inflammatorischen Infiltrat (Moorchung et al. 2014). Es wird ein Ungleichgewicht zwischen anti-apoptotischen und Zellzyklus-hemmenden Effekten des Transkriptionsfaktors vermutet. Eines der wichtigsten Zytokine in der Pathogenese der Psoriasis ist TNFa, welches nachweislich zu einer Aktivierung von NF-kB führt (Banno et al. 2004).

\begin{tabular}{|c|c|}
\hline Genklasse & NF-kB-abhängige Gene \\
\hline Zytokine und Chemokine & $\begin{array}{l}\text { TNFa, IL-2, IL-6, Interferon } \beta \text { und } \mathrm{y}, \text { CXCL8 } \\
\text { (IL-8),CXCL1 (Gro- } \alpha) \text {, CCL2 (MCP-1) }\end{array}$ \\
\hline Adhäsionsmoleküle & $\begin{array}{l}\text { ICAM-1, VCAM-1, E-Selektin, P-Selektin, } \\
\text { Fibronektin }\end{array}$ \\
\hline Wachstumsfaktoren & VEGF, G-CSF, GM-CSF \\
\hline Transkriptionsfaktoren & Rel/NF-kB-Protein, IkB-Protein, c-myc \\
\hline Immunrezeptoren & $\begin{array}{l}\text { CD21, CD40, CD 40-Ligand, CD 48, MHC } \\
\text { Klasse I (HLA), } \beta 2 \text {-Mikroglobulin, Ig k } \\
\text { Leichtkette }\end{array}$ \\
\hline Akute- Phase-Proteine & CRP, Angiotensinogen, Tissue Factor 1 \\
\hline Stressantwort & COX-2, Angiotensin II \\
\hline
\end{tabular}

Tab. 1: Ausgewählte NF-kB- abhängige Genprodukte (Baeuerle und Henkel 1994; Kumar et al. 2004). Hervorgehobene Genprodukte wurden in der vorliegenden Arbeit untersucht. 


\section{$1.4 \quad$ NF-kB-Inhibitoren}

\subsubsection{Allgemeines}

Da NF-KB eine wichtige Rolle bei der Psoriasis-Pathogenese spielt (siehe Kapitel 1.3) und da DMF in hoher Konzentration dessen Translokation hemmt, könnte die Kombination mit NF-KB-Inhibitoren den therapeutischen Effekt von DMF verstärken. Neben den physiologischen existieren mittlerweile auch artifiziell hergestellte NF-KBInhibitoren. Die Experimente dieser Arbeit wurden mit zwei dieser Substanzen, KINK1 (kinase inhibitor of nuclear factor-kB-1) und Bortezomib, durchgeführt. Diese hemmen NF-KB auf unterschiedliche Weise. Da der genaue Inhibitionsmechanismus von DMF nicht bekannt ist, schien es angebracht, das Augenmerk nicht nur auf einen bestimmten Wirkmechanismus zu legen. Während KINK-1, durch die Verhinderung der IkB-Phosphorylierung, spezifisch den Transkriptionsfaktor NF-kB hemmt, inhibiert Bortezomib die Proteasomen und ist somit ein weniger spezifischer Inhibitor. Im Folgenden werden die beiden gewählten Inhibitoren näher vorgestellt.

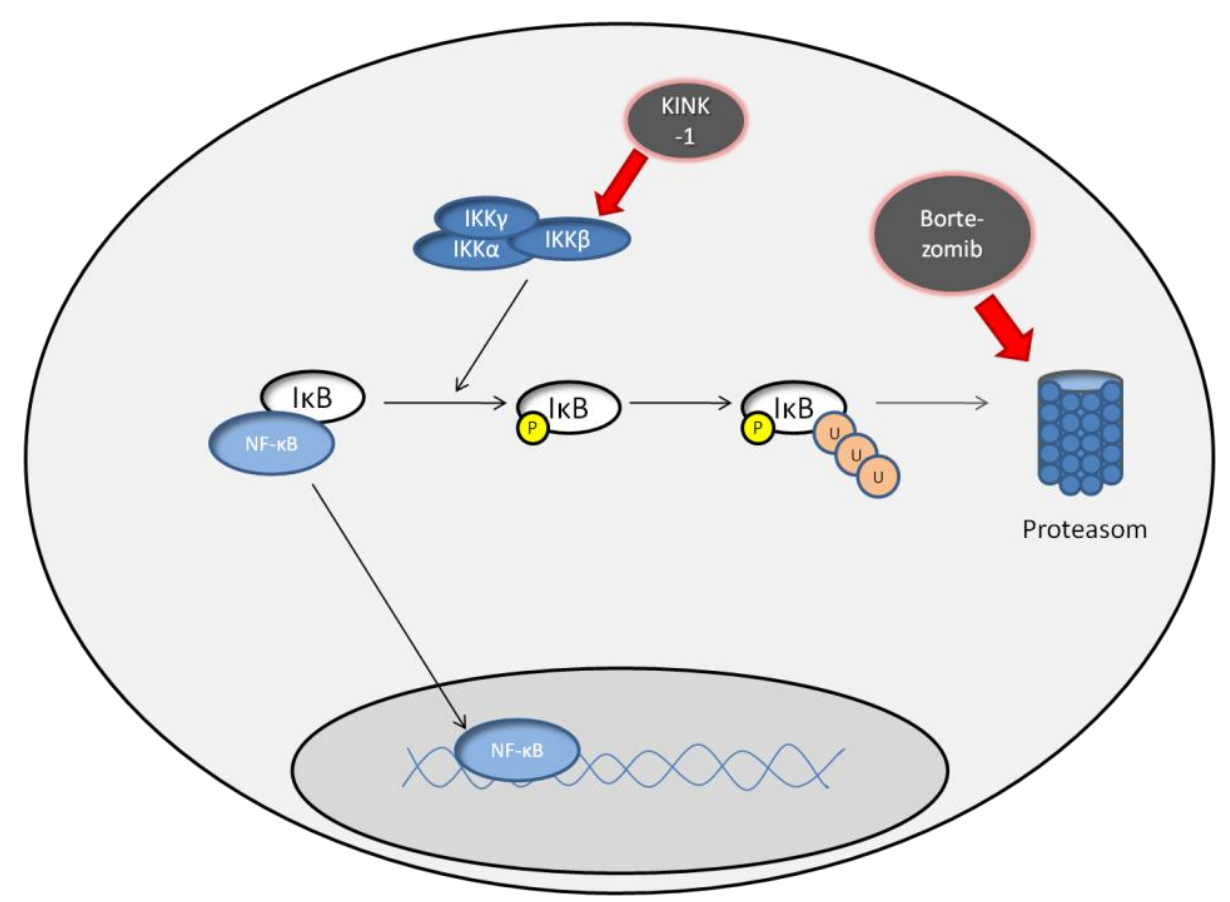

Abb. 2: Unterschiedliche Wirkorte von KINK-1 und Bortezomib innerhalb des NF-KBSignalweges (vereinfachtes Schema). 


\subsubsection{KINK-1 (kinase inhibitor of nuclear factor-KB-1)}

Der 2008 erstmals hinsichtlich seiner Wirkung auf Melanomzellen charakterisierte NF-kB-Inhibitor gehört zu einer neuen kleinmolekularen Substanzklasse, welche spezifisch die IKKß-Untereinheit der IKB-Kinase hemmt (Schön et al. 2008). KINK-1 inhibiert dosisabhängig sowohl die TNFa-induzierte, sowie die konstitutive Phosphorylierung von IKB als auch die Aktivität des Transkriptionsfaktors im Zellkern. Im nicht phosphorylierten Zustand kann IKB nicht ubiquitiniert und daher auch nicht vom Proteasom abgebaut werden. Über diesen Mechanismus reduziert KINK-1 in Melanomzellen die Expression NF-kB-abhängiger Genprodukte, welche Proliferation, Migration und Adhäsion maßgeblich beeinflussen. $\mathrm{Zu}$ den herabregulierten Genprodukten zählen CCL-2 (MCP-1), CXCL-1 (Gro- $\alpha$ ), CXCL-8 (IL-8), TNFa, IL-6, MMP-9, COX-2 und I-CAM-1. Dies sind Zytokine und Chemokine, die nicht nur in die Tumorprogression, sondern auch in die Pathophysiologie entzündlicher Krankheiten involviert sind. Außerdem besitzt KINK-1 eine anti-apoptotische Wirkung, greift reversibel in den Zellzyklus ein (G2-Arrest) und kann die Wirkung von Zytostatika, wie Doxorubicin oder Camptothecin, verstärken (Amschler et al. 2010; Schön et al. 2008). Die Substanz weist auch in höheren effektiven Dosen nur eine geringe Zelltoxizität auf. Daten über die Wirkung von KINK-1 auf Endothelzellen lagen bis zu dieser Arbeit nicht vor.

\subsubsection{Bortezomib}

Bortezomib (Handelsname Velcade ${ }^{\circledR}$ ) ist ein selektiver reversibler Inhibitor des eukaryotischen 26S-Proteasoms. Es wird seit 2003 in den USA und seit 2004 in Europa zur gezielten Therapie (targeted therapy) des multiplen Myeloms und des Mantelzelllymphoms eingesetzt. Bisher wurde Bortezomib vor allem bezüglich seiner Wirkung auf Tumorzellen, vereinzelnd aber auch auf Endothelzellen, untersucht (Roccaro et al. 2006; Belloni et al. 2010; Tamura et al. 2010). Experimentelle Daten legen auch eine Wirksamkeit gegen Psoriasis nahe (Zollner et al. 2002). Sein Wirkmechanismus beruht auf der Hemmung des 26S-Proteasoms, eines multikatalytischen, ubiquitär vorkommenden, intrazellulären Enzymkomplexes. Nach der Markierung mit Ubiquitin werden fehlgefaltete oder mutierte Proteine von der regulatorischen 19S-Untereinheit des Proteasoms erkannt und von der katalytischen 20S-Untereinheit abgebaut (Arendt und Hochstrasser 1997; Heinemeyer et al. 1997; 
Goldberg 2003). Zahlreiche Proteine, die eine wichtige Rolle in Entwicklung, Differenzierung, Apoptose, Gentranskription und Signaltransduktion übernehmen, werden ebenfalls auf diesem Weg selektiv reguliert, indem sie aktiviert oder inaktiviert werden (Hershko und Ciechanover 1998; Naujokat und Hoffmann 2002). Durch Inhibition des Proteasoms kommt es intrazellulär unter anderem zu einer Akkumulation pro-apoptotischer Proteine und somit zum programmierten Zelltod. Gleichermaßen wird der NF-KB-Inhibitor IKB nicht mehr abgebaut, wodurch NF-KB nicht aktiviert werden kann, was wiederum zu verminderter Synthese antiapoptotischer Substanzen sowie weiterer NF-kB-abhängiger Genprodukte (proinflammatorische Zytokine, zelluläre Adhäsionsmoleküle) führt (Adams 2002, 2004; Ludwig et al. 2005). Durch seinen Eingriff in das Ubiquitin-ProteasomenSystem inhibiert Bortezomib unter anderem das Zellwachstum von Endothelzellen durch Suppression der G2/M-Transition (Tamura et al. 2010), induziert Apoptose in Lymphozyten, Retinoblasten und Endothelzellen (Pahler et al. 2003; Poulaki et al. 2007; Belloni et al. 2010) und reduziert durch verminderte VEGF-Expression die Angiogenese (Roccaro et al. 2006). Außerdem greift es in die Zell-Zell-Adhäsion und Zellmigration ein (Lorch et al. 2007). Studien zeigten, dass sich Bortezomib deutlich zytotoxischer auf Tumorzellen als auf gesunde Zellen auswirkt (Chen et al. 2011). 


\subsection{Zielstellung der Arbeit}

Eine wichtige Wirkung des DMF scheint die Inhibition der Translokation des Transkriptionsfaktors NF-kB in den Zellkern zu sein. Daher besteht das Ziel der vorliegenden Arbeit darin, die experimentelle Basis für eine Kombinationstherapie mit NF-kB-Inhibitoren zu schaffen, um so die nötige Dosis an DMF und damit auch Nebenwirkungen zu reduzieren.

In der vorliegenden Arbeit wurde zunächst die Wirkung des Fumarsäureesters DMF sowie der NF-KB-Inhibitoren KINK-1 und Bortezomib auf humane Endothelzellen untersucht. Danach wurde die Wirkung der Kombination jeweils eines NF-kBInhibitors mit DMF auf die Zellen näher betrachtet. Hierbei wurden neben der Translokation des Transkriptionsfaktors NF-KB auch Veränderungen auf der mRNAsowie der Proteinebene, unter besonderer Berücksichtigung wichtiger für die Psoriasis-Pathogenese relevanter Chemokine, Adhäsionsmoleküle und Wachstumsfaktoren untersucht. Des Weiteren wurden funktionelle Parameter der Zellen wie Apoptose und Proliferation sowie ihre Interaktion mit Lymphozyten analysiert. 


\section{Material und Methoden}

\subsection{Material}

\subsubsection{Verbrauchsmaterialien}

Verbrauchsmaterialien
Aufsatz für Multipette ${ }^{\circledR} 12,5 \mathrm{ml}$
Cell culture inserts for live cell analysis
Chamber slides (Immunfluoreszenz)
Cover slips (Deckgläschen für Flusskammer)
Deckgläschen 24 × $60 \mathrm{~mm}$

Cellstar $^{\circledR}$ flat bottom well-plates 6er, 12er, 96er

Einfrierröhrchen 2ml

Eppendorf-Cups 0,5 ml, 1,5 ml, 2,5 ml

FACS- Röhrchen $5 \mathrm{ml}$

Falcon- Röhrchen $15 \mathrm{ml}, 50 \mathrm{ml}$

Glaspipetten 5, 10, $25 \mathrm{ml}$

Glaspipetten für Absauger

Kanülen Microlance ${ }^{\mathrm{TM}} 3$

Kanülen Sterican ${ }^{\circledR}$

Labortücher

PCR cups

Petrischalen 100x20 mm

Pipettenspitzen 10, 200, $1000 \mu \mathrm{l}$

Pipettenspitzen TipOne

Pipettenspitzen FilterTip $1000 \mu \mathrm{l}$

Pipettenspitzen ep T.I.P.S. rocks $10 \mathrm{ml}$

Safety-Multifly-Set (zur Blutentnahme)

Spritze $20 \mathrm{ml}$

Spritzen Injekt ${ }^{\circledR}-\mathrm{F}$ Tuberkulin $1 \mathrm{ml}$

Zellkulturflaschen 25er, 75er

\section{Hersteller}

Eppendorf, Hamburg, Deutschland

Ibidi, Planegg / Martinsried, Deutschland

BD, Franklin Lakes, NJ, USA

Thermo Fisher Scientific, Waltham, MA, USA

Gerhard Menzel GmbH, Thermo Fisher

Scientific, Braunschweig, Deutschland

GreinerBioOne, Kremsmünster, Österreich

GreinerBioOne, Kremsmünster, Österreich

Eppendorf, Hamburg, Deutschland

$\mathrm{BD}$, Franklin Lakes, NJ, USA

GreinerBioOne, Kremsmünster, Österreich

Sarstedt, Nümbrecht, Deutschland

WU. Mainz, Deutschland

BD, Franklin Lakes, NJ, USA

B. Braun, Melsungen, Deutschland

Kimberly-Clark GmbH, Koblenz-Rheinhafen,

Deutschland

Biozym, Hessisch Oldendorf, Deutschland

GreinerBioOne, Kremsmünster, Österreich

Eppendorf, Hamburg, Deutschland

Starlab, Hamburg, Deutschland

Eppendorf, Hamburg, Deutschland

Eppendorf, Hamburg, Deutschland

Sarstedt, Nümbrecht, Deutschland

BD, Franklin Lakes, NJ, USA

B. Braun, Melsungen, Deutschland

GreinerBioOne, Kremsmünster, Österreich

\subsubsection{Geräte}

\section{Geräte}

Absaugsystem Vacusafe comfort

Abzug captair ${ }^{\Theta}$ flex ${ }^{\circledR}$

Appliskan

Brutschrank HERAcell 150

Brutschrank HERAcell 150i

CoolSNAP ES (Kamera am Mikroskop)

Einkanalpipetten 10, 20, 100, 200, $1000 \mu \mathrm{l}$

Durchflusszytometer FACS Canto II

Fluoreszenzmikroskop Axio Imager M1

Flusskammer

Gel Imager system U:Genius

Inverses Mikroskop Axiovert 200

\section{Hersteller}

IBS Integra Bioscinces, Fernwald, Deutschland Erlab group, Köln, Deutschland Thermo Fisher Scientific, Waltham, MA, USA Thermo Fisher Scientific, Waltham, MA, USA Thermo Fisher Scientific, Waltham, MA, USA Photometrics, Tucson, AZ, USA

Eppendorf, Hamburg, Deutschland BD, Franklin Lakes, NJ, USA

Zeiss, Oberkochen, Deutschland

Wunschanfertigung

Syngene, Cambridge, MA, USA

Zeiss, Oberkochen, Deutschland 
Kühl-/ Gefrierschränke $+4^{\circ},-20^{\circ},-80^{\circ}$

Mehrkanalpipette Transferpette ${ }^{\circledR}$ S-12 $200 \mu \mathrm{l}$

Mikroskop Axiovert $40 \mathrm{C}$

Multipette ${ }^{\circledR}$ plus

PCR Mastercycler

Photometer Genesys 10 Bio

Pipettierhilfe Pipetboy acu

Präzisionswaage

Reagent Reservoirs Tip-Tub (für

Mehrkanalpipette, autoklavierbar)

Reinstwasserpumpe arium 611 VF

Schüttler PMR- 30

Spannungsquelle für Elektrophorese Power

Pack P25

Thermblock ThermoStat plus

Tischzentrifuge Hearaeus Pico17

Vortex Mixer L-46

Wasserbad

Zellkulturbank HERAsafe

Zellkulturbank Safe 2020

Zentrifuge Heraeus Pico17

Zentrifuge Megafuge 1.0

Zentrifuge Megafuge 1.0 R

Zentrifuge 1 S-R Heraeus

Zentrifuge Rotina B5
Liebherr, Bulle, Schweiz

BRAND GMBH + CO KG, Wertheim,

Deutschland

Zeiss, Oberkochen, Deutschland

Eppendorf, Hamburg, Deutschland

Eppendorf, Hamburg, Deutschland

Thermo Fisher Scientific, Waltham, MA, USA

IBS Integra Bioscinces, Fernwald, Deutschland

Sartorius, Göttingen, Deutschland

Eppendorf, Hamburg, Germany

Sartorius, Göttingen, Deutschland

Grant- Bio, Cambridge, MA, USA

Biometra, Göttingen, Deutschland

Eppendorf, Hamburg, Deutschland

Thermo Fisher Scientific, Waltham, MA, USA

Labinco, Breda, Niederlande

Memmert, Schwabach, Deutschland

Heraeus, Hanau, Deutschland

Thermo Fisher Scientific, Waltham, MA, USA

Thermo Fisher Scientific, Waltham, MA, USA

Thermo Fisher Scientific, Waltham, MA, USA

Thermo Fisher Scientific, Waltham, MA, USA

Thermo Fisher Scientific, Waltham, MA, USA

Hettich Zentrifugen, Tuttlingen, Deutschland

\subsubsection{Chemikalien}

\section{Chemikalien}

7AAD

Accutase solution

Agarose

Calciumchlorid-Dihydrat

CFDA-SE

4',6-Diamidin-2-phenylindol (DAPI)

Dimethylsulfoxid (DMSO)

EDTA

EGM $^{\mathrm{TM}}$ Single Quots ${ }^{\circledR}$ (Herstellung von

Endothelial Cell Growth Medium)

Endothelial Cell Basal Medium

Einfriermedium CryoSFM

Essigsäure 100\%

Ethanol

Fetal calf serum (FCS)

Ficoll Paque Plus

Formaldehyd 37\%

GelRed $^{\mathrm{TM}}$

Hank's buffered salt solution (HBSS)

Heparin

Humanes AB- Serum

2-Mercaptoethanol
Hersteller

BD Bioscience, Heidelberg, Deutschland

PAA, Pasching, Österreich

Biozym Scientific, Hessisch Oldendorf,

Deutschland

Roth, Karlsruhe, Deutschland

Invitrogen, Carlsbad, CA, USA

Sigma- Aldrich, St. Louis, MO, USA

Roth, Karlsruhe, Deutschland

Roth, Karlsruhe, Deutschland

Lonza, Basel, Schweiz

Lonza, Basel, Schweiz

Promocell, Heidelberg, Deutschland

Roth, Karlsruhe, Deutschland

Roth, Karlsruhe, Deutschland

PAA, Pasching, Österreich

GE Healthcare, Chalfont St. Giles,

Großbritannien

Chem solute, Renningen, Deutschland

Biotium, Hayward, CA, USA

Life Technologies, Carlsbad, CA, USA

Rotexmedica, Trittau, Deutschland

Sigma- Aldrich, St. Louis, MO, USA

Roth, Karlsruhe, Deutschland 
Mounting Medium

$\mathrm{NaCl}$

Neutralrot

Phosphate- buffered saline (PBS)

rhTNFa

RPMI- 1640

Türks-Lösung

Tris

Trypanblau
DAKO, Glostrup, Deutschland Roth, Karlsruhe, Deutschland Roth, Karlsruhe, Deutschland PAA, Pasching, Österreich ImmunoTools, Friesoythe, Deutschland PAA, Pasching, Österreich Merck, Darmstadt, Deutschland Merck, Darmstadt, Deutschland Sigma-Aldrich, St. Louis, MO, USA

\subsubsection{Versuchssubstanzen}

\begin{tabular}{|c|c|c|}
\hline & Stammlösung & Hersteller \\
\hline Dimethylfumarat (DMF) & $50 \mathrm{mM}$ (in DMSO) & $\begin{array}{l}\text { Aldrich® Chemistry, St. Louis, } \\
\text { MO, USA }\end{array}$ \\
\hline Bortezomib & (in $\mathrm{NaCl}$ ) & $\begin{array}{l}\text { Janssen Cilag, Neuss, } \\
\text { Deutschland }\end{array}$ \\
\hline KINK-1 & $50 \mathrm{mM}$ (DMSO) & $\begin{array}{l}\text { Bayer, Leverkusen, } \\
\text { Deutschland }\end{array}$ \\
\hline
\end{tabular}

\subsubsection{Gebrauchsfertige Reaktionssysteme}

\section{Reaktionssysteme}

CellDeath ELISA Plus Kit

Cell Proliferation Assay BrDU

CellTiter96 ${ }^{\circledR}$ Non-radioactive cell proliferation assay

E.N.Z.A. ${ }^{\mathrm{TM}}$ Total RNA-Kit I

First strand cDNA synthesis Kit

RNAsa-free DNAse I Set

Taq DNA Polymerase all inclusive

Venor $^{\circledR}$ GeM Mycoplasma DetectionKit

\section{Hersteller}

Roche, Mannheim, Deutschland

Roche, Mannheim, Deutschland

Promega, Madison, WI, USA

Omega Bio-Tek-Norcross, GA, USA

Fermentas, St. Leon-Rot, Deutschland

Omega Bio-Tek-Norcross, GA, USA

Peqlab, Erlangen, Deutschland

Minerva Biolabs, Berlin, Deutschland

\subsubsection{Medien}

\section{Medium}

Einfriermedium Cryo-SFM

Endothelial Basal Cell Medium

EGM $^{\mathrm{TM}}$ Single Quots ${ }^{\circledR}$

Endothelial Basal Cell Medium MV2

MV2 Supplements

\section{Hersteller}

Promocell, Heidelberg, Deutschland

Lonza, Basel, Schweiz

Lonza, Basel, Schweiz

Promocell, Heidelberg, Deutschland

Promocell, Heidelberg, Deutschland 


\subsubsection{Antikörper}

\begin{tabular}{|c|c|c|c|}
\hline Antikörper & Ursprungsspezies & Zielspezies & Hersteller \\
\hline NF-кB p65 & Maus, $\lg \breve{G}_{1}$ & Mensch & $\begin{array}{l}\text { Santa Cruz Biotechnology, Inc., } \\
\text { Heidelberg, Deutschland }\end{array}$ \\
\hline $\begin{array}{l}\text { Sekundärantikörper } \\
\text { Alexa Fluor }{ }^{\circledR} 488 \text { anti- } \\
\text { mouse }\end{array}$ & Ziege, IgG & Maus & Cell Signaling, Danvers, MA, USA \\
\hline $\begin{array}{l}\text { E-Selectin/ CD62E PE } \\
\text { (IF/FACS) }\end{array}$ & Maus, IgG1 & Mensch & $\begin{array}{l}\text { Antibodies online, Aachen, } \\
\text { Deutschland }\end{array}$ \\
\hline $\begin{array}{l}\text { VCAM/ CD106 purified } \\
\text { (IF/FACS) }\end{array}$ & Maus, IgG1 & Mensch & $\begin{array}{l}\text { Immunotools, Friesoythe, } \\
\text { Deutschland }\end{array}$ \\
\hline ICAM/ CD54 FITC & Maus, IgG1 & Mensch & $\begin{array}{l}\text { Immunotools, Friesoythe, } \\
\text { Deutschland }\end{array}$ \\
\hline L-Selektin/ CD62L PE & Maus, lgG1 & Mensch & $\begin{array}{l}\text { BD Pharmingen, Heidelberg, } \\
\text { Deutschland }\end{array}$ \\
\hline LFA-1/ CD11a FITC & Ratte, IgG2a & Maus & $\begin{array}{l}\text { BD Pharmingen, Heidelberg, } \\
\text { Deutschland }\end{array}$ \\
\hline CLA-1 FITC & Ratte, IgM & Mensch & BioLegend, San Diego, CA, USA \\
\hline CD49d FITC & Maus, IgG1 & Mensch & $\begin{array}{l}\text { Immunotools, Friesoythe, } \\
\text { Deutschland }\end{array}$ \\
\hline Anti-CD3 PE & Maus, lgG1 & Mensch & $\begin{array}{l}\text { Immunotools, Friesoythe, } \\
\text { Deutschland }\end{array}$ \\
\hline $\begin{array}{l}\text { Anti-CD3 FITC } \\
\text { Isotyp FITC }\end{array}$ & $\begin{array}{l}\text { Maus, IgG1 } \\
\text { Hamster, IgG1 }\end{array}$ & Mensch & $\begin{array}{l}\text { DAKO, Hamburg, Deutschland } \\
\text { BD Pharmingen, Heidelberg, } \\
\text { Deutschland }\end{array}$ \\
\hline Isotyp PE & Maus, lgG1 & & $\begin{array}{l}\text { Immunotools, Friesoythe, } \\
\text { Deutschland }\end{array}$ \\
\hline Isotyp FITC & Ratte, lgG2b & & $\begin{array}{l}\text { Immunotools, Friesoythe, } \\
\text { Deutschland }\end{array}$ \\
\hline Isotyp purified & Maus, IgG1 & & $\begin{array}{l}\text { Zymed Laboratories, Life } \\
\text { Technology Cooperation, } \\
\text { Darmstadt, Deutschland }\end{array}$ \\
\hline
\end{tabular}

\subsubsection{EDV}

\section{Programm}

AxioVision Rel 4.7

FACS Diva Software

ImageJ

MetaMorph 6.3r2

Microsoft Office 2007

\section{Hersteller}

Zeiss, Oberkochen, Germany

BD, Franklin Lakes, NJ, USA

National Institutes of Health, Bethesda, MD, USA

Molecular devices, Sunnyvale, CA, USA

Microsoft, Redmond, WA, USA

\subsubsection{Sonstiges}

Elektrophoresekammer SubCell GT Gene Ruler ${ }^{\mathrm{TM}}$ 100bp PlusDNA Ladder Isopropanol-Cryo-Container

Neubauer Zählkammer 0,0025 mm² Timer

\section{Hersteller}

Bio- Rad, Hercules, CA, USA

Fermentas, St. Leon-Rot, Deutschland

Nalgene, Rochester, New York, USA

Brand, Wertheim Deutschland

Roth, Karlsruhe, Deutschland 


\subsubsection{Puffer/Lösungen/Medien}

„Blocking“-Lösung (für Immunfluoreszenz):

$50 \mu \mathrm{FCS}+950 \mu \mathrm{PBS}$

Antikörpergrundlösung (für Immunfluoreszenz):

$25 \mu \mathrm{FCS}+975 \mu \mathrm{l}$ PBS

10fach TBE-Puffer:

$108 \mathrm{~g}$ Tris $+55 \mathrm{~g}$ Borsäure $+40 \mathrm{ml}$ 0,5 M EDTA $(\mathrm{pH} 8.0)+1000 \mathrm{ml}$ Aqua bidest

Waschlösung (Neutralrot-Test):

1. $0,5 \mathrm{~g}$ Calciumchlorid-Dihydrat in $48,65 \mathrm{ml}$ PBS geben

2. 1,35 ml 37\%iges Formaldehyd hinzugeben

Extraktionslösung (Neutralrot-Test):

1. $25 \mathrm{ml} 100 \%$ Ethanol auf 24,5 ml Aqua destillieren

2. $0,5 \mathrm{ml} 100 \%$ Essigsäure hinzugeben

Waschpuffer (Flusskammer):

$50 \mathrm{ml}$ HBSS (ohne $\mathrm{Ca}^{2+}$ und $\mathrm{Mg}^{2+}$ ) $+100 \mu \mathrm{l} 2 \mathrm{mM} \mathrm{CaCl}_{2}$

Doppeltes Einfriermedium:

DMSO (20\%) + FCS (40\%) + RPMI (40\%)

Basalmedium:

$500 \mathrm{ml}$ Basalmedium (Lonza) + 50 ml FCS (Fetales Kälberserum) 


\subsection{Methoden}

\subsubsection{Zelllinien und Kultivierung}

Bei den Human Umbilical Vein Endothelial Cells (HUVEC) handelt es sich, um makrovaskuläre Endothelzellen, die aus der Nabelschnur gesunder Neugeborener isoliert und von verschiedenen Spendern zusammengeführt (gepoo/t) werden. Human Dermal Microvascular Endothelial Cells (HDMEC) werden aus juveniler Vorhaut isoliert. Beide Zelltypen wurden in Sekundärkultur von den entsprechenden Firmen bezogen. Auf die Nutzung immortalisierter Zelllinien wurde bewusst verzichtet, da sie sich zwar leichter und länger kultivieren lassen, jedoch eine Funktionseinschränkung dieser Endothelzellen gezeigt wurde, insbesondere hinsichtlich ihres Ansprechens auf TNFa und der Expression entzündungsrelevanter Adhäsionsmoleküle (Oostingh et al. 2007).

Die adhärent wachsenden Zellen wurden im Brutschrank bei $37{ }^{\circ} \mathrm{C}$, einem $\mathrm{CO}_{2^{-}}$ Gehalt von $5 \%$ sowie einer relativen Luftfeuchtigkeit von $95 \%$ kultiviert. Ausgesät wurden die Zellen in $T_{75}$-Zellkulturflaschen in Wachstumsmedium (Endothelial Growth Medium, EGM) plus Zusätzen (Supplements). Die Verdopplungsrate der Endothelzellen schwankt passagenabhängig, wobei HUVEC bis etwa zur 16. Passage proliferierten. Die HDMEC wuchsen bereits nach der sechsten Passage nur noch sehr langsam. Bei einer Konfluenz (Bedeckung des Gefäßbodens durch die kultivierten Zellen) von etwa $90 \%$ wurden die Zellen passagiert, für die Versuche ausgesät oder eingefroren. Zunächst wurde hierfür jeweils das Medium von den Zellen abgesaugt, die Oberfläche mit $9 \mathrm{ml}$ PBS für etwa $30 \mathrm{sec}$ gewaschen und nach Absaugen des PBS mit $3 \mathrm{ml}$ Accutase ${ }^{\circledR}$ zwei Minuten lang bei $37{ }^{\circ} \mathrm{C}$ inkubiert. Anschließend wurde der Überstand mit $2 \mathrm{ml} \mathrm{EGM}$ in ein Zentrifugenröhrchen überführt und zentrifugiert. Accutase ${ }^{\circledR}$, ein natürliches proteolytisches und kollagenolytisches Enzym, verdaut sich anschließend selbst, wodurch ein Stoppen der Ablösungsreaktion nicht nötig ist. Nach Resuspension des Zellsediments in EGM wurde die gewünschte Zellanzahl in eine neue Flasche überführt. Für die im Folgenden beschriebenen Versuche wurden die Zellpassagen 4 bis 6 genutzt. Etwa alle drei Tage wurde das EGM gewechselt.

Jeweils 18 bis 24 Stunden vor dem Beginn der jeweiligen Versuche wurde das EGM durch basales Zellmedium (Basal Cell Medium, EBM) plus 10\% FCS ersetzt, um den 
Stoffwechsel der Zellen zu normalisieren und so die Versuchsergebnisse nicht zu verfälschen.

Die Endothelzellen wurden jeweils mit TNFa stimuliert $(25 \mathrm{ng} / \mathrm{ml})$, um eine Entzündungsreaktion zu imitieren (Wallbrecht et al. 2011; Lockmann und Schön 2014). HUVEC und HDMEC exprimieren die meisten ihrer Adhäsionsmoleküle erst im aktivierten Zustand (Thorp et al. 1992; Klein et al. 1995, 1994; Oostingh et al. 2007). Außerdem übernimmt TNFa eine wichtige Rolle bei der Pathogenese der Psoriasis (Boehncke und Schön 2015) und es wird in Psoriasis-Läsionen vermehrt exprimiert (Ettehadi et al. 1994). TNFa beeinflusst unter anderem die Immunantwort, den Zellzyklus, die Produktion von Chemokinen und die Apoptose (Banno et al. 2004).

Vor der PCR, der Durchflusszytometrie sowie den Flusskammerversuchen wurden die Endothelzellen für $4 \mathrm{~h}$ stimuliert, vor der Immunfluoreszenz zum NF-kB-Nachweis für $2 \mathrm{~h}$. Für E-Selektin beispielsweise ist die stärkste Expression $4 \mathrm{~h}$ nach TNFaStimulation bekannt (Bevilacqua et al. 1987).

\subsubsection{Zellzahlbestimmung mit Neubauer-Zählkammer}

Vor dem Aussäen und Einfrieren der Zellen wurden diese jeweils zentrifugiert, das Zellsediment in $1 \mathrm{ml}$ Medium resuspendiert und eine 1:10 Verdünnung mit Trypanblau hergestellt. Trypanblau ermöglicht die Unterscheidung vitaler von toten Zellen, da der blaue Farbstoff sich in die Zellwand toter Zellen einlagert. $10 \mu \mathrm{l}$ der Suspension wurden auf eine Neubauer-Zählkammer aufgetragen und die ungefärbten Zellen in allen vier Quadranten der Zählkammer gezählt. Die Zellzahl wurde mit folgender Formel bestimmt:

Zellzahl $\left(\mathrm{ml}^{-1}\right)=$ (Mittelwert der vier Quadranten) $\times 10^{4} \times$ Verdünnungsfaktor $(10) x$ Ausgangsvolumen (1ml)

\subsubsection{Kryokonservierung und Revitalisierung der HUVEC}

Zur Kryokonservierung wurde das Zell-Accutase ${ }^{\circledR}-$ PBS-Gemisch, nach vorheriger Bestimmung der Zellzahl, bei $250 \mathrm{~g}$ für 5 min bei Raumtemperatur (RT) zentrifugiert und anschließend in $4{ }^{\circ} \mathrm{C}$ kaltem Einfriermedium aufgenommen. Die Zellen wurden hierbei auf Konzentrationen von $7,5 \times 10^{5} / \mathrm{ml}$ bis $1 \times 10^{6} / \mathrm{ml}$ verdünnt. Jeweils $1 \mathrm{ml}$ der Zellsuspension wurde in vorbeschriftete Einfrier-Röhrchen pipettiert und zunächst 
über Nacht bei $-80^{\circ} \mathrm{C}$ in einem Isopropanol-Tank eingefroren. Durch das Isopropanol kühlen die Proben langsam um $1{ }^{\circ} \mathrm{C}$ pro min ab. Am folgenden Tag wurden die Zellen zur dauerhaften Lagerung in flüssigen Stickstoff $\left(-196^{\circ} \mathrm{C}\right)$ überführt.

Zum Auftauen der Zellen wurden die Einfrier-Röhrchen ohne Verzögerung im Wasserbad bei $37^{\circ} \mathrm{C}$ aufgetaut. Das aufgetaute Zell-Einfriermedium-Gemisch wurde in eine mit Medium gefüllte $\mathrm{T}_{75}$-Kulturflasche pipettiert, welche zuvor bei $37^{\circ} \mathrm{C}$ im Brutschrank vorgewärmt wurde. Nach spätestens $24 \mathrm{~h}$ wurde das Medium ausgetauscht, da das Einfriermedium Dimethylsulfoxid (DMSO) enthielt. DMSO verhindert die Bildung extra- und intrazellulärer Kristalle während des Einfrierprozesses, kann allerdings auch toxisch auf Endothelzellen wirken (Layman 1987; Koizumi et al. 2003).

\subsubsection{Indirekte Immunfluoreszenz}

Das Prinzip der indirekten Immunfluoreszenz beruht auf der Markierung des zu bestimmenden Proteins mit einem Antikörper, welcher wiederum durch die spätere Bindung eines zweiten, mit einer fluoreszierenden Substanz gekoppelten Antikörpers, im Fluoreszenzmikroskop nachweisbar wird. In der vorliegenden Arbeit wurde mit Hilfe der Immunfluoreszenz die Translokation der Untereinheit p65, welche die in Endothelzellen häufigste Untereinheit des Transkriptionsfaktors NF-kB ist, in den Zellkern nachgewiesen. Dies geschah jeweils unter Einfluss von DMF, Bortezomib oder KINK-1. Die Ergebnisse dienten in Vorbereitung der weiteren Versuche zur Bestimmung der optimalen Einzelkonzentrationen der drei Stoffe und ihrer Auswirkung auf die Zellen. Außerdem erlaubt die Auswertung der mikroskopischen Bilder eine erste orientierende Aussage über die Toxizität der drei Wirkstoffe.

Für die indirekte Immunfluoreszenz wurden zunächst $40 \mathrm{~h}$ vor Versuchsbeginn HUVEC in gekammerte Objektträger (Chamber slides) mit je $30.000 \mathrm{HUVEC/}$ Kammer in jeweils $500 \mu \mathrm{l} \mathrm{EGM}$ ausgesät. Auf den Chamber slides wachsen die Zellen in Plastikkämmerchen, welche auf einem Glasobjektträger befestigt sind. Nach Beendigung der Versuchsdurchführung können die Kämmerchen abgetrennt und die Zellen ohne Beeinträchtigung der Zellschicht fixiert und unter dem Mikroskop betrachtet werden. 
Zuvor wurde nach einer 36 -stündigen Inkubation bei $37^{\circ} \mathrm{C}$ ein Mediumwechsel auf EBM durchgeführt, $4 \mathrm{~h}$ später wurden die HUVEC wie nachfolgend beschrieben behandelt:

\section{Auflistung der Ansätze für die Immunfluoreszenz:}

1. unbehandelt, unstimuliert

2. unbehandelt, stimuliert

3. Vehikel (DMSO), stimuliert

4. Isotypkontrolle

5. unbehandelt, stimuliert

6. unbehandelt, stimuliert

7. - 12. DMF 5-300 $\mu \mathrm{mol}$

13. - 15. KINK-1 0,3-50 $\mu \mathrm{M}$

16. - 18. Bortezomib $5-50 \mathrm{ng} / \mathrm{ml}$
1. $A K+2 \cdot A K$

1. $A K+2 . A K$

1. $A K+2 \cdot A K$

kein AK

nur 2. AK

1.AK + 2.AK

$1 . A K+2 \cdot A K$

$1 . A K+2 \cdot A K$

Die mit DMF behandelten Zellen wurden zunächst $2 \mathrm{~h}$ im Brutschrank bei $37{ }^{\circ} \mathrm{C}$ inkubiert, daraufhin erfolgte die Stimulation mit TNFa $(25 \mathrm{ng} / \mathrm{ml})$ für weitere $30 \mathrm{~min}$. Nach der Behandlung wurde das Medium vorsichtig entfernt und zwei Waschgänge mit jeweils $500 \mu \mathrm{l}$ PBS $\left(4^{\circ} \mathrm{C}\right)$ durchgeführt. Zur anschließenden Fixierung der Zellen wurden in jede Kammer $500 \mu \mathrm{l}$ Methanol $\left(-20^{\circ} \mathrm{C}\right)$ gegeben und für $5 \mathrm{~min}$ im Gefrierschrank bei $-20{ }^{\circ} \mathrm{C}$ inkubiert. Das Methanol wurde durch ausklopfen und zweimaliges Waschen mit PBS vollständig entfernt. Hierauf folgte die Inkubation mit $500 \mu \mathrm{l}$ „Blocking“-Lösung (5\% FCS in PBS) pro Kammer bei RT auf dem Schüttler. Nach Entfernen der „Blocking"-Lösung erfolgte die Zugabe des 1. Antikörpers (AK), welcher zuvor in einer AK-Grundlösung (2,5 \% FCS in PBS) verdünnt wurde. Die Proben wurden damit über Nacht bei $4{ }^{\circ} \mathrm{C}$ auf dem Schüttler inkubiert. Am folgenden Tag wurde die Grundlösung entfernt und die Kammern dreimal für jeweils 10 min mit PBS auf dem Schüttler gewaschen. Anschließend wurde der zuvor ebenfalls in der AK-Grundlösung verdünnte 2. AK auf die Kammern gegeben und für $1 \mathrm{~h}$ lichtgeschützt bei RT auf dem Schüttler inkubiert. Danach wurden die Kammern erneut mit PBS gewaschen und nachfolgend einige Minuten an der Luft getrocknet. Nach Entfernen der Plastikkammern wurden $15 \mu \mathrm{l}$ Einbettmedium (mounting medium) plus 4`,6-Diamidin-2-phenylindol (DAPI), in einer Konzentration von 1:100 
hinzugegeben und das Ganze vorsichtig mit einem Deckglas abgedeckt, leicht angedrückt und mit Klarlack verschlossen.

Bei DAPI handelt sich um einen Fluoreszenzfarbstoff der sich in die AT-reichen Regionen der kleinen Furche der DNA-Doppelhelix einlagert und damit in der Lage ist, DNA-reiche Regionen wie den Zellkern zu markieren. Das Emissionsmaximum von DAPI liegt im Bereich des kurzwelligen Lichtes, weshalb es möglich ist, Stoffe mit einem langwelligen Emissionsmaximum wie Alexa488, gleichzeitig einzusetzen. Abschließend wurden die Färbungen mit dem Mikroskop Axio Imager M1 sowie der Software Axio Vision ausgewertet. Unter dem Fluoreszenzmikroskop fluoreszierten die DAPI-markierten Zellkerne blau, während der mit Alexa488 gekoppelte Transkriptionsfaktor NF-kB grün fluoreszierte.

\subsubsection{Polymerase-Kettenreaktion (polymerase chain reaction, PCR)}

\subsubsection{Prinzip der PCR}

Die Methode der PCR erlaubt es, Primer-markierte DNA-Abschnitte mit Hilfe der hitzestabilen Taq-Polymerase des Bakteriums Thermus aquaticus zu amplifizieren. Durch aufeinanderfolgende Zyklen wird die DNA exponentiell vermehrt, wobei sich die Amplifikation in Denaturierung, Primer-Hybridisierung (Annealing) und Elongation gliedert. Durch hohe Temperaturen von $92{ }^{\circ} \mathrm{C}$ bis $94{ }^{\circ} \mathrm{C}$ werden zunächst die Wasserstoffbrückenbindungen innerhalb der DNA gespalten, so dass diese in ihren Einzelsträngen vorliegt und sich die Primer in der Annealing-Phase $\left(55^{\circ} \mathrm{C}\right.$ bis $\left.62{ }^{\circ} \mathrm{C}\right)$ anlagern können. Während der Elongationsphase lagert die Taq-Polymerase bei 72 ${ }^{\circ} \mathrm{C}$ in 5'-3'-Richtung Nukleotide an die Primer an. Die Elongationsdauer variiert je nach Größe des zu amplifizierenden DNA-Abschnitts ebenso wie die optimale Anzahl der Reaktionszyklen.

\subsubsection{Probengewinnung}

Um die Wirkung der drei Stoffe DMF, KINK-1 und Bortezomib auf mRNA-Ebene zu untersuchen, wurden vier Tage vor der Behandlung jeweils 100.000 Zellen pro 25 $\mathrm{cm}^{2}$-Kulturflasche ausgesät und $24 \mathrm{~h}$ vor der Behandlung in EBM kultiviert. Die drei Substanzen wurden dann direkt in die Kulturflaschen pipettiert, in denen sich ein Endvolumen von $5 \mathrm{ml}$ befand. Die Zellkulturen wurden mit DMF $(5-200 \mu \mathrm{M}), \mathrm{KINK}-1$ 
(5-100 $\mu \mathrm{M})$, Bortezomib (1,25-50 $\mathrm{ng} / \mathrm{ml})$ oder einer Kombination dieser Stoffe (5-100 $\mu \mathrm{M}$ DMF + 5-100 $\mu \mathrm{M}$ KINK-1 beziehungsweise 0,625-5 $\mu \mathrm{M}$ KINK-1; 5-50 $\mu \mathrm{M}$ DMF + 2,5-50 $\mathrm{ng} / \mathrm{ml}$ Bortezomib) versetzt und nach einer Stunde zusätzlich mit $25 \mathrm{ng} / \mathrm{ml}$ TNFa stimuliert. Nach weiteren $4 \mathrm{~h}$ Inkubationszeit bei $37^{\circ} \mathrm{C}$ im Brutschrank wurde die Behandlung der Zellen durch Waschen mit PBS gestoppt und die Zellen lysiert.

\subsubsection{Lyse}

Nach Abschluss der Behandlung mit DMF, KINK-1 oder Bortezomib wurde das Medium vorsichtig aus den Flaschen entfernt, die Zellen mit $3 \mathrm{ml}$ PBS gewaschen und anschließend 7 min mit $1 \mathrm{ml}$ Accutase bei $37^{\circ} \mathrm{C}$ im Brutschrank inkubiert. Anschließend wurden die Zellen mit zusätzlichen $5 \mathrm{ml}$ PBS in $15 \mathrm{ml}$ Zentrifugenröhrchen überführt und für 5 min bei $250 \times$ g zentrifugiert. Der Überstand wurde verworfen und die Zellsedimente in $350 \mu$ TRK-Lysis-Puffer (TRK lysis buffer) resuspendiert. Der TRK-Puffer wurde zuvor mit 2\% vol. 2-Mercaptoethanol versetzt. Nach Überführung in 1,5-ml-Eppendorf-Zentrifugenröhrchen erfolgte das Umschreiben in mRNA.

\subsubsection{4 mRNA-Isolierung und DNAse-Verdau}

Zunächst wurde das Lysat durch mehrmaliges Auf- und Abpipettieren homogenisiert und mit $350 \mu \mathrm{l}$ 70\%-igem Ethanol versetzt. Anschließend wurde die Probe in eine HiBind RNA Spin Column überführt, welche zuvor in ein $2 \mathrm{ml}$-Sammelgefäß eingesetzt wurde. In der Säule befindet sich eine Silika-Gel-Membran an die die RNA reversibel bindet. Durch die im Folgenden beschriebenen Waschschritte wurden Verunreinigungen der Probe minimiert und durch den DNAse-Verdau eine DNAKontamination beseitigt. Die Probe wurde nun für $1 \mathrm{~min}$ bei $10.000 \times \mathrm{g}$ zentrifugiert. Nachdem der Inhalt des Sammelgefäßes verworfen wurde, wurden $250 \mu \mathrm{l}$ Waschpuffer I je Probe aufgetragen und erneut bei $10.000 \mathrm{x}$ g für 1 min zentrifugiert. Anschließend erfolgte der DNAse-Verdau, indem 73,5 $\mu$ INAse-Verdau-Puffer mit 1,5 $\mu \mathrm{l}$ RNAse-freier DNAse vermischt direkt auf die Membran innerhalb der Säule aufgetragen wurden. Nach 15-minütiger Inkubation bei RT wurden $500 \mu \mathrm{l}$ Waschpuffer I auf die Säule pipettiert und nach weiteren 2 min Inkubationszeit wurden die Säulen für 1 min bei $10.000 \times$ g zentrifugiert. Darauffolgend wurden die Proben zweimal mit Waschpuffer II gewaschen und zentrifugiert. Ohne weitere 
Hinzugabe eines Puffers wurden die Säulen zwei Minuten lang bei Höchstgeschwindigkeit $(17.000 \times \mathrm{g})$ zentrifugiert, um die Flüssigkeit vollständig zu entfernen. Nach diesem Schritt wurden die Säulen in ein 1,5-ml-EppendorfZentrifugenröhrchen eingesetzt und jeweils $40 \mu \mathrm{l}$ auf $70^{\circ} \mathrm{C}$ vorgewärmtes RNAsefreies Wasser (DEPC-Wasser) auf jede Säule gegeben. Die Säulen wurden nun 1 min inkubiert und anschließend ein letztes Mal für $2 \mathrm{~min}$ bei höchster Geschwindigkeit zentrifugiert. Die Proben wurden nun bei $-80^{\circ} \mathrm{C}$ gelagert oder gleich weiterverarbeitet.

\subsubsection{Photometrische Bestimmung der mRNA-Konzentration und Reverse Transkription}

Vor dem Umschreiben der mRNA in cDNA wurde die mRNA-Konzentration mittels eines Spektralphotometers ermittelt. Die Bestimmung erfolgte bei einer Wellenlänge von $260 \mathrm{~nm}$. Hinzukommend wurde die Absorption bei $280 \mathrm{~nm}$ gemessen, um mögliche Verunreinigungen durch Proteine zu bestimmen. Der Quotient der gemessenen optischen Dichte bei $260 \mathrm{~nm}$ und bei $280 \mathrm{~nm}$ sollte zwischen 1,8 und 2,0 liegen. Danach wurde die mRNA mit nukleasefreiem Wasser auf $10 \mu \mathrm{l}$ aufgefüllt und zu jeder dieser Proben jeweils $1 \mu \mathrm{ldT} \mathrm{d}_{18}$-Primer aus dem First Strand cDNA Synthesis Kit hinzugegeben. Nach gründlichem Mischen und kurzer Zentrifugation wurden die Proben 5 min auf $70{ }^{\circ} \mathrm{C}$ erhitzt. Daraufhin wurden die Proben auf Eis abgekühlt und zu jeder Probe $9 \mu$ des folgenden Mastermixes pipettiert:

\begin{tabular}{ll}
\multicolumn{2}{l}{ Mastermix cDNA } \\
5 x Reaktionspuffer $^{2}$ & $4 \mu \mathrm{l}$ \\
RiboLock $^{\mathrm{TM}}$ RNAse Inhibitor & $1 \mu \mathrm{l}$ \\
dNTP Mix & $2 \mu \mathrm{l}$ \\
Reverse Transkriptase & $2 \mu \mathrm{l}$
\end{tabular}

Nun wurden die Proben mit einem Endvolumen von $20 \mu \mathrm{l}$ für 65 min bei $37{ }^{\circ} \mathrm{C}$ inkubiert. Anschließend folgte eine 10-minütige Inkubation bei $70^{\circ} \mathrm{C}$, durch welche die Reaktion gestoppt wurde. Die cDNA wurde sofort weiterverwendet oder bei -20 ${ }^{\circ} \mathrm{C}$ gelagert. 


\subsubsection{Durchführung der PCR}

Zur Durchführung der PCR wurden zunächst in jedes Reaktionsgefäß $24 \mu \mathrm{l}$ eines zuvor hergestellten Mastermixes (siehe unten) und $1 \mu \mathrm{l}$ der jeweiligen cDNA gegeben. Für jede PCR wurde zusätzlich eine Negativkontrolle (Mastermix $+1 \mu \mathrm{l}$ Aqua dest.) erstellt, welche später auch auf das Gel aufgetragen wurde.

\section{Mastermix PCR}

\begin{tabular}{lr} 
Vorwärts-Primer & $0,5 \mu \mathrm{l}$ \\
Rückwärts-Primer & $0,5 \mu \mathrm{l}$ \\
dNTP $10 \mathrm{mM}$ & $0,5 \mu \mathrm{l}$ \\
$10 \times$ Puffer S & $2,5 \mu \mathrm{l}$ \\
Taq- Polymerase & $0,1 \mu \mathrm{l}$ \\
Aqua dest & $19,9 \mu \mathrm{l}$ \\
\hline Endvolumen & $24 \mu \mathrm{l}$
\end{tabular}

Die PCRs wurden in einem Thermozykler durchgeführt. Zunächst erfolgte eine Denaturierung für $3 \mathrm{~min}$ bei $94{ }^{\circ} \mathrm{C}$, dann eine Denaturierungsphase für $30 \mathrm{sec}$ bei ebenfalls $94^{\circ} \mathrm{C}$ und das Annealing mit anschließender Elongation bei $72{ }^{\circ} \mathrm{C}$. Die Annealing-Temperatur variierte je nach Gen zwischen $55^{\circ} \mathrm{C}$ und $62^{\circ} \mathrm{C}$, ebenso die Anzahl der Zyklen. Die genauen Versuchsbedingungen der durchgeführten PCRs finden sich in der folgenden Tabelle: 


\begin{tabular}{|c|c|c|c|}
\hline Gen & Sequenz des Vorwärts-Primers & Sequenz des Rückwärts-Primers & $\begin{array}{c}\text { Größe/ } \\
\text { Annealingtemp./ } \\
\text { Zyklenanzahl }\end{array}$ \\
\hline GAPDH & $\begin{array}{c}5^{\star}- \\
\text { CTTTGGTATCGTGGAAGGACTC- } \\
3^{\prime}\end{array}$ & 5'-TTCGTTGTCATACCAGGAAATG-3“ & $\begin{array}{c}451 \mathrm{bp} \\
58^{\circ} \mathrm{C} / 26 \text { Zyklen }\end{array}$ \\
\hline $\begin{array}{l}\text { CD106 } \\
\text { (VCAM- } \\
1 \text { ) }\end{array}$ & $\begin{array}{c}5^{\star}- \\
\text { CCAGAATCTAGATATCTTGCTC-3، }\end{array}$ & 5'-CAGCCTGTCAAATGGGTATAC-3' & $\begin{array}{c}355 \text { bp } \\
58^{\circ} \mathrm{C} / 30 \text { Zyklen }\end{array}$ \\
\hline $\begin{array}{l}\text { CD54 } \\
(\text { ICAM-1) }\end{array}$ & 5'-TGACCAGCCCAAGTTGTTGG-3“ & 5‘-АTCTCTCCTCACCAGCACCG-3‘ & $\begin{array}{c}379 \mathrm{bp} \\
55^{\circ} \mathrm{C} / 26 \text { Zyklen }\end{array}$ \\
\hline $\begin{array}{l}\text { CD62E } \\
\text { (E- } \\
\text { Selektin) }\end{array}$ & 5'- AAGCCTGGCAGTTCCGGG-3‘ & 5'-GGCTTTGGCAGCTGCTGG-3" & $\begin{array}{c}308 \mathrm{bp} \\
56^{\circ} \mathrm{C} / 26 \text { Zyklen }\end{array}$ \\
\hline VEGF & $\begin{array}{c}\text { 5'-CGAAGTGGTGAAGTTCATGGA- } \\
3^{\prime}\end{array}$ & 5‘-TTCTGTATCAGTCTTTCCTGGT- 3“ & $\begin{array}{c}469 \mathrm{bp} \\
55^{\circ} \mathrm{C} / 30 \text { Zyklen }\end{array}$ \\
\hline $\begin{array}{l}\text { CXCL8 } \\
(\mathrm{IL}-8)\end{array}$ & $\begin{array}{l}5^{5-} \\
\text { ACAAGCTTCTAGGACAAGAGCCA } \\
\text { GGAAG- 3، }\end{array}$ & $\begin{array}{c}5^{\circ}- \\
\text { GTGAATTCAGTGGTCCACTCTCAAT } \\
\text { C-3“ }\end{array}$ & $\begin{array}{c}253 \mathrm{bp} \\
62{ }^{\circ} \mathrm{C} / 26 \text { Zyklen }\end{array}$ \\
\hline $\begin{array}{l}\text { CCL2 } \\
(\mathrm{MCP}-1)\end{array}$ & $\begin{array}{c}5^{4}- \\
3^{\prime}\end{array}$ & $\begin{array}{c}5^{\prime} \text {-TGCAGATTCTTGGGTTGTGGAG- } \\
3^{\prime}\end{array}$ & $\begin{array}{c}297 \mathrm{bp} \\
58^{\circ} \mathrm{C} / 26 \text { Zyklen }\end{array}$ \\
\hline $\begin{array}{l}\text { CXCL1 } \\
(\text { Gro- } \alpha)\end{array}$ & $\begin{array}{c}5^{\star} \text {-ATGGCCCGCGCTGCTCTCTCC- } \\
3^{\prime}\end{array}$ & 5'-CTTAACTATGGGGGATGCAGG-3، & $\begin{array}{c}282 \mathrm{bp} \\
58^{\circ} \mathrm{C} / 26 \text { Zyklen }\end{array}$ \\
\hline
\end{tabular}

Tab. 11: Primersequenzen und PCR-Versuchsbedingungen

\subsubsection{Agarose-Gelelektrophorese}

Zuerst wurden für die Herstellung des Gels $2 \mathrm{~g}$ Agarose-Pulver und $200 \mathrm{ml}$ TBEPuffer vermischt und in der Mikrowelle bis zum Siedepunkt erhitzt. Dann wurden zu je $200 \mathrm{ml}$ des Gemisches $6 \mu \mathrm{l} \mathrm{GelRed}{ }^{\mathrm{TM}}$, ein interkalierender Fluoreszenzfarbstoff, hinzupipettiert, da nur durch diesen die DNA später unter UV-Licht sichtbar wurde. Die noch heiße Lösung wurde anschließend in eine vorbereitete Gelkammer gegossen, in die zur Taschenbildung Kämme hineingesteckt wurden. Nach etwa 20 min konnten die Kämme entfernt und die Proben aufgetragen werden. Jede Probe wurde hierzu mit $2 \mu$ l blaugefärbtem Ladungspuffer gründlich vermischt bevor jeweils $10 \mu \mathrm{l}$ der Probe in eine Geltasche pipettiert wurden. Um die Größe des DNAProduktes später beurteilen zu können, wurden in die erste Geltasche jeder Reihe jeweils $5 \mu \mathrm{l}$ eines DNA-Oligomers bekannter Größe (Größenstandard 100 bp) pipettiert. In der Elektrophoresekammer wanderten die Nukleinsäuren für $2 \mathrm{~h}$ bei 120 $\checkmark$ aufgrund ihrer Ladung durch das Gel und trennten sich entsprechend ihrer Größe 
auf, wobei sich kleine Moleküle schneller durch das Gel bewegen als größere. Anschließend wurden die Banden in den Gelen unter einer UV-Lampe sichtbar gemacht und fotografiert.

\subsubsection{Zelltod-ELISA}

Der Zelltod-ELISA wurde zur Bestimmung der Apoptose-induzierenden DMF-, KINK1 und Bortezomib-Konzentration durchgeführt. Für die Durchführung der Versuche wurde das CellDeath Detection ELISA Plus-System der Firma Roche genutzt, wobei streng nach dem vom Hersteller gelieferten Protokoll vorgegangen wurde. Der Test weist spezifische DNA-Fragmente und Histon-assoziierte Nukleosomen nach, welche bei der Apoptose enstehen.

$24 \mathrm{~h}$ vor Versuchsbeginn wurden HUVEC in einer 96-Kammer-Platte in EGM ausgesät. Nach $20 \mathrm{~h}$ Inkubation erfolgte der vorsichtige Wechsel von EGM auf EBM. Nach weiteren $4 \mathrm{~h}$ wurden die Zellen mit DMF (50-300 $\mu \mathrm{M})$, KINK-1 (5-100 $\mu \mathrm{M})$ und Bortezomib $(3,3-50 \mathrm{ng} / \mathrm{ml})$ behandelt. Zusätzlich wurden folgende Kontrollen verwendet:

a) unbehandelte, unstimulierte Zellen

b) EBM plus DMSO

c) unbehandelte, stimulierte Zellen

d) Positivkontrolle mit Staurosporin.

Nach $1 \mathrm{~h}$ Inkubation im Brutschrank erfolgte jeweils die Zugabe von TNFa und die anschließende Inkubation über Nacht. Jede Probe beziehungsweise Kontrolle wurde als Triplett (jede Versuchsbedingung dreifach) angelegt. Nach Ablauf der Inkubationszeit wurden die Zellen für $10 \mathrm{~min}$ bei $200 \mathrm{x} \mathrm{g}$ zentrifugiert und der Überstand verworfen. Nach Hinzugabe von $200 \mu$ Lysepuffer, erfolgte eine 30minütige Inkubation unter der Sterilbank (RT). Hierdurch werden die Zellen aufgebrochen und die Nukleosomen freigesetzt. Anschließend wurden die Zellen erneut für 10 min zentrifugiert und jeweils $20 \mu \mathrm{l}$ des Lysat-Überstandes in eine der 45 mit Streptavidin beschichteten Kammern überführt. Zusätzlich wurden in jede Kammer $80 \mu \mathrm{l}$ Immunreagenz (bestehend aus $240 \mu \mathrm{l}$ Anti-DNA-POD, $240 \mu \mathrm{l}$ AntiHiston und $4320 \mu \mathrm{l}$ Inkubationspuffer) gegeben. Mit selbstklebender Folie verschlossen, folgte eine 2-stündige Inkubation bei RT auf dem Plattenschüttler. Darauffolgend wurde die Lösung aus den Kammern entfernt und die Zellen dreimal 
mit $250 \mu \mathrm{l}$ Inkubationspuffer gewaschen. Schließlich wurden $100 \mu \mathrm{l}$ ABTS-Lösung (2,2'-Azino-di-(3-ethylbenzthiazolin-6-sulfonsäure) in jede Kammer gegeben und die Platte 10 bis 20 min auf dem Plattenschüttler inkubiert bis eine Farbreaktion sichtbar wurde (Farbumschlag von farblos zu grün). Gestoppt wurde die Reaktion mit $100 \mu \mathrm{l}$ ABTS-Stopplösung je Kammer. Die photometrische Messung erfolgte durch Messung der Absorption bei $405 \mathrm{~nm}$ und einer Referenzwellenlänge von $490 \mathrm{~nm}$.

\subsubsection{Neutralrot-Test}

Der Neutralrot-Test erlaubt den Nachweis lebender Zellen, da das Neutralrot an anionische Gruppen in lysosomalen Membranen vitaler Zellen gebunden wird. Defekte oder tote Zellen hingegen vermögen es nicht, den Farbstoff aufzunehmen und färben sich daher nicht rot.

Zunächst wurden $200 \mu \mathrm{l} \mathrm{EGM} \mathrm{mit} \mathrm{jeweils} 25.000$ Zellen in jede Kammer einer 96Kammer-Platte ausgesät und bei $37{ }^{\circ} \mathrm{C}$ im Brutschrank kultiviert. $24 \mathrm{~h}$ vor der Behandlung wurde das EGM durch EBM ausgetauscht, welches zuletzt durch $200 \mu \mathrm{l}$ Inkubationslösung (DMF, KINK-1, Bortezomib oder die Kombinationen plus EBM) ersetzt wurde. Die Zellen wurden mit dieser Inkubationslösung für $24 \mathrm{~h}$ behandelt und nach einer Stunde zusätzlich für $23 \mathrm{~h}$ mit TNFa stimuliert. Da das Neutralrot als Pulver geliefert wird, wurde dieses zunächst in Aqua dest. gelöst $(10 \mathrm{mg} / \mathrm{ml})$ und mit dem Kulturmedium auf $0,1 \mathrm{mg} / \mathrm{ml}$ weiter verdünnt. Die Neutralrot-Lösung wurde über Nacht inkubiert, eventuell verbliebene Farbstoffkristalle wurden am nächsten Tag mit einem 0,2 $\mu \mathrm{m}$-Sterilfilter entfernt. Die Behandlung der Zellen wurde durch Absaugen der Inkubationslösung und Waschen mit PBS gestoppt. In jede Kammer wurden anschließend $100 \mu \mathrm{l}$ der Neutralrot-Lösung pipettiert und es folgten $3 \mathrm{~h}$ Inkubation bei $37^{\circ} \mathrm{C}$. Nach dem Absaugen der Neutralrot-Lösung wurden die Kammern jeweils mit $100 \mu \mathrm{l}$ Waschlösung (1\% Formaldehyd/ 1\% Calciumchlorid-Lösung in PBS) gewaschen, abgesaugt und mit jeweils $100 \mu \mathrm{l}$ Extraktionslösung (1\% Essigsäure in $50 \%$ Ethanol und Aqua dest.) für 10 min bei RT inkubiert. Durch Schütteln wurde der Farbstoff anschließend gleichmäßig in den Kammern verteilt und im Photometer bei einer Messwellenlänge von $540 \mathrm{~nm}$ und einer Referenzwellenlänge von $405 \mathrm{~nm}$ gemessen. 


\subsubsection{MTT-Test}

Der MTT-Test erlaubt den Nachweis der Zellviabilität nach der Behandlung mit toxischen Substanzen. Die Zellviabilität wird durch Verstoffwechselung des gelben wasserlöslichen membrangängigen Farbstoffs 3-(4,5-Dimethylthiazol-2-yl)-2,5diphenyltetrazoliumbromid (MTT) durch mitochondriale Dehydrogenasen zu einem blau-violetten wasserunlöslichen Formazan nachgewiesen. Das Formazan bildet nicht-membrangängige Kristalle und akkumuliert in vitalen Zellen.

Für die Durchführung des Tests wurde der Cell Titer $96^{\circledR}$ Non-radioactive Cell Proliferation Assay von Promega genutzt. Zunächst wurden 10.000 Zellen/ $100 \mu \mathrm{l}$ EGM auf einer 96-Kammer-Platte ausgesät und $24 \mathrm{~h}$ inkubiert. Nach dem Wechsel des Mediums auf EBM und weiteren $24 \mathrm{~h}$ Inkubation wurden die Zellen für $24 \mathrm{~h}$ mit den drei Substanzen beziehungsweise ihren Kombinationen plus TNFa behandelt. Darauffolgend wurden $15 \mu \mathrm{l}$ der im Kit enthaltenen Dye Solution (Färbelösung) in jede Kammer gegeben und für $4 \mathrm{~h}$ inkubiert. Die Reaktion wurde mit $100 \mu \mathrm{l}$ Stop Solution über Nacht gestoppt. Nach kurzem Schütteln wurden die Proben bei $570 \mathrm{~nm}$ im Photometer gemessen. Die Bildung des blauen Formazans ist hierbei direkt proportional zu der Zahl der vitalen Zellen.

\subsubsection{BrdU-Test}

5-Bromo-2'-desoxyuridin (BrdU) ist ein chemisches Analogon der Base Thymidin. Es wird von den Zellen aufgenommen und während der S-Phase des Zellzyklus in phosphorylierter Form in die DNA eingebaut. Der Cell Proliferation ELISA von Roche beruht darauf, das in die DNA inserierte BrdU nachzuweisen und so die Zellproliferation zu messen.

Vor der Durchführung des ELISAs wurden zunächst 25.000 Zellen/Kammer in $100 \mu \mathrm{l}$ EGM auf einer 96-Kammer-Platte ausgesät. $24 \mathrm{~h}$ vor Behandlungsbeginn mit den drei Substanzen (DMF, KINK-1, Bortezomib) wurde das Kulturmedium durch EBM ersetzt und $8 \mathrm{~h}$ nach Behandlungsbeginn wurden in jede Kammer $10 \mu \mathrm{l} 10 \mathrm{x}$ BrdULösung hinzugegeben. Nach weiteren $16 \mathrm{~h}$ wurde das Medium-BrdU-Gemisch von den Zellen abgezogen und jede Kammer dreimal mit PBS gewaschen. In jede Kammer wurden nun $200 \mu \mathrm{l} \mathrm{Fix/Denat-Lösung} \mathrm{(Fix/Denat} \mathrm{Solution)} \mathrm{pipettiert} \mathrm{und} \mathrm{das}$ Gemisch bei RT 30 min inkubiert. Durch vorsichtiges Ausklopfen wurde die Lösung wieder aus den Kammern entfernt und durch jeweils $100 \mu$ Anti-BrdU-POD-Lösung 
(anti-BrdU-POD working solution) ersetzt. Nach 90-minütiger Inkubation bei RT wurde die Flüssigkeit durch dreimaliges Waschen mit 200 bis $300 \mu \mathrm{l}$ Waschlösung (washing solution, 1x PBS) entfernt. Durch Hinzugabe der Substrat-Lösung in die

flüssigkeitsfreie Kammer entwickelte sich die Farbreaktion. Nach 5 bis $30 \mathrm{~min}$ Inkubation wurden $25 \mu \mathrm{l}$ Stopplösung (stop solution, $1 \mathrm{M} \mathrm{H}_{2} \mathrm{SO}_{4}$ ) hinzupipettiert und die Platte 1 min geschüttelt. Die Messung erfolgte innerhalb von 5 min nach Zugabe der Stopp-Lösung im Photometer bei $405 \mathrm{~nm}$.

\subsubsection{Durchflusszytometrie (fluorescence-activated cell sorting, FACS)}

\subsubsection{Prinzip der Durchflusszytometrie}

Das FACS (fluorescence-activated cell sorting) ermöglichst es, Zellen betreffend ihrer Größe, Granulation und Anzahl näher zu bestimmen. Mit Hilfe fluoreszenzmarkierter Antikörper lassen sich außerdem die Expression von Oberflächenmolekülen und (nach Permeabilisierung der Zellen) auch intrazellulären Antigenen messen. Die in Suspension vorliegenden Zellen fließen perlenschnurartig durch eine Kapillare und werden dabei von monochromatischem Laserlicht bestrahlt. Trifft der Laserstrahl auf die einzelnen Zellen entsteht Streulicht, welches von Photodetektoren erfasst wird. Das Vorwärtsstreulicht (forward scatter, FSC) ist hierbei ein Maß für die Größe der Zellen und das Seitwärtsstreulicht (side scatter, SSC) gibt die Granularität der Zellen wieder. Durch den Laserstrahl werden außerdem die Elektronen des verwendeten Fluoreszenzfarbstoffes (hier: FITC, PE) auf ein höheres Energieniveau angehoben. Nach dem Abebben des Laserimpulses fallen diese Elektronen unter Energieabgabe in Form von Photonen zurück auf inr Ursprungsniveau, welches dann ebenfalls von einem Photodetektor bei der jeweils typischen Emissionswellenlänge registriert wird.

\subsubsection{Durchflusszytometrische Messung der Adhäsionsmoleküle auf HUVEC}

Zunächst wurden $90.000 \mathrm{HUVEC/Kammer} \mathrm{in} \mathrm{jeweils} 1 \mathrm{ml}$ EGM auf einer 12Kammer-Platte ausgesät. $48 \mathrm{~h}$ später wurde das EGM durch EBM ersetzt. Die Zellen wurden nach weiteren $24 \mathrm{~h}$ mit den drei Substanzen in unterschiedlichen Konzentrationen jeweils einzeln und in Kombination sowie mit TNFa inkubiert. Nach 5-stündiger Behandlung wurde das Medium entfernt und die HUVEC mit PBS gewaschen, mittels Accutase ${ }^{\circledR}$ abgelöst und in jeweils $800 \mu \mathrm{l}$ PBS resuspendiert. 
Nach der Überführung in FACS-Röhrchen wurden jeweils 5\% AB-Serum hinzugegeben und es erfolgte eine 7-minütige Zentrifugation bei $1300 \mathrm{rpm}(290 \mathrm{x} \mathrm{g})$. Nach Abnahme des Überstandes wurden die HUVEC für 30 min mit dem 1. AK (0,5$10 \mu \mathrm{l} / 100 \mu \mathrm{l}$ ) im Kühlschrank inkubiert. Nach Ablauf der Inkubationszeit wurden die Zellen erneut gewaschen, zentrifugiert und der Überstand abgesaugt. Nun erfolgte nach Zugabe des 2. AK (0,5-1 $\mu \mathrm{l} / 100 \mu \mathrm{l})$ eine weitere Inkubation für $30 \mathrm{~min}$, ein erneuter Waschgang sowie das Absaugen des Überstandes. In $250 \mu \mathrm{l}$ PBS resuspendiert wurden die HUVEC mit dem FACS gemessen.

Antikörper-Ansätze:

1

unbehandelt

kein AK

2.

unbehandelt

nur 2. AK

3.

unbehandelt

Isotyp FITC + PE

4. -6 . unbehandelt

1. AK E-Selektin/ICAM-1/ VCAM-1 + 2. AK

7. -9 . unbehandelt, stimuliert

1. AK E-Selektin/ICAM-1/ VCAM-1 + 2. AK

10. - 12. DMSO

1. AK E-Selektin/ ICAM-1/ VCAM-1 + 2. AK

14. -17 .

5- $200 \mu \mathrm{M}$ DMF

1. AK E-Selektin + 2. AK

18. -21 .

5- $200 \mu \mathrm{M}$ DMF

1. AK ICAM-1 PE

22. -25 . 5- $200 \mu \mathrm{M}$ DMF

1. AK VCAM-1 + 2. AK

26. -30 .

0,015- $5 \mu \mathrm{M}$ KINK-11. AK E-Selektin + 2. AK

31. -35 .

0,015- $5 \mu \mathrm{M}$ KINK-11. AK ICAM-1 PE

36. -40 .

0,015- $5 \mu \mathrm{M}$ KINK-11. AK VCAM-1 + 2. AK

41. -43 .

2,5- $10 \mathrm{ng} / \mathrm{ml}$ Bortezomib

1. AK E-Selektin + 2. AK

44. -46 .

2,5- $10 \mathrm{ng} / \mathrm{ml}$ Bortezomib

1. AK ICAM-1 PE

47. -49 .

2,5- $10 \mathrm{ng} / \mathrm{ml}$ Bortezomib

1. AK VCAM-1 + 2. AK

50. -52 .

$\mathrm{DMF}+\mathrm{KINK}-1$

1. AK E-Selektin + 2. AK

53. -55 .

$\mathrm{DMF}+\mathrm{KINK}-1$

1. AK ICAM-1 PE

56. -58 .

$\mathrm{DMF}+\mathrm{KINK}-1$

1. AK VCAM-1 + 2. AK

59. -61 .

$\mathrm{DMF}+$ Bortezomib

1. AK E-Selektin + 2. AK

61. -63 .

DMF + Bortezomib

1. AK ICAM-1 PE

64. -66

$\mathrm{DMF}+$ Bortezomib

1. AK VCAM-1 + 2. AK 


\subsubsection{Durchflusszytometrische Messung der Oberflächenmoleküle von Leukozyten}

Zunächst erfolgte die Lymphozytenisolierung aus frischem Blut wie in Kapitel 2.3.6 beschrieben. Eine CFDA-SE-Färbung erfolgte hierbei nicht. Nach dem letzten Zentrifugationsschritt wurde das Zellsediment in $1 \mathrm{ml}$ supplementiertem RPMI ( $1 \%$ Glutamin, 5\% FCS, 0,01\% $\beta$-Mercaptoethanol) aufgenommen und ausgezählt. Anschließend wurden jeweils 2 Mio. Zellen in 50-ml-Röhrchen überführt und für $2 \mathrm{~h}$ bei $37^{\circ} \mathrm{C}$ inkubiert. Nach anschließender Zentrifugation und Entfernen des Mediums erfolgte die Resuspension in $1 \mathrm{ml}$ PBS. Im Anschluss an eine weitere Zentrifugation bei $300 \mathrm{xg}$ für 5 min wurden die Zellen in $1 \mathrm{ml}$ PBS mit $5 \%$ AB-Serum aufgenommen, gezählt und jeweils ca. 100.000 Zellen in FACS-Röhrchen überführt. Nach erneuter 7-minütiger Zentrifugation, wurde der Überstand bis auf $100 \mu \mathrm{l}$ abgesaugt und unten aufgeführte Antikörper (AK) zu den behandelten Proben pipettiert.

Antikörper- Ansätze:

1. Kein AK

2. CD3- Isotyp FITC/ PE

3. CD3 FITC

4. CD3 PE

5. CD3 FITC + Isotyp PE

6. CD3 PE + Isotyp FITC

7. CD3 FITC + L-Selektin

8. $\mathrm{CD} 3 \mathrm{PE}+\mathrm{VLA} 4$

9. $\mathrm{CD} 3 \mathrm{PE}+\mathrm{LFA}-1$

10. CD3 PE + CLA-1

11.7AAD

Nach 30-minütiger Inkubation wurden überschüssige Antikörper mittels Waschen mit PBS entfernt, die einzelnen FACS-Röhrchen mit jeweils $150 \mu \mathrm{l}$ PBS aufgefüllt und gemessen. 


\subsubsection{Lymphozytenisolierung}

Um die Lymphozyten (PBMC, peripheral blood mononuclear cells- nachfolgend synonym verwendet) für die anschließenden Versuche zu isolieren, wurden $20 \mathrm{ml}$ frisch abgenommenes venöses Blut freiwilliger gesunder Spender in ein Röhrchen gegeben und mit der gleichen Menge an HBSS versetzt (Antragsnummer: DOK_9_2015, durch Ethikkommission genehmigt). Von diesem Blut-HBSS-Gemisch wurden anschließend $20 \mathrm{ml}$ vorsichtig auf $10 \mathrm{ml}$ Ficoll-Paque Plus gegeben und für $30 \mathrm{~min}$ bei $400 \times \mathrm{g}$ zentrifugiert. Bei Ficoll handelt es sich um ein Dichtegradientenmedium mit hohem molekularem Eigengewicht zur Herstellung eines Gradienten. Die mittlere milchig-trübe Lymphozyten "„Scheibe“ wurde vorsichtig aus dem zentrifugierten Röhrchen abgenommen, in ein neues Röhrchen überführt und mit auf $37{ }^{\circ} \mathrm{C}$ vorgewärmtem HBSS aufgefüllt. Nach erneuter zehnminütiger Zentrifugation bei $300 \times$ g, wurden die Zellen für die FACS-Analysen in $1 \mathrm{ml}$ RPMl mit 1\% Glutamin und 5\% FCS aufgenommen und ausgezählt. Anschließend wurden die Zellen in 50-ml-Röhrchen überführt, behandelt und im Brutschrank bei $37^{\circ} \mathrm{C}$ inkubiert.

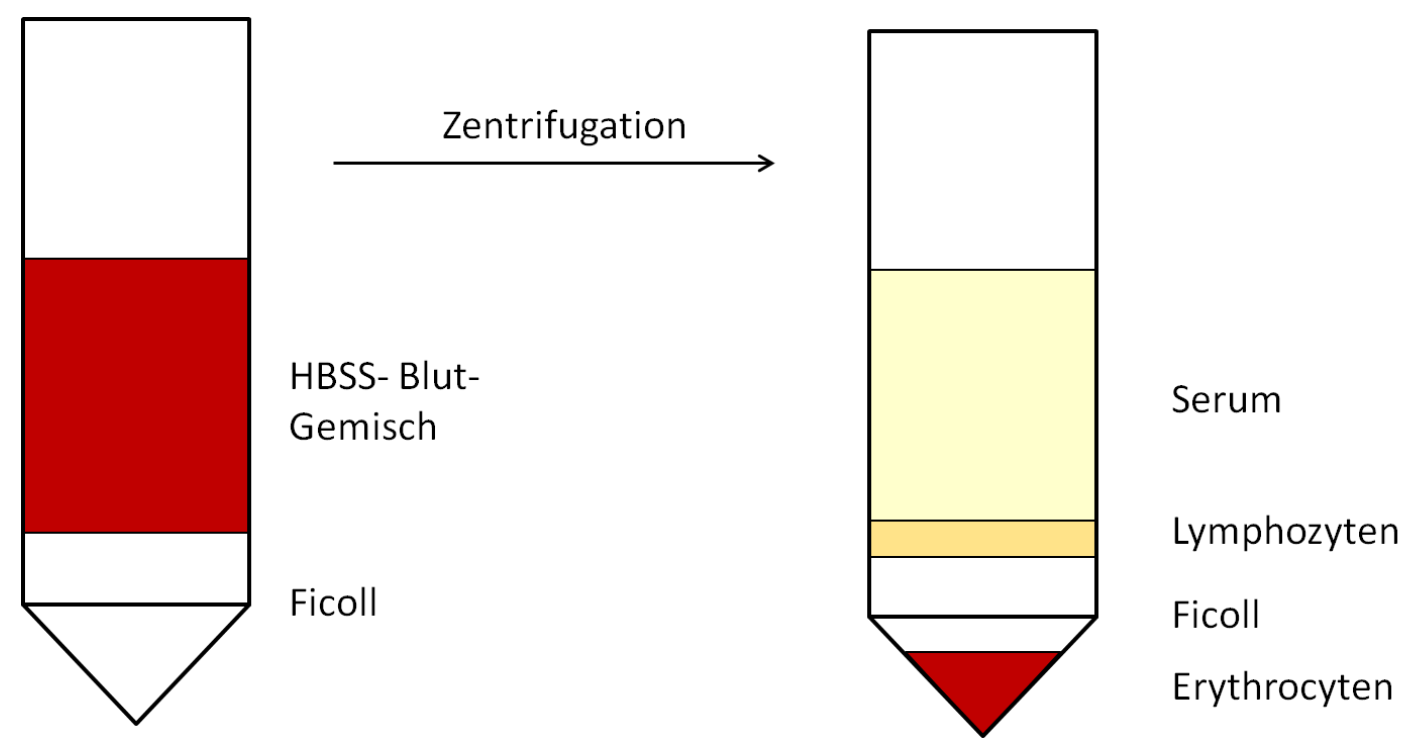

Abb. 3: Lymphozytenisolierung mittels Ficoll-Gradient

\subsubsection{Lymphozytenfärbung mit CFDA-SE}

Wenn die Lymphozyten nach Ihrer Aufreinigung aus dem Blut für einen Flusskammerversuch verwendet wurden, wurden sie nach der zweiten oben 
genannten Zentrifugation mit CFDA-SE (Carboxyfluorescein Diacetate Succinimidyl Ester) gefärbt. Hierbei handelt es sich um eine membrangängige Substanz, welche nach der Spaltung durch Esterasen zu CFDA fluoreszierende Eigenschaften erhält. Für die Färbung wurde CFDA-SE in einer Endkonzentration von $5 \mu \mathrm{M}$ in warmes (37 $\left.{ }^{\circ} \mathrm{C}\right)$ HBSS gemischt und die Zellen in diesem Gemisch resuspendiert. Nach anschließender 15 -minütiger Inkubation bei $37^{\circ} \mathrm{C}$, während derer der Farbstoff in die Zellen eindringen konnte, wurden die Zellen erneut für $10 \mathrm{~min}$ bei $200 \times \mathrm{g}$ zentrifugiert, in HBSS resuspendiert und 30 min bei RT inkubiert. Es folgten zwei weitere Zentrifugations- und Resuspensionsschritte in HBSS.

\subsubsection{Einfrieren der Lymphozyten}

Zum Einfrieren wurden die Lymphozyten nach der letzten Zentrifugation der Aufreinigungs-Prozedur in RPMI-1640 bei $4^{\circ} \mathrm{C}$ resuspendiert und auf $18 \times 10^{6} / \mathrm{ml}$ verdünnt. Anschließend wurden die Lymphozyten mit der gleichen Menge des doppelt konzentrierten Einfriermedium aufgefüllt. Je $1 \mathrm{ml}$ der Zell-RPMIEinfriermedium-Suspension wurde in vorbeschriftete Gefrierröhrchen gegeben, in einem Isopropanol-Tank bei $-80{ }^{\circ} \mathrm{C}$ gekühlt und am folgenden Tag in einen Stickstofftank überführt. Untersuchungen hatten gezeigt, dass die Kryokonservierung der Lymphozyten keinen Einfluss auf ihre Zusammensetzung (Anteil von CD13-, CD14- und CD-19-positiven Zellen) oder auf ihre funktionellen Eigenschaften nimmt (Lockmann und Schön 2013).

\subsubsection{Flusskammerversuche}

\subsubsection{Prinzip der Flusskammer}

Die Flusskammer ermöglicht es, (bio)physikalische Bedingungen in Blutgefäßen zu modellieren, um die Interaktion zwischen Endothelzellen (stationäre Phase) und suspendierten Zellen (beispielsweise Lymphozyten; mobile Phase) in Echtzeit oder Videoaufnahmen zu untersuchen. Die Flusskammer besteht aus einem Acrylquader mit einer rechteckigen, $0,5 \mathrm{~cm} \times 3,5 \mathrm{~cm}$ großen Aussparung von $50 \mu \mathrm{m}$ Tiefe auf der Unterfläche. Von den Schmalseiten der Aussparung führen zwei schmale Kanäle als Zu- oder Abfluss nach außen. Der Quader wird mit Hilfe zweier exzentrisch gelagerter Plastikschrauben in einem Metallgestell fixiert, nachdem bei 
Versuchsbeginn eine mit Endothelzellen bewachsene Glasplatte (Coverslip) unter der Aussparung platziert wurde. Durch eine Spritzenpumpe am Zufuhrschlauch der Kammer wird ein annähernd laminarer Strom mit definierten Scherkräften erzeugt.

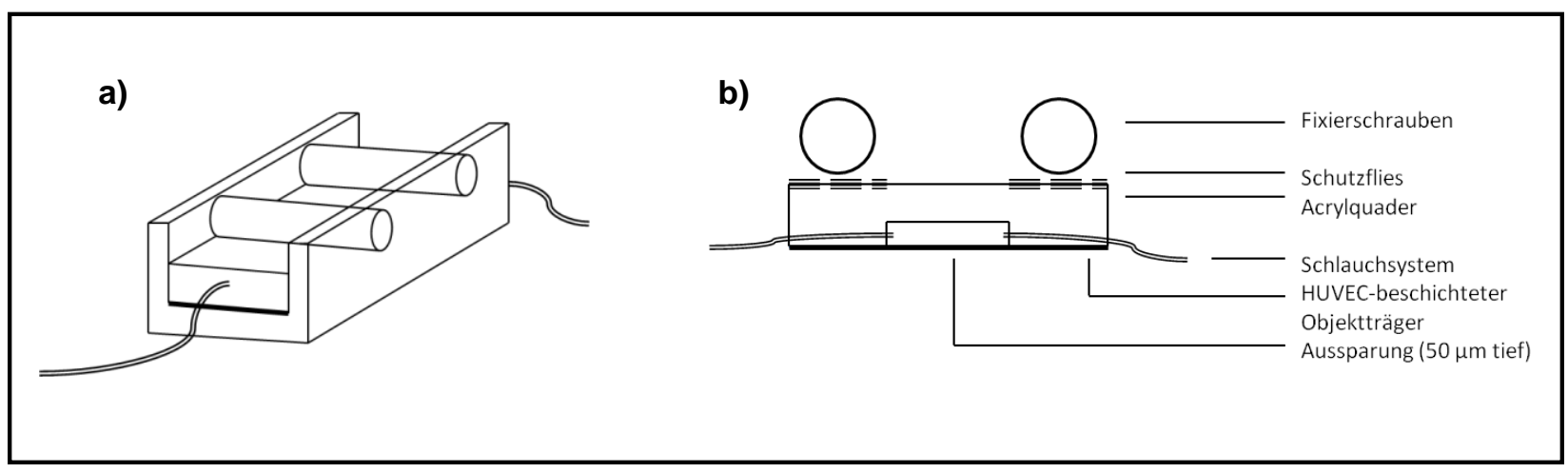

Abb. 4: Flusskammer - a) Schematische Gesamtansicht der Flusskammer. b) Querschnitt der Flusskammer. Durch den Zufuhrschlauch an der rechten Seite der Kammer gelangen die Lymphozyten in die an der Unterseite des Acrylquaders befindliche, $50 \mu \mathrm{m}$ tiefe Aussparung. Auf dieser Aussparung liegt der mit HUVEC beschichtete Objektträger auf, so dass beide Zelltypen miteinander interagieren können. Acrylquader und Objektträger werden mit Hilfe exzentrisch gelagerter Plastikschrauben im Metallgestell fixiert. Das Verhalten der Zellen kann durch ein inverses Fluoreszenz- oder Phasenkontrast-Mikroskop beobachtet und fotografiert werden. Durch den Schlauch auf der linken Seite der Kammer strömen die Lymphozyten wieder aus der Aussparung heraus.

\subsubsection{Vorbereitung der Flusskammerversuche}

Vor Versuchsbeginn erfolgte die Beschichtung der Coverslips mit HUVEC. Auf jeden Coverslip wurden zunächst 100.000 Zellen in 1 ml EGM vorsichtig ausgesät. Der in einer Petrischale platzierte Coverslip wurde nun einige Stunden im Brutschrank inkubiert, bevor weitere $7 \mathrm{ml}$ Medium zu den mittlerweile adhärenten Zellen hinzugegeben wurden. $18 \mathrm{~h}$ vor Versuchsbeginn wurde das EGM gegen $8 \mathrm{ml}$ EBM ausgetauscht. Die PBMC wurden wie beschrieben aus dem Blut freiwilliger gesunder Spender isoliert und mit CDFA-SE gefärbt.

$\mathrm{Zu}$ den HUVEC wurden die drei Testsubstanzen anschließend einzeln oder in Kombination direkt in das Medium pipettiert. Die Proben wurden dann jeweils für $5 \mathrm{~h}$ bei $37^{\circ} \mathrm{C}$ inkubiert. Nach der ersten Stunde wurde TNFa $(25 \mathrm{ng} / \mathrm{ml})$ hinzupipettiert, um die Endothelzellen zu stimulieren. Die Behandlung der einzelnen Proben erfolgte zeitlich versetzt, um die Behandlungsdauer genau einhalten zu können und ausreichend Zeit für die einzelnen Arbeitsschritte zu haben. 


\subsubsection{Durchführung der Flusskammerversuche}

Nach Entnahme des Coverslips aus der Petrischale wurde dieser unter dem Acrylquader platziert und das Schlauchsystem mit Waschpuffer (HBSS mit $\mathrm{CaCl}_{2}$ ) durchspült, um Luftbläschen, die den laminaren Strom stören würden, aus dem System zu entfernen. Acrylquader und Coverslip wurden nun vorsichtig in die Flusskammer eingespannt, auf dem Mikroskop-Tisch montiert und die Spritze mit der Lymphozyten-Suspension an den zuführenden Schlauch des Systems angeschlossen. Die Spritze wiederum wurde in eine Spritzenpumpe eingespannt, welche die Zellen automatisch und gleichmäßig mit einer Flussgeschwindigkeit von $1,12 \mathrm{ml} / \mathrm{h}$ durch das System befördert. Zunächst wurde die Lymphozyten-HBSSLösung über die Endothelzellschicht laufen gelassen, bis sich ein gleichmäßiger Fluss gebildet hatte und die Zellen zu adhärieren begannen. Nun wurde der Fluss 10 min lang unter dem Mikroskop beobachtet und während dieser Zeit alle rollenden Zellen gezählt. Nach Ablauf der 10 min wurden jeweils 16 Gesichtsfelder im mittleren Bereich der Kammer einem standardisierten Schema folgend auf dem Coverslip abfotografiert. Die Verteilung der Gesichtsfelder findet sich nachstehend aufgeführt:

\begin{tabular}{|l|l|l|l|l|l|l|l|l|l|}
\hline & & & 5 & & & & 13 & & \\
\hline & 1 & 4 & & & 9 & 12 & & & \\
\hline & & & 6 & 8 & & & 14 & 16 & \\
\hline & 2 & 3 & & & 10 & 11 & & & \\
\hline & & & & 7 & & & & 15 & \\
\hline
\end{tabular}

Abb. 5: Verteilung der Gesichtsfelder für die Auszählung der adhärenten PBMC. Die Festlegung der Gesichtsfelder erfolgte bei 80-facher Vergrößerung.

\subsubsection{Auswertung der Flusskammerversuche}

Nachdem die rollenden Lymphozyten auf den Endothelzellen bereits während des Versuches gezählt wurden, wurden nach Beendigung des Versuches die adhärenten Lymphozyten in den 16 fotografierten Gesichtsfeldern quantifiziert. Hierzu wurden die Fotos im Programm ImageJ aufgerufen, der Kontrast verstärkt und die kleinen Lymphozyten sorgfältig ausgezählt. 


\subsubsection{Statistische Auswertung}

Die statistische Auswertung erfolgte größtenteils mit der Microsoft Excel Software. Es wurden jeweils der Mittelwert und der Standardfehler berechnet. Zur Beurteilung der Signifikanz wurde der zweiseitige Student's T-Test verwendet, wobei p-Werte $<0,05$ (Konfidenzintervall 95\%) als signifikant angesehen wurden. Für die Immunfluoreszenz- und PCR-Versuche war eine derartige statistische Auswertung nicht möglich, die Auswertung erfolgte rein qualitativ. 


\section{Ergebnisse}

\subsection{Auswirkungen der unterschiedlichen Einzelstoffe sowie ihrer}

Kombinationen auf die Translokation des Transkriptionsfaktor NF-kB/ p65

Die Inhibition des Transkriptionsfaktors NF-kB wird als eine der Hauptwirkungen von DMF diskutiert, was zu der Hypothese führte, das eine Kombination mit NF-kBInhibitoren zu einer Augmentation des Effektes führen könnte. Loewe et al. beschrieben 2002 eine verminderte Translokation von NF-kB in den Zellkern (als Surrogat-Parameter für die Aktivierung) von HUVEC bei einer Konzentration von 80 $\mu \mathrm{M}$ (Loewe et al. 2002).

Die Beurteilung der Translokation erfolgte immunfluoreszenzmikroskopisch (Abb. 6). Zuvor wurden die HUVEC mit DMF, KINK-1, Bortezomib oder Kombinationen von DMF mit jeweils einem der beiden NF-kB-Inhibitoren behandelt. Während der letzten 30 min wurden die Zellen mit TNFa, einem potenten Induktor des NF-kBSignalweges (Siebenlist et al. 1994), stimuliert.

DMF bewirkte in hohen Konzentrationen von $100 \mu \mathrm{M}$ eine partielle Inhibition (noch vereinzelte positive Kernsignale) der NF-KB-Untereinheit p65, eine vollständige Inhibition trat erst bei einer Konzentration von $200 \mu \mathrm{M}$ auf. KINK-1 hemmt NF-KB bereits in geringen Konzentrationen von $5 \mu \mathrm{M}$ vollständig, Bortezomib bei Konzentrationen $>40 \mathrm{ng} / \mathrm{ml}$. Alle drei Substanzen inhibierten die NF-kB-Aktivierung in dosisabhängiger Weise. Die Kombinationen der drei Substanzen in jeweils geringen Konzentrationen verstärkte die Hemmung der NF-kB-Translokation im Vergleich zu den jeweiligen Einzelsubstanzen. Beispielsweise zeigen Kombinationen aus $15 \mu \mathrm{M}$ DMF und $0.0375 \mu \mathrm{M}$ KINK-1 beziehungsweise $5 \mu \mathrm{M}$ DMF und $5 \mathrm{ng} / \mathrm{ml}$ Bortezomib bereits eine Inhibition der Translokation von NF-KB in den Zellkern und damit eine Steigerung des Effektes. 
a

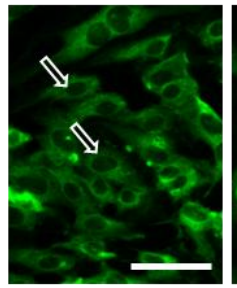

$\operatorname{DMF}(\mu \mathrm{M})$

TNF $\alpha$

b

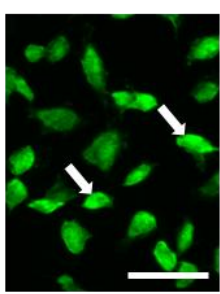

KINK- $1(\mu \mathrm{M}) \quad 0.0375$

TNFa

$+$

C

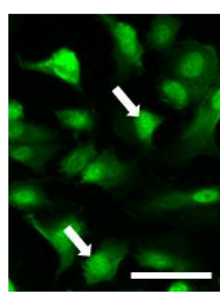

Borte.
TNFa

d

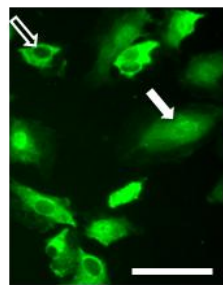

$\operatorname{DMF}(\mu \mathrm{M})$

KINK- $1(\mu \mathrm{M})$

Borte. $(\mathrm{ng} / \mathrm{ml})$

TNFa

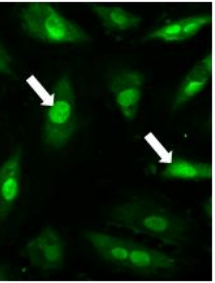

0

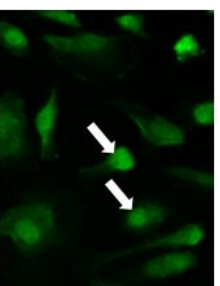

0.07

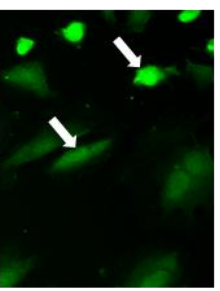

10
+

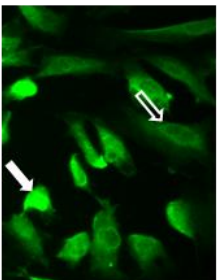

5

0

10

$+$

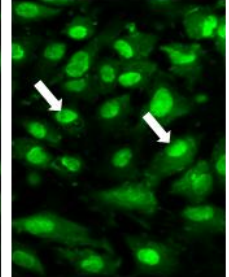

5

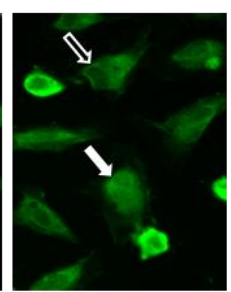

0.625

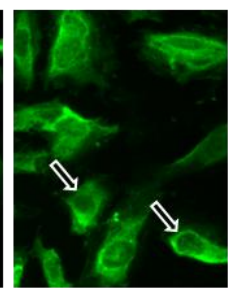

40

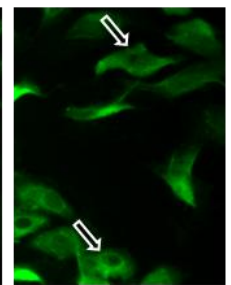

15

0.0375

0

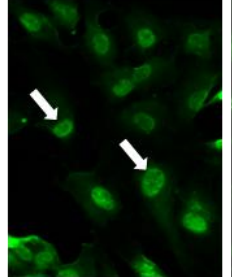

50

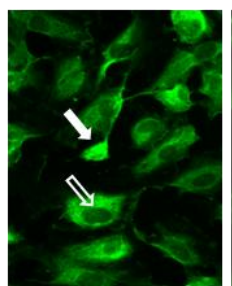

5

$+$

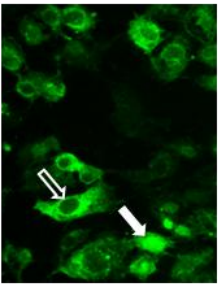

100

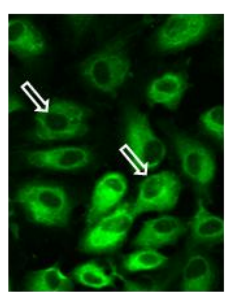

25

$+$

Abb. 6: Inhibition des Transkriptionsfaktors NF-kB. Um die nukleäre Translokation von NF-kB zu hemmen, wurden HUVECs den in der Abbildung genannten Substanzen für jeweils $2,5 \mathrm{~h}$ ausgesetzt und gleichzeitig für die letzten 30 min mit TNFa stimuliert (- kein TNF, + TNF-stimuliert). DMF inhibiert die Translokation von NF-KB in den Zellkern der HUVEC nur teilweise bei einer vergleichsweise hohen Konzentration von $100 \mu \mathrm{M}$ (a). KINK-1 (b) und Bortezomib (c) inhibieren NF-kB dosisabhängig. Unter Verwendung der Kombinationen wurde eine partielle Inhibition von NF-KB bereits bei niedrigen Konzentrationen erreicht (d) $\Rightarrow$ NF-KB im Zellkern, $\Rightarrow$ signalfreier Zellkern, Maßstabsbalken $50 \mu \mathrm{m}$. (modifiziert nach Hund et al. 2016, die Verwendung erfolgte mit freundlicher Genehmigung des Verlags John Wiley \& Sons A/S.) 


\subsection{Auswirkungen der unterschiedlichen Einzelsubstanzen sowie ihrer Kombinationen auf mRNA-Ebene}

\subsubsection{Wirkungen der Einzelsubstanzen auf mRNA-Ebene}

\subsubsection{Wirkung von DMF auf die Transkription von Adhäsionsproteinen, Chemokinen und VEGF}

Um das TNF $\alpha$-reiche Mikromilieu psoriatischer Läsionen, in welchem die Expression proinflammatorischer Zytokine und Adhäsionsmoleküle induziert ist, zu modellieren, wurden die Endothelzellen für $4 \mathrm{~h}$ mit TNFa stimuliert. Mit semiquantitativer RT-PCR wurde dann der DMF-Einfluss auf die Expression der Adhäsionsmoleküle VCAM-1 (CD106), ICAM-1 (CD54) und E-Selektin (CD62E), der Chemokine CXCL1 (Gro- $\alpha$ ), CXCL8 (IL-8) und CCL2 (MCP-1) sowie des vaskulären endothelialen Wachstumsfaktors (VEGF) untersucht. Hierzu wurde mRNA sowohl von HUVEC als auch von HDMEC verwendet. Die Verwendung jeweils gleicher mRNA-Mengen wurde durch Bestimmung der konstitutiv exprimierten GAPDH kontrolliert (Abb. 7).

VCAM-1, ICAM-1, E-Selektin, CCL2, CXCL1 und CXCL8 wurden im nicht stimulierten Zustand der Endothelzellen nur sehr schwach exprimiert. Nach der Stimulation mit TNFa zeigten sowohl HUVEC als auch HDMEC einen deutlichen Anstieg der Expression aller drei Adhäsionsmoleküle und Chemokine. Mit TNFa stimulierte HUVEC und HDMEC exprimierten VCAM-1-mRNA unter der Behandlung mit DMF unverändert bis zu einer Konzentration von $25 \mu \mathrm{M}$, unter der Behandlung mit $50 \mu \mathrm{M}$ zeigte sich eine Abschwächung der Transkription und ab $100 \mu \mathrm{M}$ waren keine Signale mehr nachweisbar. Die ICAM-1-mRNA wurde bis zu einer Konzentration von $50 \mu \mathrm{M}$ DMF (HUVEC) beziehungsweise $25 \mu \mathrm{M}$ DMF (HDMEC) unverändert exprimiert, danach zeigte sich eine Abschwächung der Banden bis hin zu einem vollständigen Bandenverlust bei 100 MM DMF. Die E-Selektin-Expression verhielt sich ähnlich: In HUVEC war eine Abschwächung des E-Selektin-Signals bei einer DMF-Konzentration von $50 \mu \mathrm{M}$ nachweisbar, ab $100 \mu \mathrm{M}$ verschwand das Signal vollständig. In HDMEC zeigten sich ab $100 \mu \mathrm{M}$ DMF nur noch sehr schwache Banden. CXCL8 wurde bis zu einer Konzentration von $150 \mu \mathrm{M}$ DMF in HUVEC, beziehungsweise $200 \mu \mathrm{M}$ DMF in HDMEC unverändert exprimiert. Insgesamt exprimierten HDMEC CXCL8 deutlich stärker als HUVEC. Auf die mRNA der Chemokine CXCL1 und CCL2 fand sich ein vergleichbarer Effekt. Sowohl in HUVEC 
als auch HDMEC präsentierte sich hinsichtlich beider Signale eine Abschwächung ab $100 \mu \mathrm{M}$ DMF, und ab 150 beziehungsweise $200 \mu \mathrm{M}$ trat kein Signal mehr auf.

Auf den Wachstumsfaktor VEGF hingegen wirkte sich DMF Expressions-steigernd aus. Die Signalstärke der VEGF-mRNA nahm in HUVEC und HDMEC ab einer Konzentration von $50 \mu \mathrm{M}$ DMF stetig zu, unter dem Einsatz geringerer Konzentrationen zeigten die Banden eine ähnliche Intensität wie die nicht stimulierter Zellen. Die GAPDH-mRNA blieb unter allen Versuchsbedingungen unbeeinflusst.

Zusammenfassend entfaltete DMF in beiden Zelllinien bei Konzentrationen ab $50 \mu \mathrm{M}$ eine hemmende Wirkung auf die untersuchten endothelialen Rezeptoren und Mediatoren (vollständige Wirkung auf alle Parameter erst bei $200 \mu \mathrm{M}$ ).

HUVEC

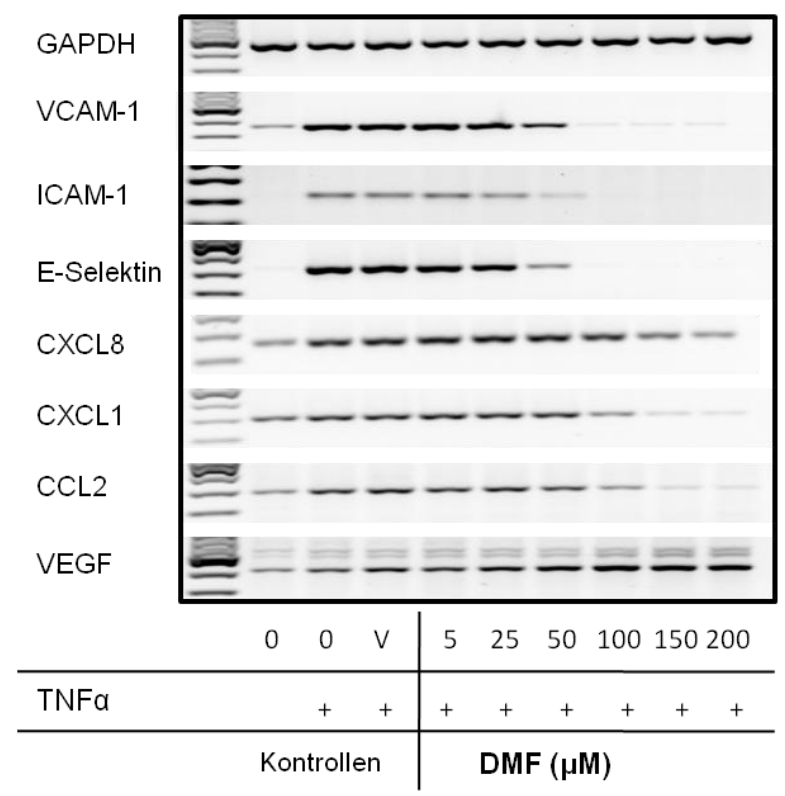

HDMEC

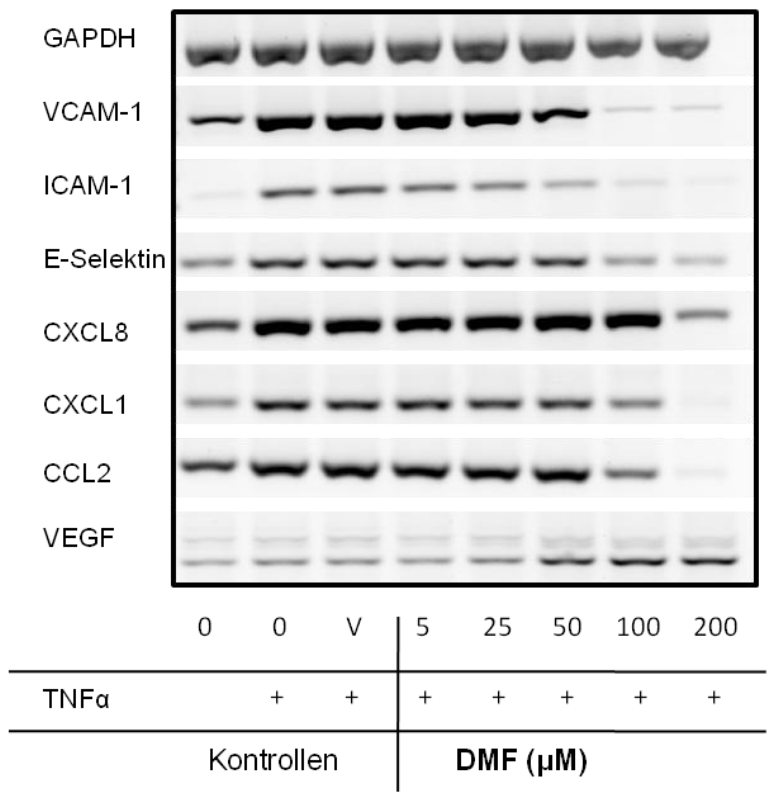

Abb. 7: Wirkung von DMF auf mRNA-Ebene. Die Transkription NF-kB-abhängiger Gene wurde mittels RT-PCR untersucht. HUVEC (linke Abb.) und HDMEC (rechte Abb.) wurden mit DMF in den angegebenen Konzentrationen für $5 \mathrm{~h}$ behandelt und die letzten $4 \mathrm{~h}$ parallel mit TNFa stimuliert. GAPDH-mRNA diente als interne Kontrolle. Als weitere Kontrollen dienten: unbehandelte/ nichtstimulierte, unbehandelte/ stimulierte und DMSO-behandelte (V für Vehikel)/ stimulierte Zellen. DMF bewirkt in beiden Zelllinien eine dosisabhängige Reduktion der mRNA von VCAM-1, ICAM-1, ESelektin, CXCL88, CXCL1 und CCL2 ab Konzentrationen von $50 \mu \mathrm{M}$. VEGF hingegen zeigt sich sowohl in HUVEC als auch in HDMEC ab $50 \mu \mathrm{M}$ DMF steigend. 


\subsubsection{Wirkung von KINK-1 und Bortezomib auf die Transkription von Adhäsionsproteinen, Chemokinen und VEGF}

Der Einfluss der beiden NF-KB-Inhibitoren auf die Expression endothelialer Antigene wurde ebenfalls durch semiquantitative RT-PCR untersucht. Die Stimulierbarkeit der Transkription entzündungsassoziierter Antigene durch TNFa bestätigte sich. GAPDH diente erneut als interne Kontrolle (Abb. 8).

KINK-1 wirkte in HUVEC bereits bei einer Konzentration von $5 \mu \mathrm{M}$ hemmend auf die Transkription aller drei Adhäsionsmoleküle. Ab $25 \mu \mathrm{M}$ zeigten sich bei VCAM-1 nur noch sehr schwache Banden, bei ICAM-1 und E-Selektin keine Banden mehr. HDMEC reagierten sehr ähnlich. Zusätzlich wurde KINK-1 auch in geringen Konzentrationen untersucht. Hierbei wurde die mRNA aller drei Adhäsionsmoleküle bereits ab 0,625 $\mu \mathrm{M}$ KINK-1 herabreguliert. Insbesondere auf ICAM-1 zeigte sich ein starker Effekt. Das CXCL8-Signal nahm in HUVEC ab $25 \mu \mathrm{M}$ KINK-1 deutlich ab, in HDMEC wurde bei Konzentrationen von 0,625 bis $50 \mu \mathrm{M}$ nur eine sehr schwache Reduktion der mRNA-Expression beobachtet. Die Transkription von CXCL1 und CCL2 war sowohl in HUVEC als auch in HDMEC ab $25 \mu \mathrm{M}$ KINK-1 reduziert. VEGF zeigte sich unter der KINK-1-Behandlung in beiden Zelllinien unbeeinflusst.

Bortezomib bewirkte in HUVEC eine konzentrationsabhängige Abschwächung des VCAM-1-Signals bei Konzentrationen von 2,5 bis $50 \mathrm{ng} / \mathrm{ml}$. Noch höhere BortezomibKonzentrationen konnten diesen Effekt nicht weiter verstärken. In HDMEC zeigte sich keine Veränderung der VCAM-1-mRNA durch Bortezomib. ICAM-1 hingegen wurde in HUVEC schon unter $2,5 \mathrm{ng} / \mathrm{ml}$ Bortezomib auf das Niveau unbehandelter Zellen herabreguliert, in HDMEC wurde dieser Effekt ab $20 \mathrm{ng} / \mathrm{ml}$ nachgewiesen. Die ESelektin-mRNA zeigte eine deutlich verminderte Expression bei Konzentrationen von 2,5 und $5 \mathrm{ng} / \mathrm{ml}$ Bortezomib. Ab $25 \mathrm{ng} / \mathrm{ml}$ trat jedoch wieder eine Signalverstärkung auf. CXCL8 und CXCL1 blieben sowohl in HUVEC als auch in HDMEC unbeeinflusst. Ebenso wurde CCL2 in HUVEC durch Bortezomib nicht beeinflusst, in HDMEC wurde die CCL2-mRNA ab $10 \mathrm{ng} / \mathrm{ml}$ leicht reduziert. CXCL1 sank in HUVEC ab 5 $\mathrm{ng} / \mathrm{ml}$ Bortezomib ab. Bortezomib änderte das VEGF-Signal nicht. 
HUVEC

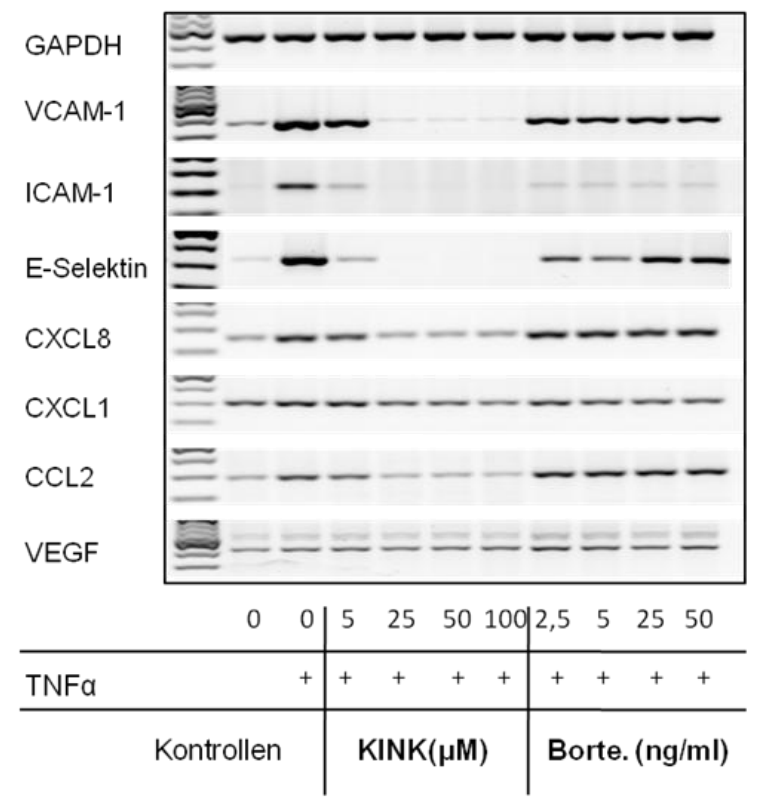

HDMEC

\section{HDMEC}
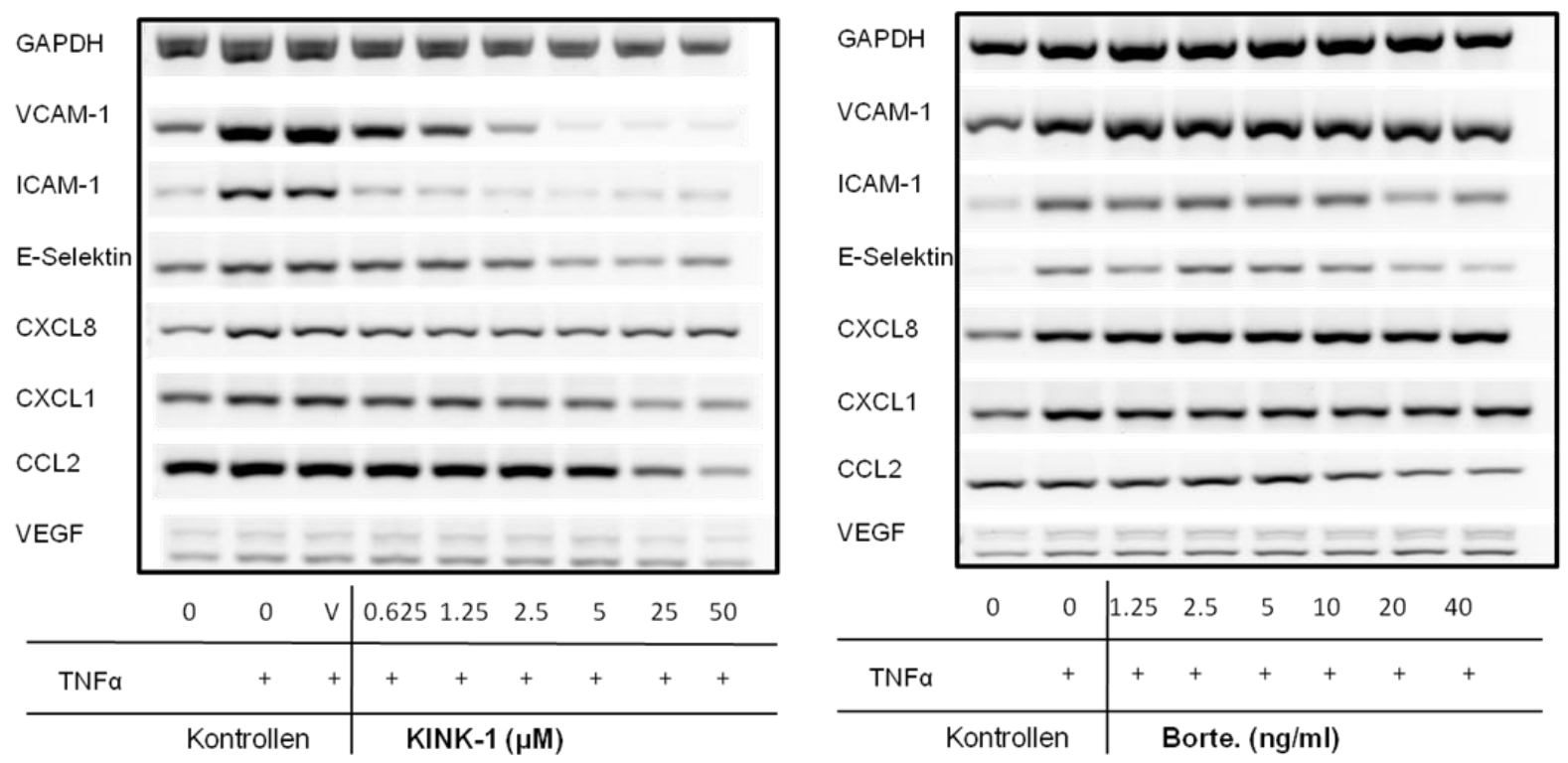

Abb. 8: Wirkung von KINK-1 und Bortezomib auf mRNA-Ebene. Die Transkription NF-KBabhängiger Gene wurde mittels RT-PCR untersucht. HUVEC und HDMEC wurden mit den angegebenen Substanzen in den aufgeführten Konzentrationen für $5 \mathrm{~h}$ behandelt und die letzten $4 \mathrm{~h}$ parallel mit TNFa stimuliert. GAPDH-mRNA diente als interne Kontrolle. Als weitere Kontrollen dienten: unbehandelte/ nicht-stimulierte, unbehandelte/ stimulierte und DMSO-behandelte ( $V$ für Vehikel)/ stimulierte Zellen. KINK-1 bewirkt eine deutliche Reduktion aller Adhäsionsmoleküle (VCAM1, ICAM-1, E-Selektin) bei einer Konzentration von $5 \mu \mathrm{M}$. CXCL8, CXCL1 sowie CCL2 wurden ab 25 $\mu \mathrm{M}$ KINK-1 beeinflusst. KINK-1 zeigt keine Auswirkung auf VEGF. Bortezomib reduziert die Expression von VCAM-1, I-CAM-1 und E-Selektin. 


\subsubsection{Wirkungen der Kombinationen von DMF mit NF-kB-Inhibitoren auf mRNA-Ebene}

\subsubsection{Wirkung der Kombination von DMF und KINK-1 auf die Transkription von Adhäsionsproteinen, Chemokinen und VEGF}

Im nächsten Schritt wurde die Wirkung der Kombinationen von DMF mit NF-kBInhibitoren auf die Transkription der genannten Gene in HUVEC und HDMEC untersucht (Abb. 9).

Bereits bei der Kombination von DMF und KINK-1 in geringen Konzentrationen (je 5 $\mu M)$ konnte VCAM-1-, ICAM-1- und E-Selektin-mRNA nicht mehr nachgewiesen werden. Das CXCL8-Signal war bei sämtlichen Kombinationen der beiden Stoffe abgeschwächt, was bei höheren Konzentrationen (5 $\mu \mathrm{M}$ DMF + $100 \mu \mathrm{M}$ KINK-1 beziehungsweise $100 \mu \mathrm{M}$ DMF $+5 \mu \mathrm{M}$ KINK-1) noch deutlicher zutage trat. Eine vollständige Inhibition der CXCL8-Transkription wurde bei den verwendeten Konzentrationen nicht erreicht. Durch Kombinationen von $5 \mu \mathrm{M} \mathrm{KINK-1} \mathrm{mit} \mathrm{5,} 25$ oder $50 \mu \mathrm{M}$ DMF kam es zu einer deutlichen Herabregulation der CXCL1-mRNA; bei $5 \mu \mathrm{M}$ KINK-1 und $100 \mu \mathrm{M}$ DMF beziehungsweise $5 \mu \mathrm{M}$ DMF und $100 \mu \mathrm{M}$ KINK-1 zeigten sich keine Banden mehr. Die CCL2-mRNA war bei Kombinationen von $5 \mu \mathrm{M}$ KINK und 5 oder $25 \mu \mathrm{M}$ DMF bereits deutlich abgeschwächt, bei sämtlichen höheren Konzentrationen verschwand das Signal.

VEGF wurde erst bei hohen Konzentrationen beeinflusst: Bei der Kombination von 5 $\mu \mathrm{M}$ KINK-1 mit $100 \mu \mathrm{M}$ DMF kam es zu einem Anstieg der mRNA-Expression, während sich bei hoher KINK-1-Konzentration $(100 \mu \mathrm{M})$ in Kombination mit $5 \mu \mathrm{M}$ DMF nur eine sehr schwache Bande präsentierte.

Die HDMEC wurden mit $5 \mu \mathrm{M}$ DMF und KINK-1 in Konzentrationen von 0,625 bis 5 $\mu \mathrm{M}$ behandelt. Hier zeigte sich eine dosisabhängige Abnahme der VCAM-1-mRNA bereits ab einer KINK-1-Konzentration von 0,625 $\mu \mathrm{M}$. Auch die ICAM-1- und ESelektin-Signale präsentierten sich ab 0,625 $\mu \mathrm{M}$ abgeschwächt und verschwanden ab Konzentrationen von 2,5 $\mu \mathrm{M}$ KINK-1 vollends. Die CXCL1-mRNA zeigte eine leichte Reduktion ab der Kombination von DMF mit 1,25 $\mu \mathrm{M}$ KINK-1, CCL2 ab der Kombination mit $5 \mu \mathrm{M}$ KINK-1. Die Transkription von VEGF und CXCL8 wurde unter den verwendeten Kombinationen nicht sichtbar beeinflusst. 
HUVEC

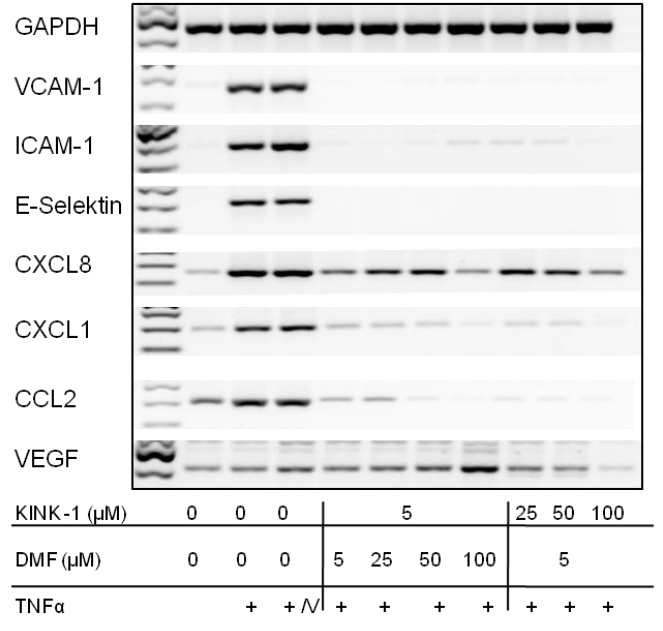

HDMEC

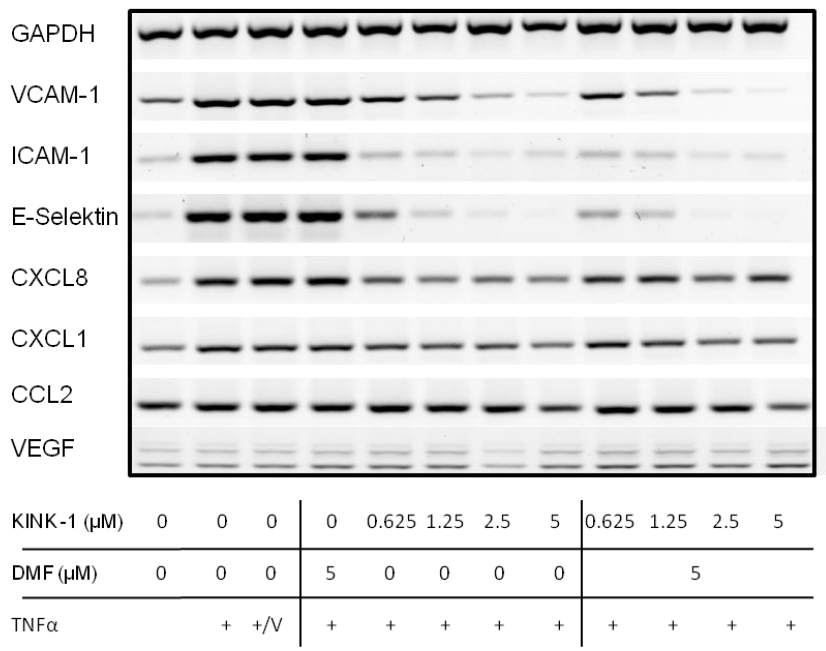

Abb. 9: Wirkung der Kombination von DMF und KINK-1 auf die Transkription in HUVEC und HDMEC. Die Transkription NF-KB-abhängiger Gene wurde mittels RT-PCR untersucht. HUVEC und HDMEC wurden auch hier mit DMF und KINK-1 in den angegebenen Konzentrationen für $5 \mathrm{~h}$ behandelt und die letzten $4 \mathrm{~h}$ zusätzlich parallel mit TNFa stimuliert. GAPDH-mRNA diente als interne Kontrolle. Als weitere Kontrollen: unbehandelte/ nicht-stimulierte, unbehandelte/ stimulierte und DMSO (V für Vehikel) behandelte/ stimulierte Zellen. Bei den Kombinationen der Substanzen zeigte sich in HUVEC bereits ab $5 \mu \mathrm{M}$ DMF mit $5 \mu \mathrm{M}$ KINK-1 eine deutliche Reduktion von VCAM-1, ICAM-1, ESelektin, CXCL1 sowie CCL2. Für CXCL8 trat bei niedrigeren Konzentrationen der kombinierten Substanzen DMF und KINK-1 eine leichte Herabregulation auf, erst bei hohen Konzentrationen wurden die Banden deutlich schwächer. Die VEGF-Signale sind bei der Kombination $100 \mu \mathrm{M}$ DMF und $5 \mu \mathrm{M}$ KINK-1 verstärkt, bei $5 \mu \mathrm{M}$ DMF und $100 \mu \mathrm{M}$ KINK-1 abgeschwächt. In HDMEC wird ein ähnlicher reduzierender Effekt bereits bei KINK-Konzentrationen ab 0,625 $\mu \mathrm{M}$ erreicht.

\subsubsection{Wirkung der Kombination von DMF und Bortezomib auf die Transkription von Adhäsionsproteinen, Chemokinen und VEGF}

In dieser Versuchsreihe wurden Konzentration 5 bis $50 \mu \mathrm{M}$ DMF mit 2,5 bis $50 \mathrm{ng} / \mathrm{ml}$ Bortezomib kombiniert (Abb. 10). Die Expression der VCAM-1-, ICAM-1- und ESelektin-mRNA in HUVEC wurde durch Kombinationen von Bortezomib in verschiedenen Konzentrationen mit jeweils $5 \mu \mathrm{M}$ DMF vermindert. Diese Wirkung verstärkte sich bei Kombinationen mit jeweils $25 \mu \mathrm{M}$ DMF, und bei $50 \mu \mathrm{M}$ DMF waren keine Signale mehr nachweisbar. Die CXCL8- und CXCL1-Transkription wurde erst durch die Kombination von Bortezomib mit $50 \mu \mathrm{M}$ DMF reduziert. Für CCL2 zeigte sich eine Reduktion der mRNA bereits bei der Kombination von $25 \mu \mathrm{M}$ DMF und Bortezomib, bei der Kombination mit $50 \mu \mathrm{M}$ DMF zeigten sich nur noch sehr schwache Banden. Die VEGF-Signale wurden durch Kombinationen aus DMF und Bortezomib konzentrationsabhängig verstärkt. 
In den Versuchen mit HDMEC wurden nur geringe DMF-Konzentrationen von $5 \mu \mathrm{M}$ eingesetzt, da in HUVEC bereits für diese ein Effekt gezeigt werden konnte. Die Kombinationen aus $5 \mu \mathrm{M}$ DMF und 2,5 bis $40 \mathrm{ng} / \mathrm{ml}$ Bortezomib zeigten in HDMEC eine geringe Abschwächung der ICAM-1-, E-Selektin- und CCL2-Banden.

HUVEC

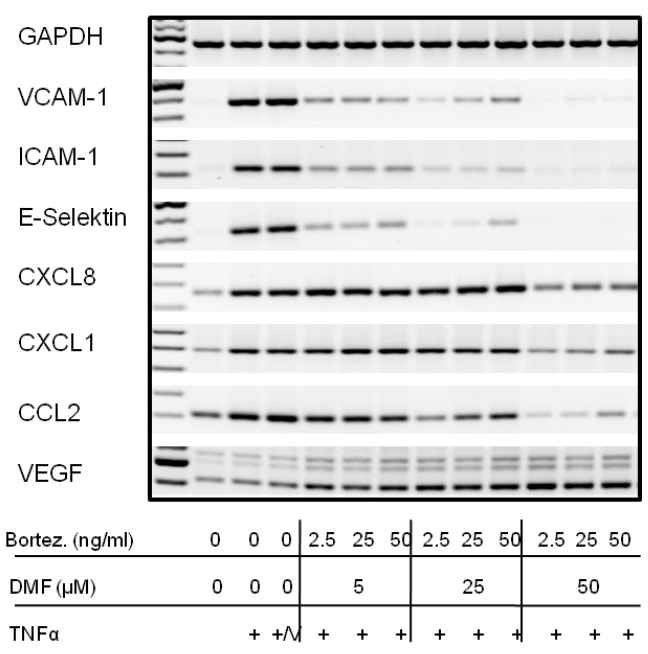

HDMEC

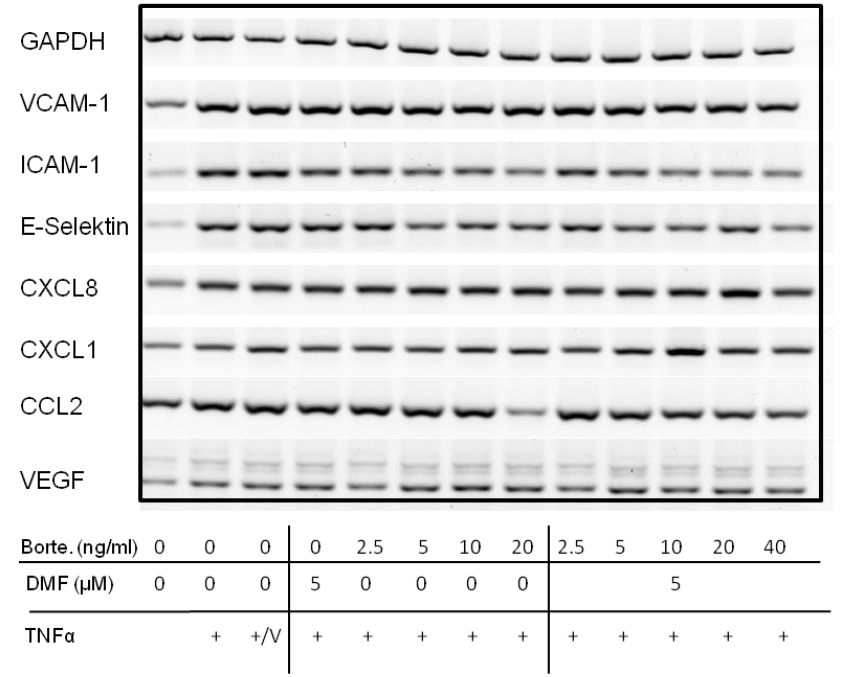

Abb. 10: Wirkung der Kombination von DMF und Bortezomib auf die Transkription in HUVEC und HDMEC. Bestimmung mittels RT-PCRs. HUVEC und HDMEC wurden mit den angegebenen Substanzen für jeweils $5 \mathrm{~h}$ behandelt und die letzten $4 \mathrm{~h}$ parallel mit TNFa stimuliert. GAPDH-mRNA diente als interne Kontrolle. Als weitere Kontrollen: unbehandelte/ nicht-stimulierte, unbehandelte/ stimulierte und DMSO (V für Vehikel)-behandelte/ stimulierte Zellen eingesetzt. In HUVEC zeigte sich bereits bei der Kombination von $5 \mu \mathrm{M}$ DMF und 2,5 $\mathrm{ng} / \mathrm{ml}$ Bortezomib eine deutliche Reduktion von VCAM-1, ICAM-1 und E-Selektin. CXCL8, CXCL1 sowie CCL2 wurden erst ab einer Kombination von $50 \mu \mathrm{M}$ DMF mit 2,5 ng/ml Bortezomib sichtbar herabreguliert. VEGF wurde bereits bei Kombination der geringsten Substanzmengen verstärkt exprimiert. In HDMEC bleiben die Transkriptionen durch die Behandlung mit DMF und Bortezomib kaum beeinflusst. Es zeigen sich lediglich leichte Abschwächungen der ICAM-1, E-Selektin und CCL2-Banden. 


\subsection{Auswirkungen der unterschiedlichen Einzelstoffe sowie ihrer Kombinationen auf Protein-Ebene}

\subsubsection{Einfluss auf endotheliale Adhäsionsproteine}

\subsubsection{Allgemeines}

Nachdem eine transkriptionelle Reduktion endothelialer Adhäsionsmoleküle durch DMF in Kombination mit NF-KB-Inhibitoren nachgewiesen wurde, sollte die Expression von E-Selektin, VCAM-1 und ICAM-1 auf Proteinebene überprüft werden. In durchflusszytometrischen Messungen wurden sowohl die mittlere Fluoreszenzintensität (MFI) als auch der prozentuale Anteil positiver Zellen ermittelt.

Da DMF als Einzelstoff in Konzentrationen von 50 bis $200 \mu \mathrm{M}$ zu einer signifikanten Reduktion der E-Selektin- und VCAM-1-Expression führt (Wallbrecht et al. 2011), wurden für die Kombinationen in erster Linie niedrige DMF-Konzentrationen von 5 bis $25 \mu \mathrm{M}$ genutzt.

\subsubsection{Einfluss auf die Expression von E-Selektin}

3.3.1.2.1 Einfluss der Kombination von DMF und KINK-1 auf die E-SelektinExpression

TNFa stimulierte die Expression endothelialen E-Selektins. Die durchschnittliche MFI stieg von 717 auf 24.659 an. Auch die Zahl positiver Zellen stieg von 4,3\% auf $78,8 \%$.

Nach der Behandlung mit DMF sank die MFI auf 19.242 (5 $\mu$ M DMF SEM \pm 5.848 ) beziehungsweise 11.665 (15 $\mu \mathrm{M}$ SEM \pm 5.417$)$. KINK-1 bewirkte eine Reduktion der MFI auf 14.588 (SEM \pm 5.415 ) beziehungsweise 12.502 (SEM \pm 5.389$)$. Durch DMF fiel die MFI somit um bis zu 53\%, unter KINK-1 um 49,3\%. Die Zahl E-Selektin exprimierender Zellen wurde ebenfalls gesenkt (DMF $5 \mu \mathrm{M}$ auf 73,8\% SEM $\pm 3,33$, DMF $15 \mu \mathrm{M}$ auf 54,7\% SEM \pm 7,45, KINK-1 0,015 $\mu \mathrm{M}$ auf 69,1\% SEM \pm 4,25, KINK$10,0375 \mu \mathrm{M}$ auf $60,2 \% \mathrm{SEM} \pm 6,68)$. Die kombinierte Behandlung mit DMF und KINK-1 führte zu einer weiteren Reduktion der E-Selektin-Expression. So fiel die MFI beispielsweise unter der Kombination von $15 \mu \mathrm{M}$ DMF und 0,015 $\mu \mathrm{M}$ KINK auf 3.345,6 (SEM \pm 1.108$)$, die positiven Zellen wurden auf $39,1 \%$ herabgesetzt $(p<0,05$ im Vergleich zu der unbehandelten stimulierten Kontrolle, SEM $\pm 9,36)$. Dies 
bedeutete eine Reduktion der MFI um 86,5\% und der Zahl positiver Zellen um 50\% im Vergleich zu unbehandelten stimulierten Kontrollen (Abb. 11).

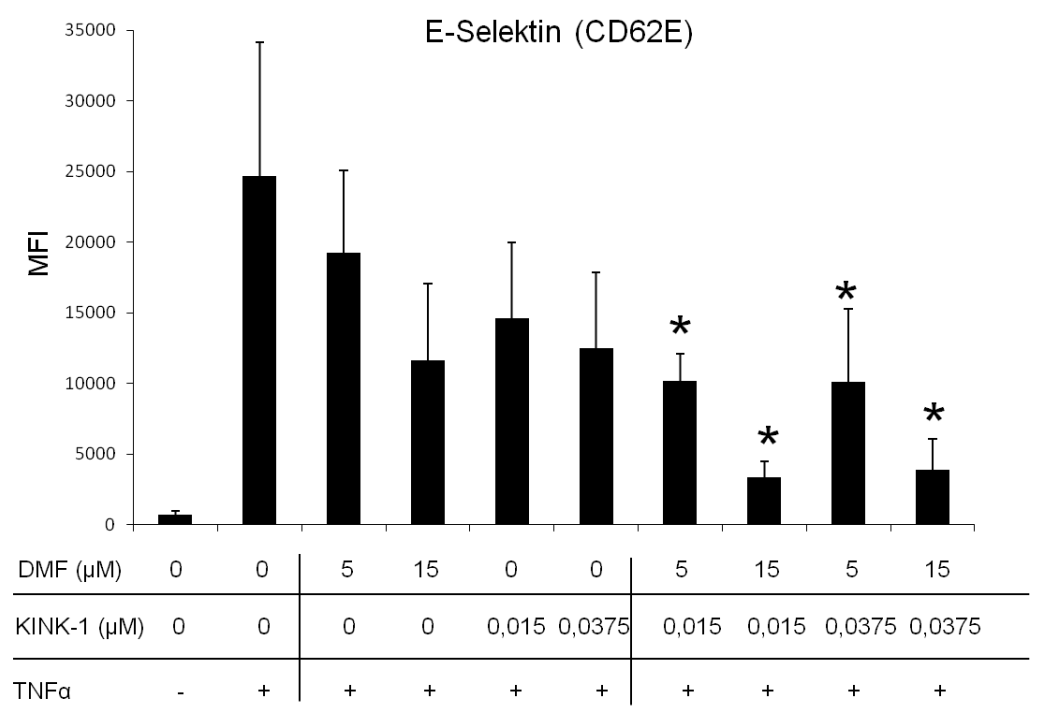

Abb. 11: Einfluss der Kombination von DMF und KINK-1 auf die Expression von E-Selektin an der Zelloberfläche von HUVEC. Untersuchung der MFI von E-Selektin mittels Durchflusszytometrie nach Behandlung der Zellen mit DMF und KINK-1 in den angegebenen Konzentrationen. Dargestellt sind Mittelwerte und Standardfehler (SEM). $n=3$ unabhängige Experimente. ${ }^{*} p<0,05,{ }^{* *} p<0,01 \mathrm{im}$ Vergleich zu der unbehandelten stimulierten Kontrolle.

3.3.1.2.2 Einfluss der Kombination von DMF und Bortezomib auf die E-SelektinExpression

Nach Stimulation der HUVEC mit TNFa steigerte sich die MFI von 608 auf 24.683, der Anteil positiver Zellen von 6,2\% auf $84,43 \%$. Durch die Behandlung mit DMF fiel die MFI auf 17.174 (5 $\mu \mathrm{M}$ DMF SEM \pm 1.421$)$ beziehungsweise 9.883 (15 $\mu \mathrm{M}$ DMF SEM \pm 918$)$. Nach der Behandlung mit Bortezomib zeigte sich ein Abfall der MFI auf $13.974(5 \mathrm{ng} / \mathrm{ml}$ SEM \pm 840$)$ beziehungsweise $11.394(10 \mathrm{ng} / \mathrm{ml} \mathrm{SEM} \pm 2.282)$. Verglichen mit der MFI unbehandelter stimulierter HUVEC bedeutete dies einen maximalen Rückgang der MFI um 60\% durch DMF und um 54\% durch Bortezomib. Der Anteil positiver Zellen fiel durch 5 beziehungsweise $15 \mu \mathrm{M}$ DMF auf 78,8\% (SEM $\pm 1,53$ ) beziehungsweise $65,2 \%$ (SEM $\pm 3,83$ ), unter 5 beziehungsweise $10 \mathrm{ng} / \mathrm{ml}$ Bortezomib auf 75,3 (SEM $\pm 3,18$ ) beziehungsweise $62,9 \%$ (SEM $\pm 4,89$ ). Dieses entspricht einer maximalen Reduktion der positiven Zellen um 25,5\%. Auch hier zeigte sich bei der Kombination der Substanzen eine Verstärkung des reduzierenden Effektes. So führte die Kombination von $15 \mu \mathrm{M}$ DMF mit $10 \mathrm{ng} / \mathrm{ml}$ Bortezomib zu 
einer Reduktion der MFI um 86\% ( $p<0,05$ im Vergleich zu der unbehandelten stimulierten Kontrolle, SEM \pm 620 ), die positiven Zellen fielen unter gleicher Kombination um 51\% ( $p<0,01$ im Vergleich zu der unbehandelten stimulierten Kontrolle, SEM $\pm 6,8)$ (Abb. 12).

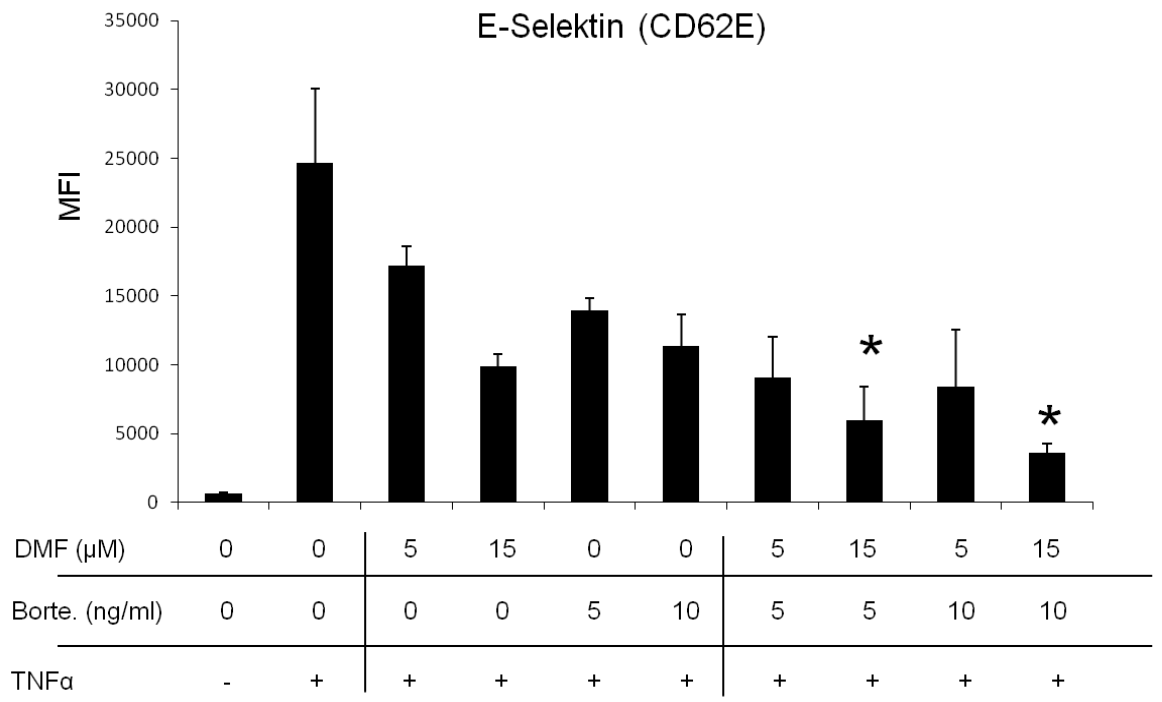

Abb. 12: Einfluss der Kombination von DMF und Bortezomib auf die Expression von E-Selektin an der Zelloberfläche von HUVEC. Untersuchung der MFI mittels Durchflusszytometrie nach Behandlung der Zellen mit DMF und Bortezomib (Borte.) in den angegebenen Konzentrationen. Dargestellt sind Mittelwerte und Standardfehler (SEM). $n=3$ unabhängige Experimente. ${ }^{*} p<0,05$, * $p<0,01 \mathrm{im}$ Vergleich zu der unbehandelten stimulierten Kontrolle.

\subsubsection{Einfluss auf die Expression von VCAM-1}

3.3.1.3.1 Einfluss der Kombination von DMF und KINK-1 auf die VCAM-1Expression

Die Oberflächen-Expression des endothelialen VCAM-1 war ebenfalls durch TNFainduzierbar. So stieg die MFI von 49,3 auf 15.600 an (SEM \pm 998). Auch der Anteil positiver Zellen erhöhte sich von 0,9\% auf $80,96 \%$ (SEM $\pm 0,12$ ). Unter der Behandlung mit DMF fiel die MFI auf 13.227 (5 $\mu \mathrm{M}$ DMF SEM \pm 743) beziehungsweise 8.434 (15 $\mu \mathrm{M}$ DMF SEM \pm 1.380$)(p<0,05 \mathrm{im}$ Vergleich zu der unbehandelten stimulierten Kontrolle). Nach der Behandlung mit KINK-1 zeigte sich ebenfalls eine Reduktion der MFI auf $16.347(0,015 \mu \mathrm{M}$ KINK-1 SEM \pm 1.844$)$ beziehungsweise $10.142(0,0375 \mu \mathrm{M}$ KINK-1 SEM \pm 1.657$)(p<0,05 \mathrm{im}$ Vergleich zu der unbehandelten stimulierten Kontrolle). Unter DMF fiel die MFI somit um maximal 
45,9\%, unter KINK-1 um 34,9\%. Die Anzahl der positiven Zellen fiel unter der Behandlung mit 5 beziehungsweise $15 \mu \mathrm{M}$ DMF auf 77,1 (SEM \pm 1,82) beziehungsweise $64,9 \%$ (SEM $\pm 2,5$ ), unter 0,0375 $\mu \mathrm{M}$ KINK-1 auf 69,9\% (SEM \pm 1,86), während eine Konzentration von 0,015 $\mu \mathrm{M}$ KINK-1 zu keiner Reduktion der positiven Zellen führte. Somit reduzierte DMF allein die positiven Zellen um $20 \%$, KINK-1 um 13,7\%. Die Kombinationen führten zu einer weiteren Reduktion der VCAM-1-Expression. So fiel die MFI beispielsweise unter der Kombination von 15 $\mu \mathrm{M}$ DMF mit 0,0375 $\mu \mathrm{M}$ KINK-1 auf 4673 (SEM \pm 710 ) herab, was einer prozentualen Reduktion von $70 \%$ entspricht $(p<0,001$ im Vergleich $z u$ der unbehandelten stimulierten Kontrolle). Die positiven Zellen wurden unter gleicher Kombination um $43 \%$ reduziert (Abb. 13).

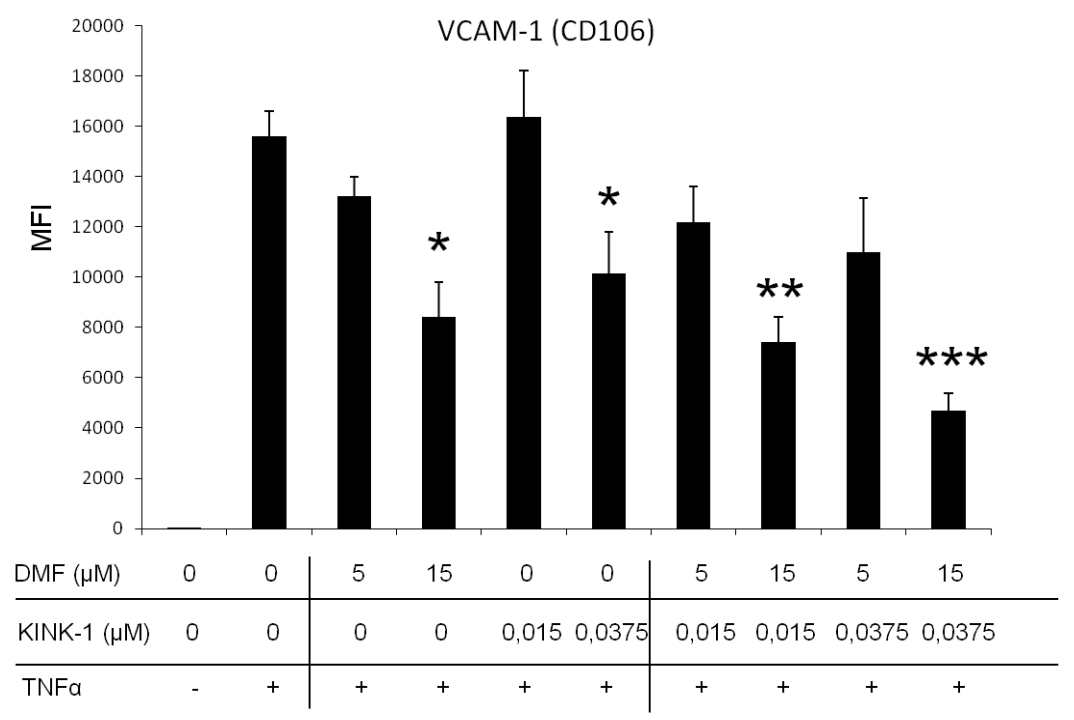

Abb. 13: Einfluss der Kombination von DMF und KINK-1 auf die Expression von VCAM-1 an der Zelloberfläche von HUVEC. Untersucht mittels Durchflusszytometrie nach Behandlung der Zellen mit DMF und KINK-1 in den angegebenen Konzentrationen. Dargestellt sind Mittelwerte und Standardfehler (SEM). $n=3$ unabhängige Experimente. ${ }^{*} p<0,05,{ }^{* *} p<0,01,{ }^{* * *} p<0,01 \mathrm{im}$ Vergleich zu der unbehandelten stimulierten Kontrolle.

3.3.1.3.2 Einfluss der Kombination von DMF und Bortezomib auf die VCAM-1Expression

Nach der Behandlung mit $5 \mu \mathrm{M}$ DMF fiel die MFI von 13.283 auf 10.899,6 (SEM \pm 2.177) herab, unter $15 \mu \mathrm{M}$ DMF auf 7.016,6 (SEM \pm 994 ). Auch die positiven Zellen verringerten sich von $81,5 \%$ auf $75,26 \%$ (SEM $\pm 1,27$ ) beziehungsweise $64 \%$ (SEM \pm 1,58). Wie erwartet führte auch Bortezomib in Einzelkonzentration zu einer Reduktion 
des VCAM-1-Signals. Hier verringerte sich die MFI auf 8.738 ( $5 \mathrm{ng} / \mathrm{ml} \mathrm{SEM} \pm 1.779)$ und $6.226(10 \mathrm{ng} / \mathrm{ml}$ SEM \pm 569$)$, die positiven Zellen fielen jeweils auf 64\% (SEM \pm 2,2 beziehungsweise 1,46). Dies bedeutet eine maximale Reduktion der MFI unter DMF um 47,2\%, unter Bortezomib um 53,2\% ( $p<0.05$ im Vergleich zur unbehandelten stimulierten Kontrolle). Die positiven Zellen fielen unter beiden Stoffen um maximal 26,5\% ( $p<0,001$ im Vergleich zur unbehandelten stimulierten Kontrolle). Unter der Behandlung mit den Kombinationen reduzierten sich die MFI sowie die positiven Zellen erneut. Die MFI sank um max. 83\%, die Zahl der positiven Zellen um 65\% (Abb. 14).

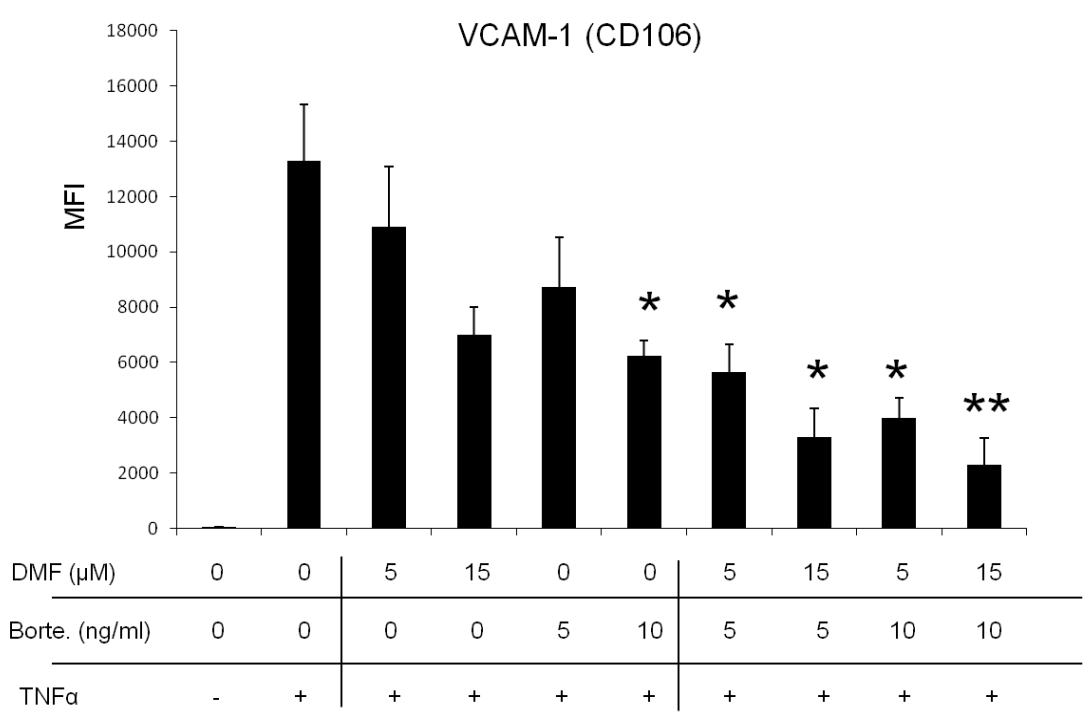

Abb. 14: Einfluss der Kombination von DMF mit Bortezomib auf die Expression von VCAM-1 an der Zelloberfläche von HUVEC. Untersucht mittels Durchflusszytometrie nach Behandlung der Zellen mit DMF und Bortezomib (Borte.) in den angegebenen Konzentrationen. Dargestell sind Mittelwerte und Standardfehler (SEM). $n=3$ unabhängige Experimente. ${ }^{*} p<0,05,{ }^{* *} p<0,01$ im Vergleich zu der unbehandelten stimulierten Kontrolle.

\subsubsection{Einfluss auf die Expression von ICAM-1}

3.3.1.4.1 Einfluss der Kombination von DMF und KINK-1 auf die ICAM-1Expression

Im Fall des Adhäsionsmoleküls ICAM-1 kam es unter TNFa-Stimulation ebenfalls zu einem deutlichen Anstieg der MFI sowie der positiven Zellen. Erste stieg von 340,6 auf 2.926 (SEM \pm 448). Auch die positiven Zellen stiegen von 5 auf 68,1\% (SEM \pm $10,05)$ deutlich an. Unter der Behandlung mit DMF fiel die MFI nur wenig auf 2.815,6 
(5 $\mu$ M DMF SEM \pm 664 ) beziehungsweise 2.548 (15 $\mu$ M DMF SEM \pm 148$)$. Nach der Behandlung mit KINK-1 zeigte sich ebenfalls eine Reduktion der MFI auf 1.896 $(0,015 \mu \mathrm{M}$ KINK-1 SEM \pm 348$)$ beziehungsweise 1732,6 (0,0375 $\mu \mathrm{M}$ KINK-1 SEM \pm 274). Unter DMF fiel die MFI somit um maximal 13\%, unter KINK-1 um 40,8\%. Die Anzahl der positiven Zellen fiel unter der Behandlung mit 5 beziehungsweise $15 \mu \mathrm{M}$ DMF auf 62,5 (SEM $\pm 15,85$ ) beziehungsweise. 66\% (SEM $\pm 5,4)$, unter 0,0375 $\mu \mathrm{M}$ KINK-1 auf 53,4\% (SEM $\pm 9,95)$. Somit reduzierte DMF allein die positiven Zellen um max. 8,3\%, KINK-1 um 21,6\%. Die Kombinationen führten zu einer stärkeren Reduktion der ICAM-1-Expression. So fiel die MFI beispielsweise unter der Kombination von $15 \mu \mathrm{M}$ DMF mit 0,0375 $\mu \mathrm{M}$ KINK-1 auf 1186,3 (SEM \pm 81), was einer prozentualen Reduktion von 59,5\% entspricht ( $p<0,05$ im Vergelich zu der unbehandelten stimulierten Kontrolle). Die positiven Zellen wurden unter gleicher Kombination um 43,7\% reduziert (Abb. 15).

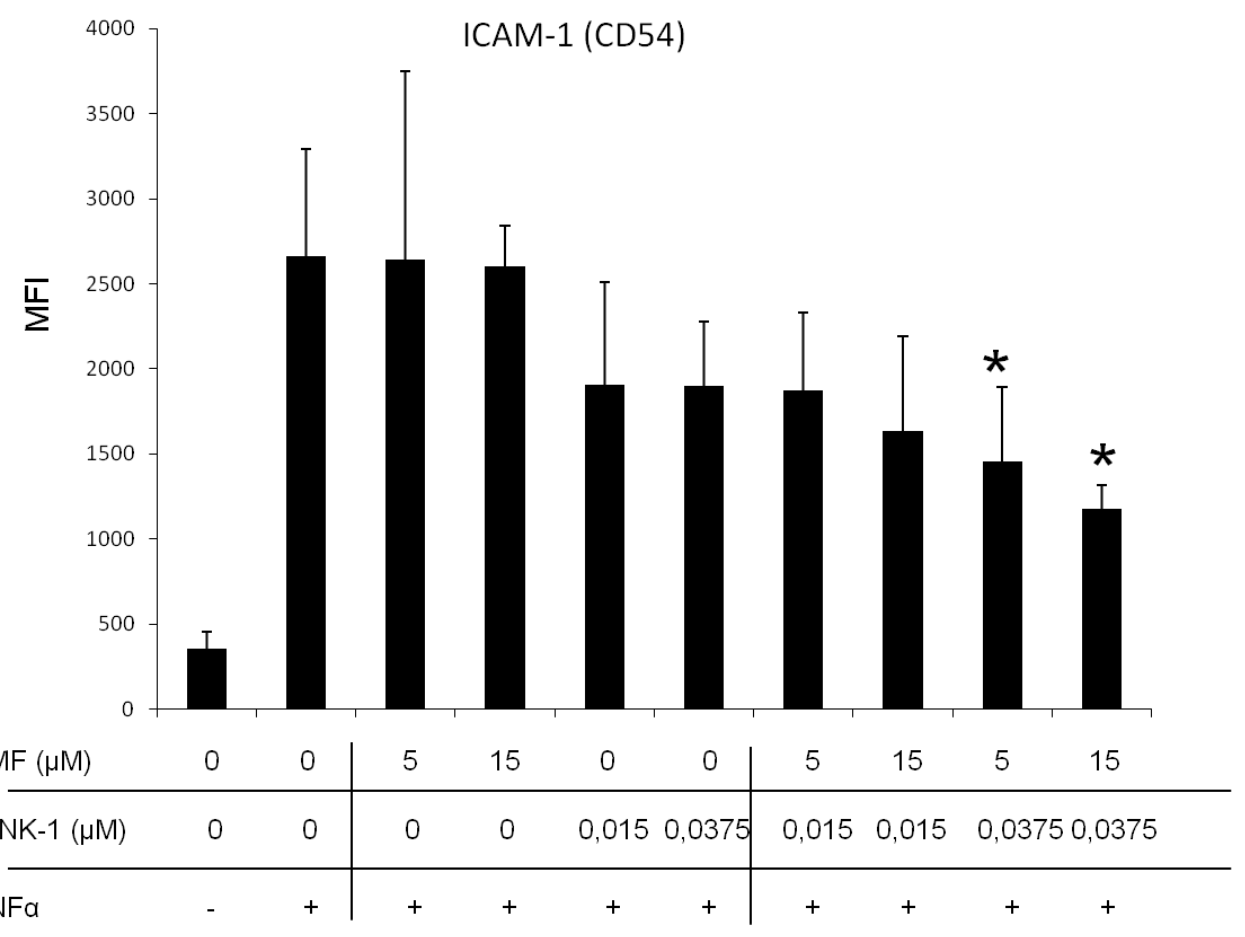

Abb. 15: Einfluss der Kombination von DMF und KINK-1 auf die Expression von ICAM-1 an der Zelloberfläche von HUVEC. Untersucht mittels Durchflusszytometrie nach Behandlung der Zellen mit DMF und KINK-1 in angegebenen Konzentrationen. Dargestellt sind Mittelwerte und Standardfehler (SEM). $n=3$ unabhängige Experimente. ${ }^{*} \mathrm{p}<0,05$ im Vergleich zu der unbehandelten stimulierten Kontrolle. 
3.3.1.4.2 Einfluss der Kombination von DMF und Bortezomib auf die ICAM-1Expression

Nach Stimulation mit TNFa steigerte sich die MFI für ICAM-1 von 358 auf 2.666 (SEM \pm 362 ), die positiven Zellen von 4,9\% auf 67,4\% (SEM $\pm 5,8$ ). Nach der Behandlung mit DMF fiel die MFI auf 2.643,6 (5 $\mu \mathrm{M}$ DMF SEM \pm 640) beziehungsweise 2.614,8 (15 $\mu \mathrm{M}$ DMF SEM \pm 139). Nach der Behandlung mit Bortezomib zeigte sich ebenfalls ein Abfall der MFI auf 2.579 ( $5 \mathrm{ng} / \mathrm{ml}$ Bortezomib SEM \pm 500 ) beziehungsweise 2.363,6 (10 $\mathrm{ng} / \mathrm{ml}$ Bortezomib SEM \pm 699$)$. Verglichen mit der MFI der unbehandelten stimulierten HUVEC bedeutete dies einen maximalen Rückgang der MFI um 6,1\% unter DMF und um 19,5\% unter Bortezomib. Die Anzahl der positiven Zellen fiel unter der Behandlung mit 5 beziehungsweise $15 \mu \mathrm{M}$ DMF auf 63,3 (SEM $\pm 9,4$ ) beziehungsweise 65,7\% (SEM $\pm 3,6$ ), unter 5 beziehungsweise 10 $\mathrm{ng} / \mathrm{ml}$ Bortezomib auf 54,3 (SEM $\pm 5,16$ ) beziehungsweise 54,5\% (SEM $\pm 14,98$ ). Dies entspricht einer maximalen Reduktion der positiven Zellen um 19,5\%. Auch hier zeigte sich nach Behandlung mit den Kombinationen eine Verstärkung des reduzierenden Effektes. So führte die Kombination von $15 \mu \mathrm{M}$ DMF und $10 \mathrm{ng} / \mathrm{ml}$ Bortezomib zu einer Reduktion der MFI um 40,9\%, die positiven Zellen fielen unter gleicher Kombination um 29,9\% (Abb. 16).

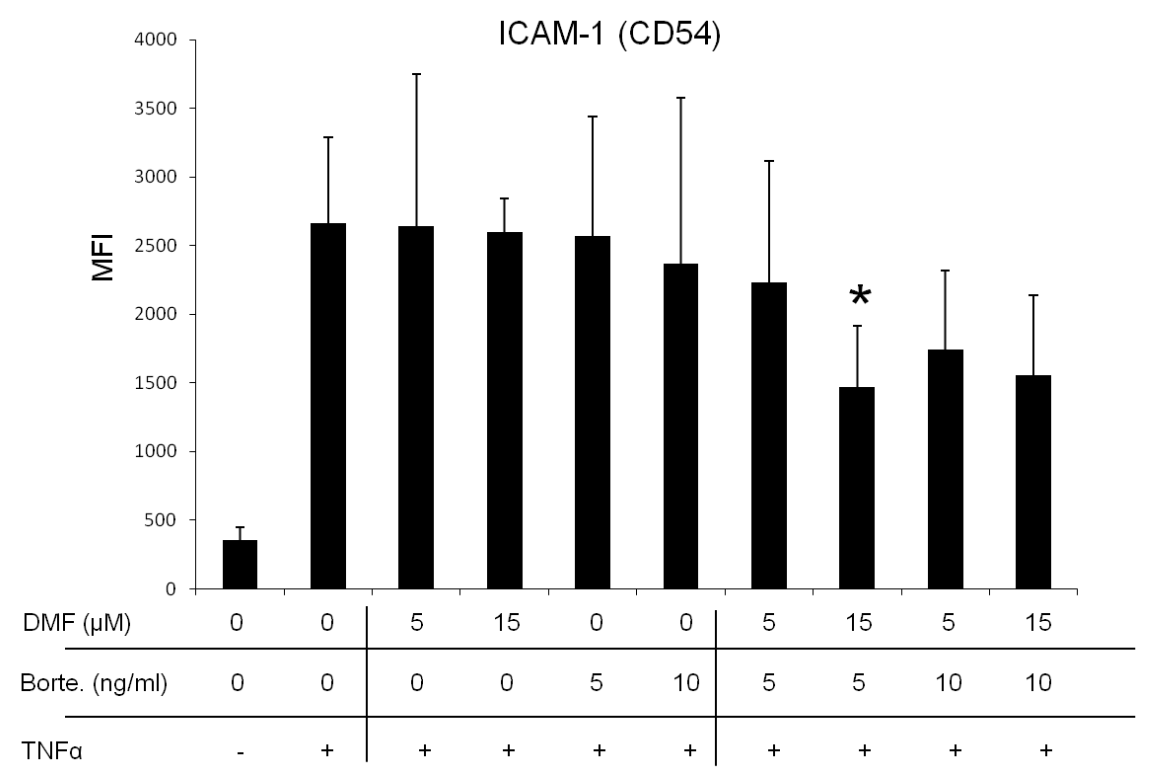

Abb. 16: Einfluss der Kombination von DMF und Bortezomib auf die Expression von ICAM-1 an der Zelloberfläche von HUVEC. Untersucht mittels Durchflusszytometrie nach Behandlung der Zellen mit DMF und Bortezomib (Borte.) in den angegebenen Kombinationen. Dargestellt sind Mittelwerte und Standardfehler (SEM). $n=3$ unabhängige Experimente. ${ }^{*} p<0,05$ im Vergleich zu der unbehandelten stimulierten Kontrolle. 


\subsubsection{Einfluss auf leukozytäre Oberflächenmoleküle}

In der nächsten Versuchsreihe wurde überprüft, ob DMF, KINK-1, Bortezomib oder Kombinationen aus DMF und je einem der beiden NF-kB-Inhibitoren auch Zelloberflächen-Rezeptoren humaner Leukozyten (frisch isolierte PBMC) beeinflussen und damit auf beide Interaktionspartner der Leukozyten-Extravasation wirken. Die leukozytären Liganden der untersuchten endothelialen Adhäsionsmoleküle, L-Selektin (lymphocyte-selectin, CD62L), LFA-1 (lymphocyte function-associated antigen-1, CD11a/CD18), CLA (cutaneous lymphocyte antigen) und VLA-4 (very late antigen-1, CD49d/CD29), wurden durchflusszytometrisch untersucht. Die PBMC wurden zuvor für $2 \mathrm{~h}$ mit den Substanzen inkubiert.

DMF hatte auch bei hohen Konzentrationen von $200 \mu \mathrm{M}$ keine signifikante Wirkung auf die Expression oben genannter Moleküle. Gleichzeitig zeigten auch die NF-kBInhibitoren KINK-1 und Bortezomib keinen Einfluss auf die Antigen-Expression. Die Kombinationen von $25 \mu \mathrm{M}$ DMF und KINK-1 (5 und $25 \mu \mathrm{M}$ ) sowie $25 \mu \mathrm{M}$ DMF und Bortezomib $(5,10,20,40 \mathrm{ng} / \mathrm{ml})$ veränderten die Expression der leukozytären Oberflächenmoleküle ebenfalls nicht.

Demnach übten Kombinationen aus DMF und NF-KB-Inhibitoren eine gegenseitig verstärkende Wirkung auf $\mathrm{TNF} \alpha$-stimulierte Endothelzellen, nicht aber auf frisch isolierte PBMC aus (Abb. 17). 
LFA-1
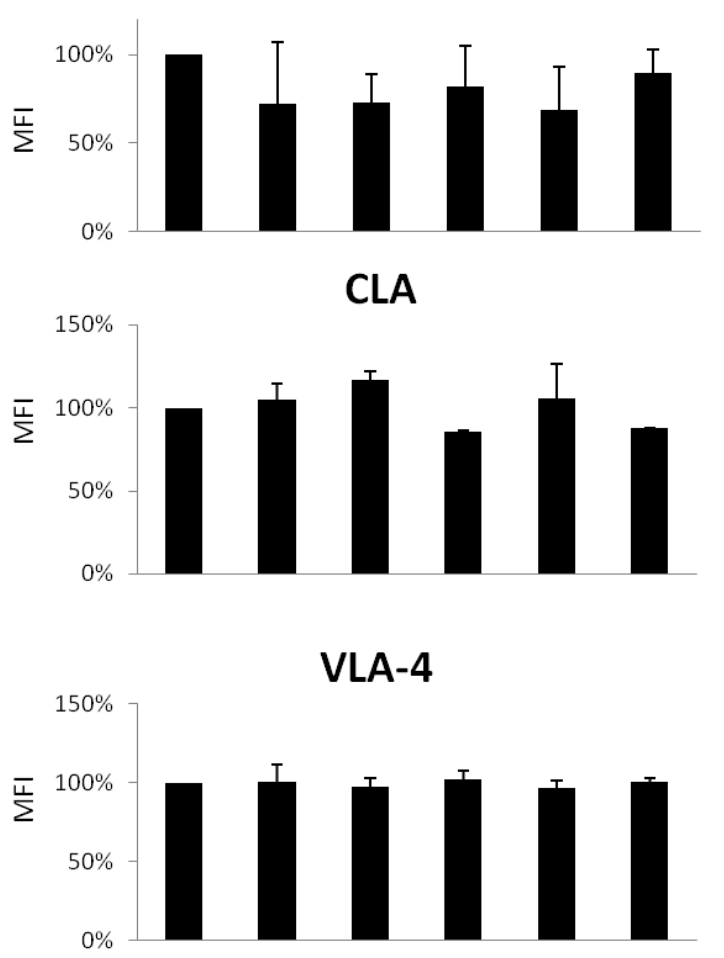

L-Selektin

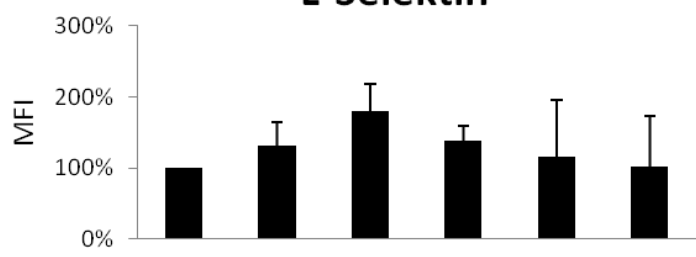

\begin{tabular}{lcccc|cc}
$\mathrm{KINK}-1(\mu \mathrm{M})$ & $0 / \mathrm{N}$ & 0 & 5 & 25 & 5 & 25 \\
\hline $\mathrm{DMF}(\mu \mathrm{M})$ & $\mathrm{O} / \mathrm{N}$ & 25 & 0 & 0 & 25 & 25 \\
\hline
\end{tabular}
LFA-1

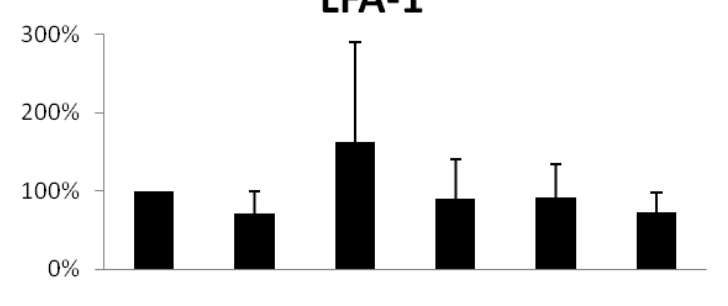

CLA

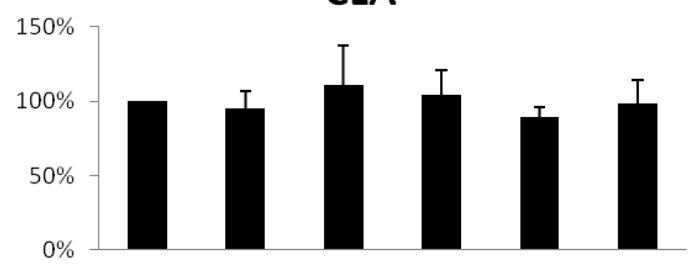

VLA-4

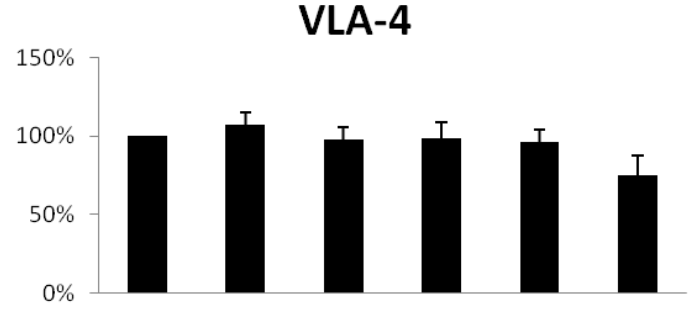

L-Selektin

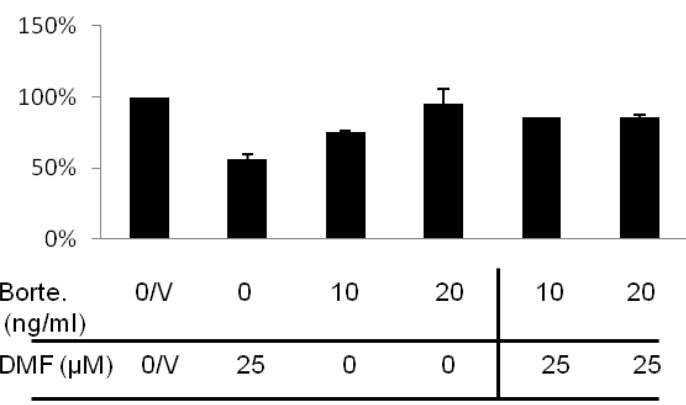

Abb. 17: Einfluss von DMF, KINK-1 und Bortezomib auf PBMC. Humane PBMC wurden aus dem Vollblut gesunder Probanden isoliert und $2 \mathrm{~h}$ mit DMF $(25 \mu \mathrm{M})$ und KINK-1 (linke Spalte) beziehungsweise Bortezomib (Borte., rechte Spalte) behandelt. Die Expression der leukozytären Oberflächenmoleküle L-Selektin, LFA-1, CLA und VLA-4 wurde mittels Durchflusszytometrie untersucht $(\mathrm{MFI}=$ mittlere Fluoreszenzintensität in \% der unbehandelten Kontrolle). Dargestellt sind Mittelwerte und Standardabweichungen von jeweils zwei unabhängigen Untersuchungen. Es zeigten sich keine deutlichen Effekte auf die Expression der untersuchten Oberflächenmoleküle, weder unter Verwendung der Einzelstoffe noch unter ihren Kombinationen. (modifiziert nach Hund et al. 2016, die Verwendung erfolgte mit freundlicher Genehmigung des Verlags John Wiley \& Sons A/S.) 


\subsection{Induktion von Apoptose, Viabilität und Proliferation humaner Endothelzellen durch DMF, KINK-1 und Bortezomib}

\subsubsection{Apoptoseinduktion/ Zytotoxizität von DMF, KINK-1 und Bortezomib}

Da für die Kombinationsbehandlungen vorzugsweise Einzelsubstanzen niedriger Zytotoxizität verwendet werden sollten, wurde zunächst die akute Toxizität von DMF, KINK-1 und Bortezomib in einer breitangelegten Versuchsreihe bestimmt. Als Parameter wurden die Apoptose mittels Zelltod-ELISA (s. Kap. 2.3.1) sowie die Anzahl vitaler HUVEC mit Hilfe des Neutralrot-Tests (s. Kap. 2.3.2) erfasst. Als positive Kontrolle diente in beiden Versuchsreihen Staurosporin, ein starker Apoptose-Induktor. Für beide Untersuchungen wurden HUVEC für $24 \mathrm{~h}$ mit je einem der drei Substanzen behandelt und zusätzlich $23 \mathrm{~h}$ davon parallel mit TNFa stimuliert.

Der Zelltod-ELISA zeigte eine dosisabhängige Zunahme der Apoptoseinduktion für DMF (>50 $\mu \mathrm{M})$ und KINK-1 (ab $5 \mu \mathrm{M})$. Bortezomib hingegen übte bereits bei geringen Konzentrationen einen dosisunabhängigen negativen Effekt aus. Eine signifikante Steigerung der Apoptose im Vergleich zu der nur TNFa-stimulierten Kulturen zeigte sich bei keinem der drei Stoffe (Abb. 18).
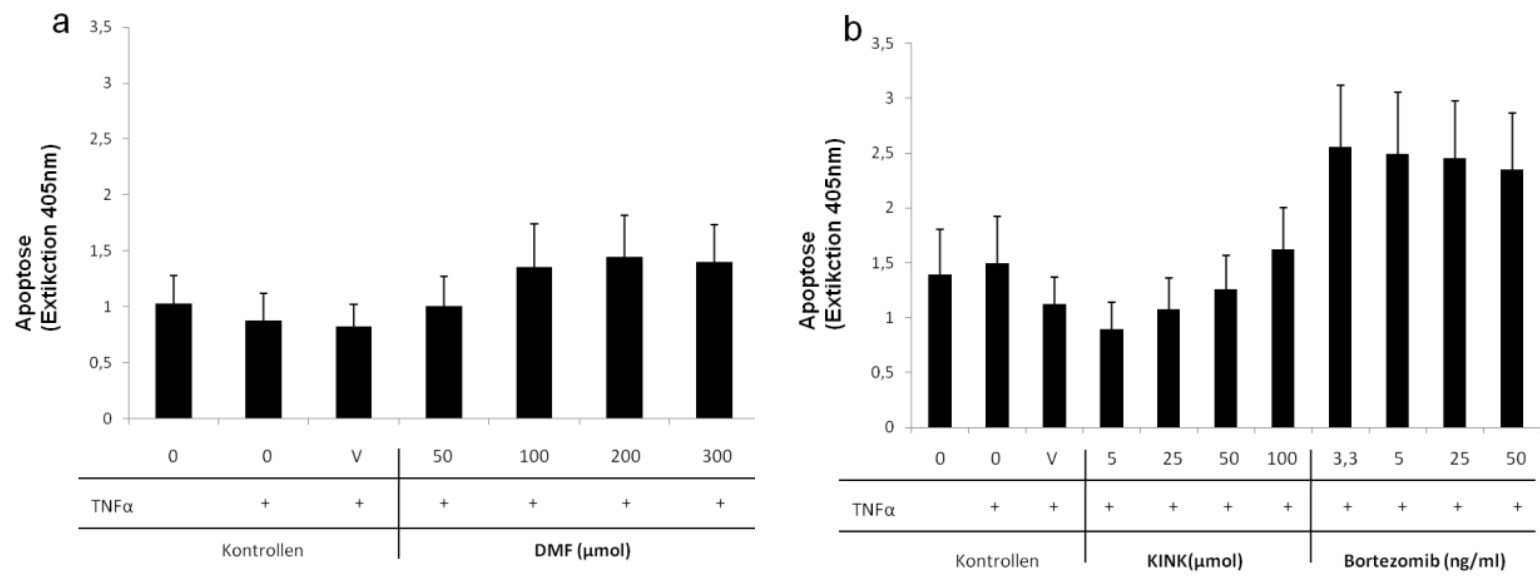

Abb. 18: Apoptoseinduktion durch DMF, KINK-1 und Bortezomib. Die Apoptoseinduktion von DMF, KINK-1 und Bortezomib wurde mittels Apoptose-ELISA betrachtet. DMF und KINK-1 zeigten eine dosisabhängige Zunahme der Apoptoserate, während Bortezomib einen dosisunabhängigen starken Effekt auf die Vitalität der Endothelzellen zeigt. Dargestellt sind Mittelwerte und Standardfehler von jeweils drei unabhängigen Versuchen. 
Im Neutralrot-Test wurde für DMF, KINK-1 und Bortezomib eine dosisabhängige Abnahme vitaler Zellen als Zeichen der Zytotoxizität gesehen. Für DMF wurde der negative Effekt ab $150 \mu \mathrm{M}$ und für KINK-1 ab $25 \mu \mathrm{M}$ beobachtet. Bortezomib zeigte eine steigende Toxizität bereits ab $5 \mathrm{ng} / \mathrm{ml}$ (Abb. 19).
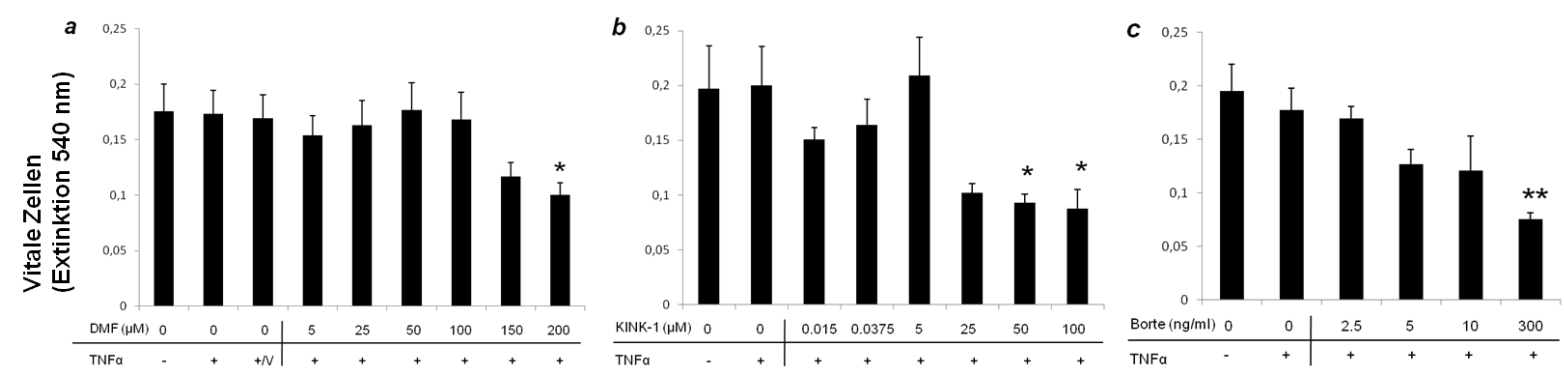

Abb. 19: Zytotoxizität von DMF, KINK-1 und Bortezomib in HUVEC. Die Zytotoxizität von DMF, KINK-1 und Bortezomib wurde mittels des Neutralrot-Tests untersucht. Alle drei Stoffe bewirken eine dosisabhängige Abnahme vitaler Zellen. Dargestellt sind Mittelwerte und Standardfehler von drei (KINK-1, Bortezomib) beziehungsweise 4 (DMF) unabhängigen Versuchen. ${ }^{*} p<0,05,{ }^{* *} p<0,01 \mathrm{im}$ Vergleich zu der nur mit TNFa stimulierten Kontrolle. (modifiziert nach Hund et al. 2016, die Verwendung erfolgte mit freundlicher Genehmigung des Verlags John Wiley \& Sons A/S.)

\subsubsection{Zellviabilität}

Um auszuschließen, dass die Kombinationen der eingesetzten Pharmaka neben den erwünschten Wirkungen auch zu einer Verstärkung negativer Effekte auf HUVEC führen, wurde die Viabilität der HUVEC mit dem MTT-Test untersucht (Abb. 20).

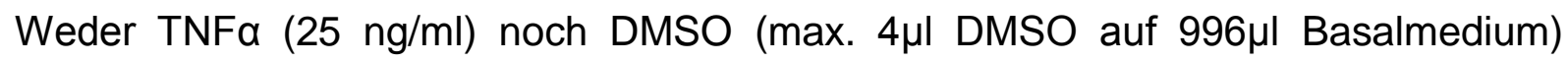
beeinflussten die Zellviabilität, wogegen sie DMF dosisabhängig bei Konzentrationen ab $50 \mu \mathrm{M}$ reduzierte (beispielhaft bei $100 \mu \mathrm{M}$ um 35\% p<0,05, bei $200 \mu \mathrm{M}$ um 68\% $\mathrm{p}<0,01 \mathrm{im}$ Vergleich zu der nur TNFa-stimulierten Kontrolle). Der IKKß-Inhibitor KINK-1 zeigte ebenfalls eine Dosisabhängigkeit in Bezug auf den untersuchten Parameter. Bei einer niedrigen Konzentration von 2,5 $\mu \mathrm{M}$ beeinträchtigte KINK-1 die Zellviabilität nicht (SEM $\pm 0,03$ ), bei $25 \mu \mathrm{M}$ KINK-1 ging die Viabilität allerdings bereits um 68\% zurück (SEM $\pm 0,06, p<0,05$ im Vergleich zur nur TNFa-stimulierten Kontrolle). Bortezomib reduzierte die Viabilität bereits bei einer Konzentration von 2,5 $\mathrm{ng} / \mathrm{ml}$ deutlich (um 83\%, SEM $\pm 0,01, \mathrm{p}<0,001 \mathrm{im}$ Vergleich zu der nur TNFastimulierten Kontrolle), es zeigte sich keine weitere Steigerung des Effektes unter höheren Dosen. 
Wurde DMF mit KINK-1 oder Bortezomib kombiniert, wurde lediglich bei hohen Konzentrationen (etwa Kombination mit $25 \mu \mathrm{M}$ KINK-1, Abfall um 71\%) ein signifikanter Anstieg $(\mathrm{p}<0,01)$ der inhibitorischen Wirkung auf Proliferation und Viabilität im Vergleich zu einer nur mit DMF behandelten Kontrollen festgestellt. Die Kombination von DMF (5 und $15 \mu \mathrm{M})$ und Bortezomib $(2,5 \mathrm{ng} / \mathrm{ml}$ ) führte sogar zu einer Verminderung des unerwünschten Effektes auf die Zellviabilität im Vergleich zu den Auswirkungen von Bortezomib allein.
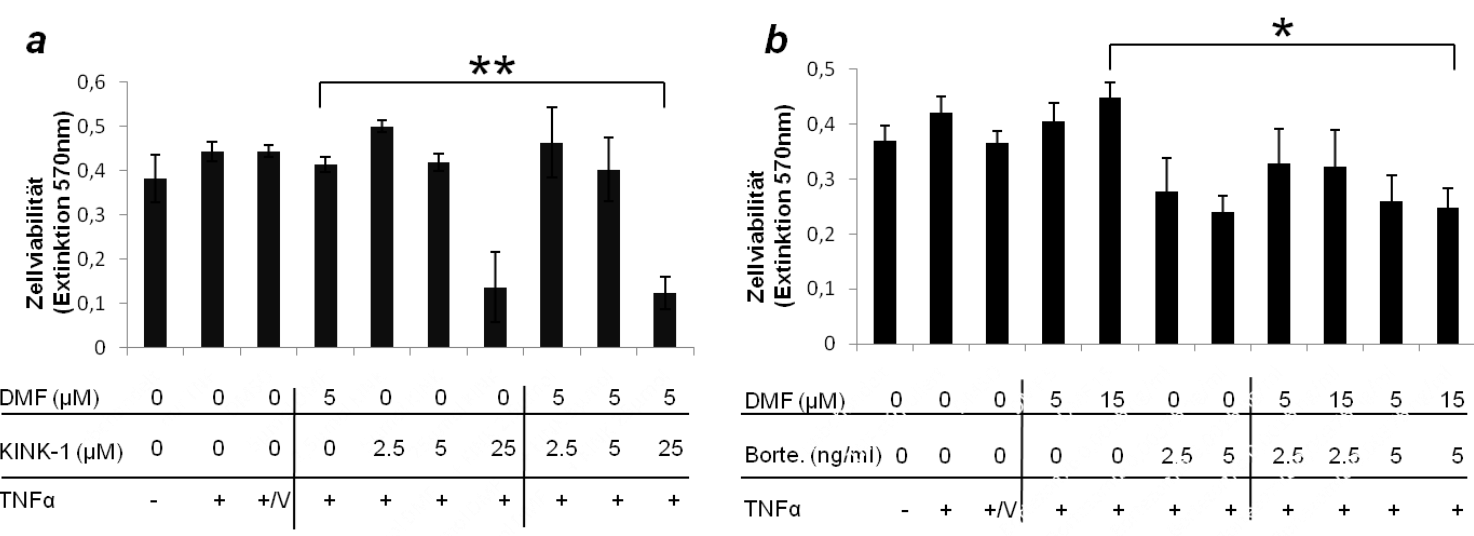

Abb. 20: Viabilität der HUVEC unter DMF, KINK-1 und Bortezomib. Die Viabilität wurde mit dem MTT- Test nach der Behandlung mit DMF und/oder den NF-KB-Inhibitoren KINK-1 und Bortezomib (Borte.) in den angegebenen Konzentrationen untersucht. Die Kombinationen von DMF mit jedem der beiden anderen Pharmaka zeigt keine Augmentation des negativen Effektes beziehungsweise diesen nur unter hohen Konzentrationen. Dargestellt sind Mittelwerte und Standardabweichungen dreier unabhängiger Versuche. ${ }^{*} p<0,05,{ }^{* *} p<0,01,{ }^{* \star *} p<0,001$ im Vergleich zu den nur mit DMF behandelten TNFa-stimulierten Kontrollen (5 oder $15 \mu \mathrm{m}$ DMF). (modifiziert nach Hund et al. 2016, die Verwendung erfolgte mit freundlicher Genehmigung des Verlags John Wiley \& Sons A/S.)

\subsubsection{Proliferation der HUVEC unter DMF, KINK-1 und Bortezomib}

Neben der Viabilität war auch die Auswirkung von DMF, KINK-1 und Bortezomib sowie der Kombinationen dieser Substanzen auf die Proliferation der HUVEC von Interesse. Die Viabilität stellt nur den Anteil vitaler Zellen an der Zellpopulation dar, lässt aber keine Aussage darüber zu, ob die Zellen auch aktiv proliferationsfähig sind. Daher wurde zusätzlich die Proliferationsfähigkeit anhand des BrdU-Einbaus in neu synthetisierte DNA bestimmt (Abb. 21).

TNFa beeinflusste die Proliferation nicht. Auch die Vehikel-Kontrolle (DMSO) bewirkte keine signifikante Veränderung. Bei Behandlung der Zellen mit DMF fiel die Proliferation bei einer Konzentration von $25 \mu \mathrm{M}$ um $44 \%$ ( $p<0,05$ im Vergleich zur nur TNFa-stimulierten Kontrolle, SEM $\pm 0,01$ ) deutlich ab, bei $5 \mu \mathrm{M}$ DMF zeigten sich 
die Zellen allerdings kaum beeinträchtigt (Reduktion um 3,9\%). KINK-1 induzierte bereits bei einer Konzentration von $5 \mu \mathrm{M}$ eine Reduktion der Proliferation um 10\%. Die Kombination von DMF und KINK-1 führte allerdings zu keinem weiteren Abfall im Vergleich zur nur KINK-1 behandelten Kontrolle. Im Vergleich zur DMF-behandelten Kontrolle zeigte sich eine signifikante Reduktion der Viabilität um 37\% ( $p<0,05$, SEM $\pm 0,01$ ). Bortezomib zeigte ebenfalls bereits bei einer Konzentration von 2,5 $\mathrm{ng} / \mathrm{ml}$ einen negativen Effekt auf die Proliferation der HUVEC (Reduktion um 51\% im Vergleich zu den nur TNFa-stimulierten Kontrollen, $p<0,01$, SEM $\pm 0,01$ ). Dieser wurde durch eine Konzentrationserhöhung auf $5 \mathrm{ng} / \mathrm{ml}$ beziehungsweise durch die Kombination mit DMF jedoch nicht weiter verstärkt. Im Vergleich zu der nur DMFbehandelten Kontrolle zeigt sich allerdings ein signifikanter Unterschied $(p<0,05)$.

a

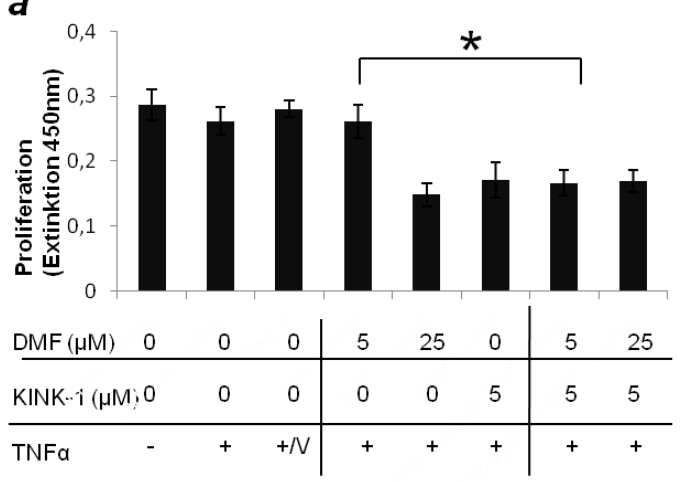

b

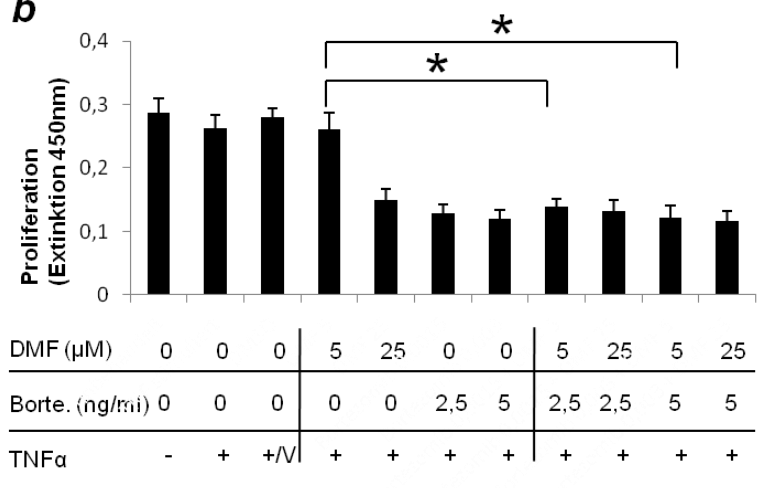

Abb. 21: Proliferationsfähigkeit der HUVEC unter Behandlung mit DMF, KINK-1 und Bortezomib. Die Proliferationsfähigkeit der HUVEC wurde nach Behandlung mit den drei Substanzen in den genannten Konzentrationen der mittels BrdU-Test untersucht. Die Kombinationen der Stoffe zeigten nur teilweise eine signifikante Verstärkung des anti-proliferativen Effektes. Dargestellt sind Mittelwerte und Standardfehler. $n=3$ unabhängige Experimente. ${ }^{*} \mathrm{p}<0,05$ im Vergleich zu den nur mit DMF-behandelten TNFa-stimulierten Kontrollen (5 oder $25 \mu \mathrm{m}$ DMF). (modifiziert nach Hund et al. 2016, die Verwendung erfolgte mit freundlicher Genehmigung des Verlags John Wiley \& Sons A/S.)

\subsection{Wirkung der unterschiedlichen Einzelstoffe sowie ihrer Kombinationen auf die Interaktion von Endothelzellen und Lymphozyten}

$\mathrm{Da}$ die Suppression endothelialer Adhäsionsmoleküle durch DMF durch die Kombination mit NF-kB-Inhibitoren verstärkt werden konnte, lag die Vermutung nahe, dass diese Kombinationen auch die Interaktion aktivierter Endothelzellen mit PBMC beeinflussen würden. Diese Hypothese wurde durch Flusskammer-Versuche überprüft. Isolierte humane PBMC wurden hierzu über einen mit HUVEC bedeckten Objektträger geleitet. Mittels Video-Mikroskopie wurden die im laminaren Strom 
bewegten Zellen in Echtzeit beobachtet und aufgenommen. Die rollenden Zellen wurden 10 min lang ausgezählt sowie die fest adhärierten Zellen nach einem standardisierten Schema nach 10 min abfotografiert und später ausgezählt (Abb. 22). Die PBMC zeigten keinerlei Interaktion mit nicht-stimulierten HUVEC. Erst nach der Stimulation mit TNFa rollten (MW 32,1 PBMC/ Feld; SEM $\pm 2,3$ ) und adhärierten die PBMC auf der Endothelzellschicht (MW 26,1 PBMC/ Feld; SEM $\pm 4,7$ ). Das Vehikel DMSO hatte keinen zusätzlichen Effekt auf die Interaktion der Zellen.

Die Behandlung der HUVEC mit $15 \mu \mathrm{M}$ DMF bei gleichzeitiger TNFa-Stimulation reduzierte das Rollen um 20,12\%; es rollten noch 26,5 PBMC/Feld (SEM $\pm 3,7$ ) im Vergleich zu 33 PBMC auf der TNFa-stimulierten und DMSO-behandelten Kontrolle. Die Inkubation mit 0,0375 $\mu \mathrm{M}$ KINK-1 inhibierte das Rollen um $17,56 \%$ auf 30 rollende Zellen pro Gesichtsfeld (SEM $\pm 2,5$ ) und die Behandlung mit $10 \mathrm{ng} / \mathrm{ml}$ Bortezomib auf 25,33 rollende Zellen (SEM $\pm 1,2$ ), was einer Reduktion um 11,6\% entspricht.

Die Behandlung der HUVEC mit der Kombination aus $5 \mu \mathrm{M}$ DMF und 0,0375 $\mu \mathrm{M}$ KINK-1 resultierte in einer Reduktion des Rollens um 58,34\% ( $p<0,01$ im Vergleich zu der unbehandelten TNFa- stimulierten Kontrolle, SEM $\pm 2,1$ ), die Kombination von $0,0375 \mu \mathrm{M}$ KINK-1 und $15 \mu \mathrm{M}$ DMF in einer Reduktion um 62,51\% $(\mathrm{p}<0,01 \mathrm{im}$ Vergleich zu der unbehandelten TNFa-stimulierten Kontrolle, SEM $\pm 2,3$ ). Die Kombination aus $10 \mathrm{ng} / \mathrm{ml}$ Bortezomib und $5 \mu \mathrm{M}$ DMF reduzierte das Rollen um $58,92 \%$ ( $p<0,05 \mathrm{im}$ Vergleich zu der unbehandelten TNFa-stimulierten Kontrolle, SEM $\pm 2,0$ ), kombiniert mit $15 \mu \mathrm{M}$ DMF nahm die Zahl rollender Zellen um 67,72\% $a b(p<0,01$ im Vergleich zu der unbehandelten TNFa-stimulierten Kontrolle, SEM \pm $1,8)$.

Gleichzeitig wurde auch die feste Adhäsion der PBMC auf den Endothelzellen durch die beschriebenen Kombinationen beeinflusst. Die Inkubation der HUVEC mit $5 \mu \mathrm{M}$ DMF resultierte in einer Inhibition der Adhäsion um 19,71\% (18,8 PBMC/Feld, SEM \pm 2,5), mit $15 \mu \mathrm{M}$ DMF um 21,76\% (18,7 PBMC/Feld SEM \pm 4,0). KINK-1 verstärkte die Inhibition der Adhäsion um 12,41\% (25,5 PBMC/Feld SEM $\pm 6,3)$ und Bortezomib um 41,35\% (11,4 PBMC/Feld SEM $\pm 3,6)$. Nach der Behandlung der HUVEC mit der Kombination aus DMF und 0,0375 $\mu \mathrm{M}$ KINK-1 betrug die Hemmung 57,24\% (5 $\mu \mathrm{M}$ DMF, SEM $\pm 1,6)$ und 69,64\% (15 $\mu \mathrm{M}$ DMF, SEM $\pm 2,0)(p<0,05 \mathrm{im}$ Vergleich zu der unbehandelten TNFa-stimulierten Kontrolle). Die Kombination aus DMF und $10 \mathrm{ng} / \mathrm{ml}$ Bortezomib resultierte in einer Inhibition um 67,84\% (5 $\mu$ M DMF, SEM $\pm 1,1 ; p<0,05$ 
Vergleich zu der unbehandelten TNFa-stimulierten Kontrolle) beziehungsweise um bis zu 80,46\% (15 $\mu \mathrm{M}$ DMF, SEM $\pm 0,1 ; p<0,01$ Vergleich zu der unbehandelten TNFa-stimulierten Kontrolle). Zusammenfassend, führten die Kombinationen zu einer Herabregulation dynamischer Interaktionen zwischen HUVEC und PBMC, die in gleichem Ausmaß nicht mit der Behandlung der Einzelkonzentrationen erreicht werden konnte.

(a)

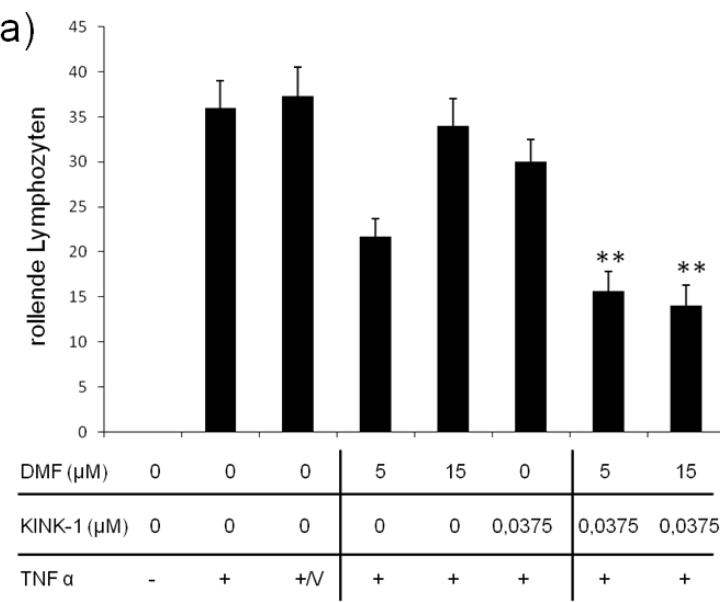

(c)

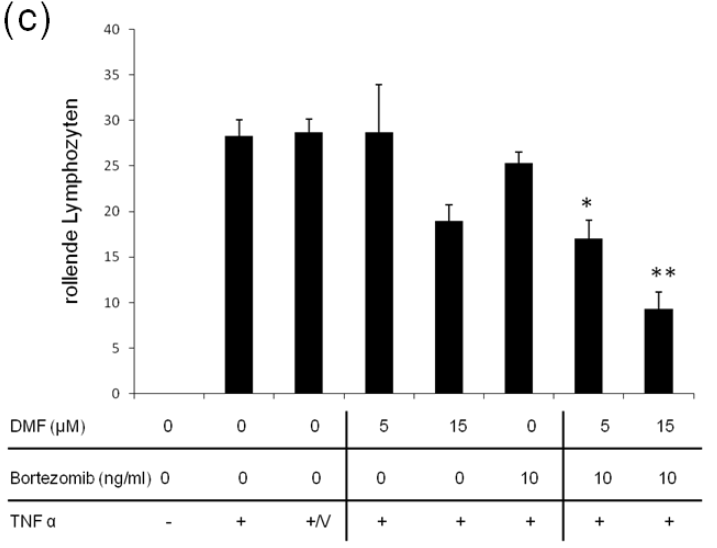

(b)

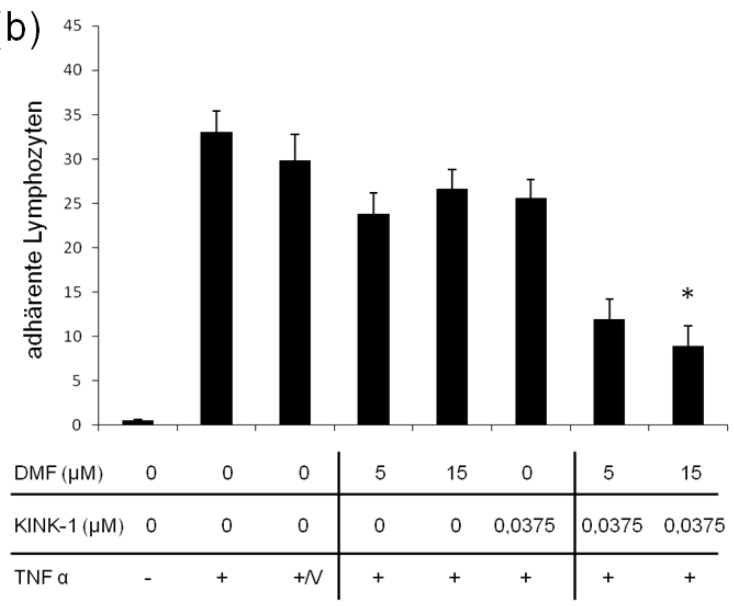

(d)

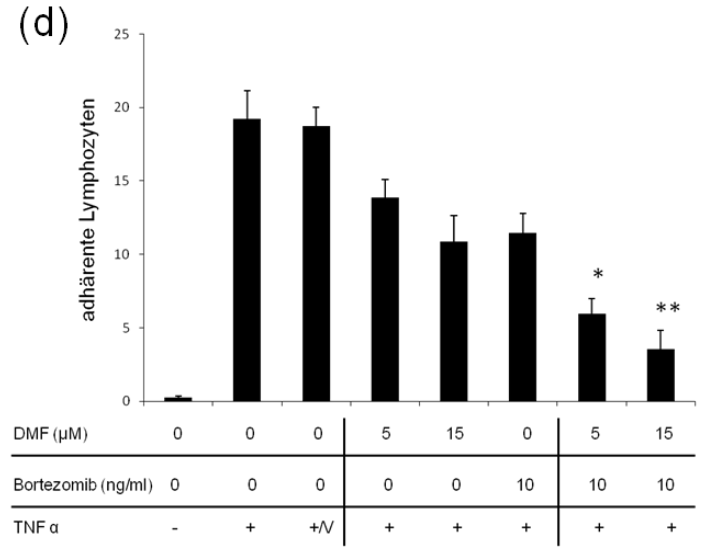

Abb. 22: Interaktion von HUVEC und Lymphozyten unter dem Einfluss von DMF, KINK-1 und Bortezomib. Dargestellt sind jeweils die Mittelwerte und Standardfehler (SEM) für Rollen und Adhäsion der PBMC aus drei unabhängigen Versuchen. (a) und (b) zeigen die Interaktion zwischen HUVEC und PBMC unter DMF und KINK-1, (c) und (d) unter DMF und Bortezomib. Die Zahl der rollenden Zellen wurde durch Auszählen innerhalb von 10 Minuten in einem Gesichtsfeld bei 160facher Vergrößerung ermittelt. Die adhärenten PBMC wurden nach Versuchsende in jeweils 16 standardisierten Gesichtsfeldern bei 80-facher Vergrößerung gezählt. * $p<0,05$, ${ }^{* *} p<0,01$ im Vergleich zu der unbehandelten TNFa-stimulierten Kontrolle. (modifiziert nach Hund et al. 2016, die Verwendung erfolgte mit freundlicher Genehmigung des Verlags John Wiley \& Sons A/S.) 
Die Behandlung mit DMF beziehungsweise KINK-1 führte nicht zu morphologischen Veränderungen der Zellen. Auch nach Kombination der beiden Stoffe blieben die HUVEC unverändert. Bortezomib induzierte spindelartige Formen der HUVEC und vergrößerte die Zell-Zell-Abstände. Zwischen den nur mit Bortezomib behandelten und den mit einer Kombination aus Bortezomib und DMF behandelten Zellen zeigten sich allerdings keine morphologischen Unterschiede.

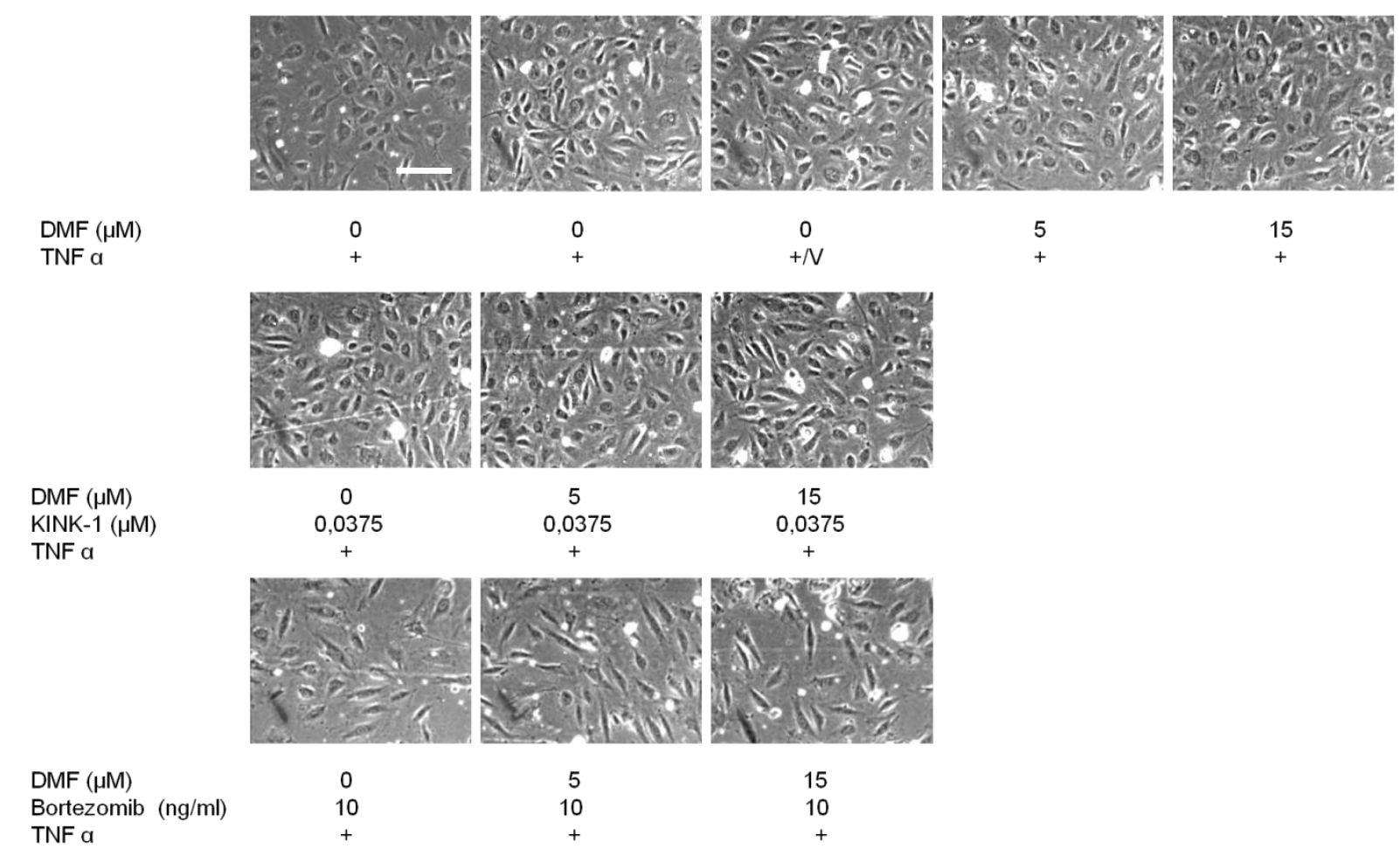

Abb. 23: Morphologie der HUVEC unter DMF, KINK-1 und Bortezomib. HUVEC aus einem exemplarischen Versuch nach $5 \mathrm{~h}$ Behandlung mit DMF und/oder NF-kB-Inhibitoren vor der Interaktion mit Lymphozyten im Flusskammerversuch. Die HUVEC wurden zuvor in festgelegter Zellzahl auf spezielle Objektträger (Coverslip) ausgesät, mit TNFa-stimuliert und mit DMF, KINK-1 oder Bortezomib in angegebenen Konzentrationen inkubiert. Bei Behandlung mit DMF und/oder KINK1 zeigen sich die HUVEC morphologisch unverändert. Unter dem Einfluss von Bortezomib fallen größere Zellabstände und vermehrt spindelförmige HUVEC auf. Zwischen der alleinigen Behandlung mit Bortezomib und der Kombinationsbehandlung mit DMF sind allerdings keine morphologischen Unterschiede feststellbar. Die Zellen wurden mit einer zehnfachen Vergrößerung aufgenommen. Der Maßstab beträgt $100 \mu \mathrm{m}$. (modifiziert nach Hund et al. 2016, die Verwendung erfolgte mit freundlicher Genehmigung des Verlags John Wiley \& Sons A/S.) 


\section{Diskussion}

\section{1 Übersicht}

DMF wird in der Therapie chronisch-inflammatorischer Erkrankungen wie der Psoriasis und der Multiplen Sklerose angewendet. Bei beiden handelt es sich um TNFa-dominierte Erkrankungen (Navikas und Link 1996; Liu et al. 1998; Steinman 2001; Schön und Boehncke 2005; Slavin et al. 2010; Phillips und Fox 2013; Bomprezzi 2015). Sowohl auf molekularer als auch auf zellulärer Ebene hat DMF pleiotrope Wirkungen, deren Einzelheiten bis heute nicht vollends bekannt sind. Zahlreiche Studien konnten den Einfluss von DMF unter anderem auf Endothelzellen (Vandermeeren et al. 1997; Loewe et al. 2002; Meissner et al. 2011; Wallbrecht et al. 2011), Lymphozyten (Höxtermann et al. 1998; Treumer et al. 2003), Astrozyten (Lin et al. 2011), Keratinozyten und Monozyten (Stoof et al. 2001) belegen. Die Experimente der vorliegenden Arbeit bestätigten grundsätzlich die Hemmung der Translokation des Transkriptionsfaktors NF-KB in den Zellkern (Loewe et al. 2002), zeigten aber auch, dass dafür höhere als die beschriebenen Konzentrationen nötig sind. Die Herabregulation endothelialer Adhäsionsmoleküle und Zytokine sowie die Beeinflussung dynamischer Leukozyten-Endothelzell-Interaktion bei hohen Konzentrationen (50 bis $200 \mu \mathrm{M}$ ) konnten ebenfalls bestätigt werden (Rubant et al. 2008; Wallbrecht et al. 2011).

Die meisten Nebenwirkungen des DMF sind dosisabhängig. Daher ist es von großem Interesse, die DMF-Dosis zu senken ohne die anti-inflammatorische Wirkung zu schmälern. Zu den Hauptwirkungen des DMF gehört die Hemmung des NF-kBSignalweges, welche letztlich zur Herabregulation pro-inflammatorischer Zytokine führt. Daher wurde in der vorliegenden Arbeit eine Verstärkung der Inhibition durch NF-KB-Inhibitoren angestrebt. Dies wurde zum einen über direkte IKKß-Inhibition durch KINK-1, zum anderen über Proteasomen-Hemmung durch Bortezomib erreicht. Tatsächlich hatten beide Kombinationen den theoretisch erwarteten Effekt, also eine verstärkte Wirkung auf die Expression endothelialer Adhäsionsmoleküle und Zytokine sowie auf die dynamische funktionelle Interaktion zwischen Endothelzellen und Lymphozyten, ohne negative Wirkungen (morphologische Veränderungen, Reduktion von Proliferation beziehungsweise Zellviabilität) maßgeblich zu erhöhen. 


\subsection{Verstärkung der durch DMF-induzierten NF-KB-Inhibition durch Kombination mit NF-kB-Inhibitoren}

In früheren Studien wurde die Inhibition der Translokation des Transkriptionsfaktors NF-KB in den Zellkern humaner Endothelzellen (Loewe et al. 2002), dermaler Fibroblasten (Vandermeeren et al. 2001), dendritischer Zellen (Peng et al. 2012) und glatter Muskelzellen der Atemwege (Seidel et al. 2009) durch DMF gezeigt. Diese Wirkung auf HUVEC wurde hier bei hohen DMF-Konzentrationen (100 bis $200 \mu \mathrm{M}$ ) bestätigt. Die NF-KB-Inhibitoren KINK-1 und Bortezomib führten hingegen bereits bei geringeren Konzentrationen zu einem partiellen (Bortezomib) oder vollständigen (KINK-1) Ausbleiben der Translokation in den Zellkern. Sowohl die Kombination von DMF und KINK-1 als auch von DMF und Bortezomib führte zu einer deutlichen Verstärkung des Effektes, ohne dass die Zellen - soweit mikroskopisch beurteilt werden konnte - geschädigt wurden. Hierbei wurde durch die Kombination mit KINK1 ein deutlich stärkerer inhibitorischer Effekt hervorgerufen.

Während der Wirkmechanismus der NF-kB-Inhibitoren bekannt ist, ist der molekulare Mechanismus der DMF-induzierten NF-kB-Inhibition bisher ungeklärt. Man vermutet, dass DMF den Übergang des Transkriptionsfaktors in den Zellkern direkt hemmt (Loewe et al. 2001, 2002). Sollte diese Hypothese zutreffen, griffen die Substanzen an verschiedenen Stellen in die Aktivierung des Transkriptionsfaktors ein. Die Inhibitionsverstärkung wäre also additiv.

Die verminderte NF-KB-Aktivierung durch Kombinationen passt zur gleichsinnigen Herabregulation NF-kB-abhängiger Adhäsionsmoleküle sowie der EndothelzellLeukozyten-Interaktion. Außerdem erlaubt sie den Rückschluss, dass die beobachteten Effekte der Kombinationen tatsächlich auf eine verstärkte NF-KBInhibition zurückzuführen sind.

Mit der Immunfluoreszenz-Mikroskopie konnte qualitativ beurteilt werden, ob NF-kB aktiviert wurde, indem sich das entsprechende Fluoreszenzsignal innerhalb des Zellkerns detektieren ließ. Die verminderte NF-kB-Aktivierung durch die Kombinationen konnte so ebenfalls gezeigt werden. Weiterführend wären hier Untersuchungen interessant, die auch eine quantitative Auswertung erlauben würden (beispielsweise Luciferase-Experimente). 


\subsection{Kombinationen von DMF und NF-KB-Inhibitoren zeigen bereits bei niedrigen Konzentrationen eine signifikante Herabregulation endothelialer Adhäsionsmoleküle}

Die Interaktion von Endothelzellen und Lymphozyten ist ein essentieller Schritt bei der Pathogenese inflammatorischer Erkrankungen. Vermittelt wird sie auf endothelialer Seite vor allem durch Selektine (E- und P-Selektin) und Mitglieder der Immunglobulin-Superfamilie (ICAM-1, VCAM-1) (s. Kapitel 1.1.3).

Sowohl DMF als auch KINK-1 bewirkten eine ausgeprägte Herabregulation von ESelektin, VCAM-1 und ICAM-1. Bortezomib hingegen supprimierte nur ICAM-1 eindeutig. Dies wurde sowohl auf mRNA- Ebene (PCR) als auch auf Proteinebene (Durchflusszytometrie) gezeigt. Während sich eine deutliche Reduktion der Expression der drei Adhäsionsmoleküle nur bei hohen DMF-Konzentration (100 $\mu \mathrm{M})$ fand, zeigte sich bei Kombination mit KINK-1 ein vergleichbarer Effekt bereits bei 5 $\mu M$ DMF. Somit konnte erstmals gezeigt werden, dass durch die Kombination mit NF-kB-Inhibitoren geringere DMF-Konzentrationen für diesen Effekt ausreichen.

Während E-Selektin die lockere Adhäsion und das Rollen der Leukozyten auf den Endothelzellen der Gefäßwände initiiert (Groves et al. 1991; Shimizu et al. 1991; Schön 2005), vermitteln VCAM-1 und ICAM-1 deren feste Adhäsion (Schön et al. 2003). Alle drei Adhäsionsmoleküle werden in psoriatischen Plaques verstärkt exprimiert. Manchmal können sogar erhöhte Serumkonzentrationen bei PsoriasisPatienten nachgewiesen werden (Szepietowski et al. 1999; Cabrijan et al. 2009). Die pathogenetische Bedeutung dieser Moleküle steht daher außer Zweifel.

Eine klinische Studie wies die Reduktion von E-Selektin im Serum sowie in Hautbiopsien von Patienten mit moderater bis schwerer Psoriasis nach Behandlung mit einem monoklonalen Antikörper gegen E-Selektin nach. Die erwartete klinische Verbesserung blieb allerdings aus, vermutlich wegen kompensatorischer Wirkungen anderer Rezeptoren, beispielsweise P-Selektin (Bhushan et al. 2002). Zuvor wurde in vitro die Reduktion der Bindung von E-Selektin an CLA-positive Lymphozyten unter dem Einsatz des gleichen Antikörpers gezeigt (Owens et al. 1997). In einer weiteren klinischen Studie führte auch der Einsatz eines monoklonalen Antikörpers gegen LSelektin (BNP001, Aselizumab) nicht zur klinischen Besserung der Psoriasis (Friedrich et al. 2005). Diese Beobachtung zeigt, dass die Inhibition eines Teilfaktors allein nicht ausreicht, die Leukozyten-Extravasation ausreichend zu hemmen. Dies beruht auf funktioneller Redundanz verschiedener Adhäsionsmoleküle (Schön 2005). 
Die hier gezeigte verstärkende Wirkung der Kombinationen von DMF mit NF-kBInhibitoren ist folglich noch kein ausreichender Hinweis auf eine klinische Wirkung; vielmehr müssten weitere Adhäsionsmoleküle, Zytokine und Chemokine sowie die Wirkung in präklinischen Modellen in vivo überprüft werden. Nichtsdestotrotz belegen die Ergebnisse dieser Arbeit, dass die untersuchten Parameter der Entzündung tatsächlich additiv beeinflusst werden. Die verwendeten Substanzen reduzierten in Kombination bereits bei geringen Konzentrationen die Expression dreier relevanter Adhäsionsmoleküle.

Der Effekt zeigte sich bereits nach einem vergleichsweise kurzen Behandlungszeitraum (5 h), was auf eine direkte transkriptionelle Wirkung schließen lässt. Indirekte Regulation, beispielsweise über eine Suppression von Zytokinen, würde eher ein späteres Eintreten des Effektes erwarten lassen.

\subsection{DMF, KINK-1 und Bortezomib reduzieren die Expression endothelialer, nicht aber leukozytärer Adhäsionsmoleküle}

Im Vergleich zur deutlichen Suppression endothelialer Adhäsionsmoleküle durch Behandlung mit DMF und/oder den NF-kB-Inhibitoren wurde die Expression leukozytärer Adhäsionsmoleküle unter den gewählten Bedingungen nicht beeinflusst. Eine Erklärung hierfür könnte sein, dass LFA-1, L-Selektin, VLA-4 sowie CLA, im Gegensatz zu den untersuchten endothelialen Adhäsionsmolekülen VCAM-1, ICAM1 und E-Selektin (Schindler und Baichwal 1994; Bunting et al. 2007; lademarco et al. 1992), weniger stark durch NF-KB reguliert werden. Aktuell liegen hierfür weder beweisende noch widerlegende Studien vor. Eine geringe NF-kB-Abhängigkeit der Expression würde allerdings gut zu den Beobachtungen passen, da DMF, KINK-1 und Bortezomib NF-KB auf unterschiedliche Weise hemmen und alle drei Stoffe die lymphozytären Rezeptoren nicht beeinflussten. Zusätzlich lassen die in dieser Arbeit erzielten Ergebnisse nach der Behandlung mit DMF und/oder den NF-KB-Inhibitoren keine Restaktivität des Transkriptionsfaktors mehr vermuten, die ausreichen würde, die Expression leukozytärer Oberflächenmoleküle zu induzieren, was wiederum eine NF-kB-Abhängigkeit unwahrscheinlich macht. Außerdem lässt der fehlende Einfluss der Kombinationen auf die leukozytären Oberflächenmoleküle darauf schließen, dass der Effekt der untersuchten Substanzen tatsächlich in erster Linie, allerdings nicht nur, auf die Inhibition von NF-kB zurückzuführen ist. 
Alternativ ist zu diskutieren, dass die untersuchten Leukozyten in einem nicht stimulierten Zustand behandelt wurden. Es ist denkbar, dass die eingesetzten Inhibitoren hauptsächlich die induzierte „Überproduktion“ entzündungsassoziierter Moleküle hemmen, nicht oder weniger hingegen deren konstitutive Expression. Allerdings wurde in Studien mit anderen Wirkstoffen die Expression von L-Selektin, VLA-4 und LFA-1 auch ohne vorherige Stimulation der humanen Leukozyten deutlich beeinflusst (Forkel et al. 2014) und L-Selektin wird konstitutiv auf humanen Leukozyten hoch exprimiert (Tedder et al. 1990, 1995; Oostingh et al. 2007). In einer anderen Studie wurde eine DMF-induzierte Reduktion von CLA nach 96-stündiger Stimulation mit toxic shock syndrome toxin-1 (TSST-1) beschrieben; für VLA-4 zeigte sich dieser Effekt nicht (Rubant et al. 2008). Eine Stimulation könnte also, ähnlich wie bei Endothelzellen, zu einer vermehrten Induktion der Expression der Oberflächenmoleküle und zur Nachempfindung eines inflammatorischen Milieus führen und sich somit in weiteren Versuchen als sinnvoll erweisen. Ebenso könnten interindividuelle Unterschiede und Unterschiede zwischen dem Ansprechen der Leukozyten von Psoriasis-Erkrankten und gesunden Probanden einen Einfluss auf die Versuchsergebnisse haben, so dass es interessant wäre, Leukozyten von einer größeren Zahl gesunder und an Psoriasis- erkrankter Probanden zu untersuchen.

Schließlich mussten die frisch isolierten Leukozyten rasch untersucht werden, so dass die Behandlungszeiträume möglicherweise nicht ausreichten, um transkriptionelle Änderungen zu erfassen.

\subsection{Kombinationen von DMF mit NF-kB-Inhibitoren reduzieren die Expression proinflammatorischer Chemokine, aber nicht die von VEGF}

Die Chemokine CXCL8 (IL-8), CCL2 (MCP-1) und CXCL1 (Gro- $\alpha$ ) spielen eine wichtige Rolle in der Pathogenese chronisch-inflammatorischer Erkrankungen. CXCL8 ist ein von Endothelzellen und Makrophagen produziertes proinflammatorisches Chemokin, welches chemotaktisch auf neutrophile Granulozyten wirkt und die Keratinozytenproliferation fördert (Bickel 1993; Baggiolini et al. 1995; Schön und Ruzicka 2001). Bei Psoriasis-Patienten liegt CXCL8 im Blut und in der Haut vermehrt vor (Nickoloff et al. 1991; Sticherling et al. 1999; Arican et al. 2005). CXCL-1 findet sich ebenfalls vermehrt in psoriatischen Läsionen, attrahiert neutrophile Granulozyten und fördert somit die Bildung der Munroschen Mikroabzesse (Gillitzer et al. 1996). CCL2 wirkt hingegen auf Monozyten und erhöht 
die Zahl der Makrophagen und Mastzellen in psoriatischer Haut (Schön und Ruzicka 2001).

Während DMF die untersuchten Chemokine erst unter hohen Konzentrationen herabregulierte, vermochte die Kombination von DMF und KINK-1 bereits in niedrigen Konzentrationen ihre Expression deutlich abzuschwächen. Bortezomib hingegen wirkte sich weder als Einzelstoff noch in Kombination mit DMF maßgeblich auf die Expression der Chemokine aus.

Insgesamt wirkten sich die Kombinationen von DMF mit NF-кB-Inhibitoren nicht so deutlich auf die Expression der Chemokine aus wie auf die der endothelialen Adhäsionsmoleküle, obwohl auch erstere von NF-kB reguliert werden (Anisowicz et al. 1991; Kunsch und Rosen 1993; Ueda et al. 1994; Burke et al. 2014).

Die durch DMF und/oder die NF-kB-Inhibitoren supprimierten endothelialen Adhäsionsmoleküle und Chemokine werden alle durch TNFa induziert (Groves et al. 1995; Murao et al. 2000; Osawa et al. 2002; Shieh et al. 2014). Im nicht-stimulierten Zustand zeigten die Endothelzellen keine oder nur eine geringe Expression von VCAM-1, ICAM-1, E-Selektin, CCL2, CXCL1 und CXCL-8. TNFa ist als Induktor des NF-kB-Signalweges ein zentraler Mediator der Immunantwort bei entzündlichen Erkrankungen wie Psoriasis oder Multipler Sklerose (Cheshire und Baldwin 1997). Der geringe Einfluss von Bortezomib und auch der geringere Effekt von DMF und KINK-1 auf die Chemokine lassen vermuten, dass der durch TNFa induzierte Effekt nicht ausschließlich durch NF-KB reguliert wird.

Die Expression von VEGF blieb nach Stimulation mit TNFa unverändert. Interessanterweise bestätigte sich eine bereits beschriebene dosisabhängige Steigerung der VEGF-Expression durch Behandlung mit DMF (Wallbrecht et al. 2011), während KINK-1 und Bortezomib sich weder steigernd noch reduzierend auswirkten. Durch Kombination von DMF und NF-kB-Inhibitoren blieb eine Zunahme der Expression aus. Dieses könnte sich einerseits darin begründen, dass die NF-kBInhibitoren in diesem Fall der DMF-Wirkung entgegenwirken, andererseits aber auch darin, dass für die Kombinationen DMF nur in geringen Konzentrationen verwendet wurde. Es bleibt die Frage warum VEGF als einziges der untersuchten Moleküle unter den Kombinationen nicht signifikant in seiner Expression vermindert wird, da seine Transkription ebenfalls von NF-KB reguliert wird (Kiriakidis et al. 2003; Tong et al. 2006). Außerdem zeigte sich beispielsweise eine verminderte VEGF-Expression in Mammakarzinomzellen durch NF-KB-Inhibition (Shibata et al. 2002). Es ist noch 
nicht belegt, ob die durch DMF erhöhte VEGF-Expression auf Transkriptionsebene einen negativen Effekt des Stoffes darstellt und ob es überhaupt auf Proteinebene zu einer vermehrten VEGF-Expression kommt. Grundsätzlich wäre es aber wünschenswert, dass ein anti-psoriatisches Medikament den VEGF-Spiegel senkt oder zumindest unverändert lässt, da VEGF unter anderem die Bildung proinflammatorischer Zytokine (Hao et al. 2009), die Angiogenese und die Keratinozytenproliferation fördert (Elias et al. 2008).

\subsection{Kombinationen von DMF mit NF-KB-Inhibitoren verstärken negative Effekte im Vergleich zu den Einzelsubstanzen nicht}

Zytotoxizität sowie Abnahme von Viabilität und Proliferation der HUVEC zeigten sich bei DMF-Konzentrationen ab $50 \mu \mathrm{M}$, also durchaus im Bereich therapeutischer Konzentrationen. Dies verdeutlicht erneut, dass die Reduktion der DMF-Dosis durch Kombination mit anderen Stoffen wünschenswert ist. Im Vergleich zu den nur mit DMF behandelten Proben waren Viabilität und Proliferation im Vergleich zu den Kombinationen teilweise signifikant unterschiedlich. Für Experimente zur Wirksamkeit der Kombinationen (PCR, FACS, Flusskammer) wurden nur Konzentrationen ohne signifikanten negativen Einfluss auf Viabilität und Proliferation genutzt.

Zwischen den allein mit den NF-KB-Inhibitoren (KINK-1 oder Bortezomib) behandelten Proben und den Kombinationen bestanden keine signifikanten Unterschiede. Dies legte nahe, dass die Zunahme der negativen Effekte im Vergleich zu den nur mit DMF behandelten Proben auf die NF-KB-Inhibitoren selbst und weniger auf einen additiven Effekt zurückzuführen ist.

Bei geringeren Konzentrationen von KINK-1 allein zeigten sich keine signifikanten Veränderungen der genannten Parameter, erst die Kombination von DMF und vergleichsweise hohen Dosen KINK-1 bewirkten eine deutliche Senkung der Viabilität und Proliferation der HUVEC. Für die Kombinations-Experimente zur Untersuchung der Wirkung dieser Substanzen wurden daher niedrigere Konzentrationen verwendet. Die Kombination von DMF mit Bortezomib reduzierte auch bei geringen Konzentrationen die Proliferationsfähigkeit signifikant. Hier stellt sich die Frage, ob die Reduktion der Proliferation überhaupt als negativer Effekt anzusehen ist, denn in psoriatischer Haut ist die endotheliale Hyperproliferation ein pathologischer Vorgang (Schön und Boehncke 2005). 
Bortezomib ist ein Chemotherapeutikum zur Behandlung von Patienten mit Multiplem Myelom oder Mantelzell-Lymphom (Field-Smith et al. 2006; Reece et al. 2006; Kouroukis et al. 2014). Es kann zu gastrointestinalen Problemen, Anämie, Hypotonie oder Polyneuropathie führen (Field-Smith et al. 2006). In der Tumortherapie wird Bortezomib allerdings in einer Dosis von $1,3 \mathrm{mg} / \mathrm{m}^{2}$ Körperoberfläche zweimal wöchentlich eingesetzt und nach intravenöser Gabe wurden Plasmaspiegel von 180 $\mathrm{ng} / \mathrm{ml}$ beschrieben (Piperdi et al. 2011). Dies entspricht einer bis zu 70-fach höheren Konzentration als in der vorliegenden Arbeit verwendet wurde. Daher erscheint eine deutliche Ausprägung der beschriebenen Nebenwirkungen in vivo bei den in dieser Arbeit verwendeten Konzentrationen unwahrscheinlich.

\subsection{Kombinationen von DMF und NF-kB-Inhibitoren führen zu einer verminderten Interaktion zwischen Endothelzellen und Lymphozyten}

Die durch Adhäsionsmoleküle vermittelte Leukozyten-Extravasation ist ein wichtiger Schritt in der Pathogenese inflammatorischer Erkrankungen. DMF inhibiert in hohen Konzentrationen sowohl in vitro als auch in vivo Rollen und Adhäsion von TLymphozyten auf Endothelzellen (Rubant et al. 2008; Wallbrecht et al. 2011). Die vorliegende Arbeit bestätigte die Hemmung dynamischer Interaktionen von Lymphozyten und Endothelzellen ab einer Konzentration von $100 \mu \mathrm{M}$. Durch Kombination von DMF mit den NF-KB-Inhibitoren konnte dieser Effekt verstärkt werden. Die Kombinationen vermögen es demnach, einen der wichtigsten Schritte der Entzündung zu inhibieren. In den Flusskammerversuchen wurden Lymphozyten (PBMC) gesunder Probanden verwendet. Es wäre daher interessant, auch Lymphozyten von Psoriasis-erkrankten Probanden einzusetzen. Auch Flusskammerversuche mit Endothelzellen derjenigen Probanden, von denen die Lymphozyten stammen, würde eine sinnvolle Erweiterung der Versuche sein, was allerdings eine mehrmalige invasive Probenentnahme (Blutentnahme, Stanzbiopsie) bedeuten würde. 


\subsection{Ausblick auf nebenwirkungsärmere FAE-Therapien}

Die In-vitro-Experimente dieser Arbeit sollten einen Weg aufzeigen, die hohe nebenwirkungsbedingte Abbruchrate der FAE-Therapie zu senken. Dies sollte durch Minderung der dosisabhängigen Nebenwirkungen des DMF erzielt werden.

$\mathrm{Da}$ in erster Linie gastrointestinale Nebenwirkungen therapielimitierend sind (Mrowietz et al. 1998; Hoefnagel et al. 2003; Ismail et al. 2014), könnte die Wiederholung der Experimente dieser Arbeit mit Zellen aus der Darmmukosa zielführend sein. Denkbar wäre eine lokale Minderung gastrointestinaler Symptome durch NF-kB-Inhibition in Zellen der Darmmukosa. Für die Genese gastrointestinaler Symptome wurden eine allergische Kontakt-Mukositis, eine TNFa-Freisetzung durch FAE sowie eine eosinophile Gastroenteritis diskutiert (Balak 2015).

Auch das Flushing durch Dilatation dermaler Blutgefäße beeinflusst die TherapieAdhärenz der Patienten. Wie genau dieses Phänomen entsteht, ist bisher ungeklärt. In Frage käme die Ausschüttung endothelialer Vasodilatatoren. Nikotinsäure, welche ebenfalls zur Flush-Symptomatik führen kann, beeinflusst epidermale LangerhansZellen. Folglich könnten Langerhans-Zellen an der Vasoregulation beteiligt sein (Benyó et al. 2006). Interessant wären also auch die Wirkungen der Kombinationen auf Langerhans-Zellen. Zwei Studien zeigten, dass FAE-induziertes Flushing durch den Niacinrezeptor HCA2 (hydroxycarboxylic acid receptor 2) vermittelt wird. HCA2 wird auf epidermalen Langerhans-Zellen und Keratinozyten exprimiert (Hanson et al. 2012). Da der molekulare Mechanismus der Symptomatik nicht bekannt ist und das Auftreten des Flushings letztlich nur in vivo beobachtet werden kann, könnte die Auswirkung der Kombinationen von DMF mit NF-KB-Inhibitoren auf diese Nebenwirkung vielleicht erst in vivo ausreichend evaluiert werden.

Neben DMF beinhaltet das Präparat Fumaderm ${ }^{\circledR}$, für welches die Nebenwirkungen beschrieben worden sind, auch Kalzium-, Magnesium- und Zinksalze des Ethylhydrogenfumarats. Lange wurde diskutiert, bei welchem Bestandteil es sich um den aktiven Metaboliten des Medikamentes handelt. Da gezeigt wurde, dass DMF zumindest in vitro der aktive Bestandteil ist und dass die Nebenwirkungen auch unter der Monotherapie mit DMF auftreten (Gold et al. 2012), war die vorliegende Arbeit auf DMF und seine Kombinationen mit NF-kB-Inhibitoren fokussiert. Eine Auslösung oder Verstärkung der Nebenwirkungen durch andere Bestandteile des 
Handelspräparates lässt sich nicht ausschließen, erscheint aber eher unwahrscheinlich.

Hinsichtlich der Wirksamkeit der Fumarsäureester in der Therapie der Multiplen Sklerose wären auch die Auswirkungen der Kombinationen mit NF-kB-Inhibitoren auf vaskuläre zerebrale Zellen, beispielsweise Human Brain Microvascular Endothelial Cells (HBMEC), interessant, ebenso wie die Untersuchung des Einflusses und der Wirksamkeit der Kombinationen in Tiermodellen der Multiplen Sklerose.

Neben der eigentlichen Zielstellung der Arbeit konnte auch erstmals die Wirkung des NF-KB-Inhibitors KINK-1 auf humane Endothelzellen charakterisiert werden. Bisher lagen nur Daten für Melanomzellen vor (Schön et al. 2008; Amschler et al. 2010). KINK-1 zeigte einen DMF-ähnlichen dosisabhängigen Effekt auf Endothelzellen. Eine Inhibition der Translokation des Transkriptionsfaktors NF-KB in den Zellkern zeigte sich bereits bei sehr geringen Konzentration $(0,625 \mu \mathrm{M})$. KINK-1 supprimierte auch die Expression endothelialer Adhäsionsmoleküle sehr potent. Gleichzeitig wies KINK1 eine vergleichsweise niedrige Toxizität auf. Weitere Untersuchungen der Wirkung von KINK-1 in Bezug auf chronisch-inflammatorische Erkrankungen wären von großem Interesse. So könnte KINK-1, eventuell nicht nur in Kombination mit DMF, sondern auch allein therapeutisch interessant sein.

Nachdem die verwendeten Kombinationen von DMF und NF-KB-Inhibitoren eine deutlich gesteigerte anti-inflammatorische Wirkung auf Endothelzellen in vitro offenbarten, wären zukünftig In-vivo-Studien sinnvoll. Denkbar wäre hier der Einsatz präklinischer Mausmodelle (Schön 2008). Sollten sich die Ergebnisse dieser Arbeit dann auch in klinischen Studien bestätigen, könnte die Therapie der Psoriasis beziehungsweise Multiplen Sklerose entscheidend verbessert werden. Patienten könnten mit geringeren DMF-Konzentrationen in Kombination mit einer ebenfalls niedrigen Dosis eines NF-KB-Inhibitors behandelt werden, bei nach wie vor hoher therapeutischer Wirksamkeit. Bei einer Therapieabbruchrate von bis zu $40 \%$ (Mrowietz et al. 1998; Ismail et al. 2014) und immer neuen Einsatzgebieten (s. Kapitel 1.2.2), erscheint diese mögliche Verbesserung der Therapie mit DMF von stetig zunehmender klinischer Relevanz. 


\section{$5 \quad$ Zusammenfassung}

Fumarsäureester, insbesondere Dimethylfumarat (DMF), werden seit Jahren erfolgreich in der Psoriasis-Therapie angewendet. Auch in der Therapie anderer chronisch-inflammatorischer Erkrankungen, wie der Multiplen Sklerose, nehmen sie an Relevanz zu. Durch ihr gutes Nutzen-Risiko-Profil eignen sich FAE besonders zur Langzeittherapie, doch führen Nebenwirkungen, wie gastrointestinale Probleme, zu einer Therapieabbruchrate von bis zu 40\%. Da die meisten der durch DMF bedingten Nebenwirkungen dosisabhängig sind, sollten Möglichkeiten überprüft werden, die DMF-Dosis zu reduzieren, ohne die anti-entzündliche Wirkung zu schmälern.

Die Experimente bestätigten die Inhibition des NF-kB-Signalweges, der Expression von Adhäsionsmolekülen und Zytokinen sowie eine Reduktion der EndothelzellLymphozyten-Interaktion durch DMF in hohen Konzentrationen. Da die Inhibition des NF-KB-Signalweges eine wichtige Wirkung des DMF ist, wurde eine Verstärkung der Inhibition mit Hilfe von NF-KB-Inhibitoren angestrebt. KINK-1 wirkt hierbei als direkter Inhibitor der NFKB-Aktivierung durch eine Blockade von IKKß, während Bortezomib indirekt über eine Proteasomenblockade den Abbau des natürlichen NF-kBInhibitors IKBa hemmt und damit einer Aktivierung des Transkriptionsfaktors entgegenwirkt. Tatsächlich zeigten beide Kombinationsvarianten den gewünschten Effekt sowohl auf die Expression der endothelialen Adhäsionsmoleküle E-Selektin (CD62E), VCAM-1 (CD106) und ICAM-1 (CD54) als auch auf die Interaktion zwischen Endothelzellen und Lymphozyten, ohne zu einer signifikanten Erhöhung des negativen Effektes (morphologische Veränderungen, Reduktion von Proliferation und Viabilität) zu führen. Somit zeigt die vorliegende Arbeit eine mögliche Verbesserung in der Therapie mit Fumarsäureestern auf. 


\section{$6 \quad$ Literaturverzeichnis}

Adams J (2002): Proteasome inhibition: a novel approach to cancer therapy. Trends Mol Med $\underline{8}(4), 49-54$

Adams J (2004): The proteasome: a suitable antineoplastic target. Nat Rev Cancer $4(5), 349-360$

Albrecht P, Bouchachia I, Goebels N, Henke N, Hofstetter HH, Issberner A, Kovacs Z, Lewerenz J, Lisak D, Maher P (2012): Effects of dimethyl fumarate on neuroprotection and immunomodulation. J Neuroinflammation $\underline{9}(1), 163$

Altmeyer P, Nüchel C (1996): Systemtherapie der Psoriasis. Dtsch Med Wochenschr 121(51-52), 1605-1607

Altmeyer PJ, Matthes U, Pawlak F, Hoffmann K, Frosch PJ, Ruppert P, Wassilew SW, Horn T, Kreysel HW, Lutz G (1994): Antipsoriatic effect of fumaric acid derivatives. Results of a multicenter double-blind study in 100 patients. J Am Acad Dermatol 30(6), 977-981

Amschler K, Schön MP, Pletz N, Wallbrecht K, Erpenbeck L, Schön M (2010): NFkappaB inhibition through proteasome inhibition or IKKbeta blockade increases the susceptibility of melanoma cells to cytostatic treatment through distinct pathways. J Invest Dermatol 130(4), 1073-1086

Anisowicz A, Messineo M, Lee SW, Sager R (1991): An NF-kappa B-like transcription factor mediates IL-1/TNF-alpha induction of gro in human fibroblasts. $J$ Immunol 147(2), 520-527

Arakawa A, Siewert K, Stöhr J, Besgen P, Kim SM, Rühl G, Nickel J, Vollmer S, Thomas P, Krebs S, Pinkert S, Spannagl M, Held K, Kammerbauer C, Besch R, Dornmair K, Prinz JC (2015): Melanocyte antigen triggers autoimmunity in human psoriasis. $J$ Exp Med 14;212(13), 2203-12

Arendt CS, Hochstrasser M (1997): Identification of the yeast 20S proteasome catalytic centers and subunit interactions required for active-site formation. Proc Natl Acad Sci U S A 94(14), 7156-7161

Arias A, Giles B, Eiermann TH, Sterry W, Pandey JP (1996): Tumor necrosis factoralpha gene polymorphism in psoriasis. Exp Clin Immunogenet 14(2), 118-122

Arican O, Aral M, Sasmaz S, Ciragil P (2005): Serum Levels of TNF- $\alpha$, IFN-y, IL-6, IL-8, IL-12, IL-17, and IL-18 in Patients With Active Psoriasis and Correlation With Disease Severity. Mediators Inflamm 2005(5), 273-279

Armstrong AW, Armstrong EJ, Fuller EN, Sockolov ME, Voyles SV (2011): Smoking and pathogenesis of psoriasis: a review of oxidative, inflammatory and genetic mechanisms. Br J Dermatol 165(6), 1162-1168 
Arnold T, Schaarschmidt ML, Herr R, Fischer JE, Goerdt S, Peitsch WK (2016): "Drug- Survival"-Raten und Gründe für den Abbruch von Systemtherapien bei Psoriasis. J Dtsch Dermatol Ges 14(11), 1090-1101

Augustin M, Krüger K, Radtke MA, Schwippl I, Reich K (2008): Disease severity, quality of life and health care in plaque-type psoriasis: a multicenter crosssectional study in Germany. Dermatology (Basel, Switzerland) 216(4), 366372

Baeuerle PA, Henkel T (1994): Function and Activation of NF-kappaB in the Immune System. Annu Rev Immunol 12(1), 141-179

Baggiolini M, Loetscher P, Moser B (1995): Interleukin-8 and the chemokine family. Int J Immunopharmacol 17(2), 103-108

Balak DMW (2015): Fumaric acid esters in the management of psoriasis. Psoriasis $\underline{5}$, $9-23$

Baldwin AS (1996): The NF-kB and IkB proteins: New Discoveries and Insights. Annu Rev Immunol 14(1), 649-681

Banno T, Gazel A, Blumenberg M (2004): Effects of tumor necrosis factor-alpha (TNF alpha) in epidermal keratinocytes revealed using global transcriptional profiling. J Biol Chem $\underline{279}$ (31), 32633-32642

Belloni D, Veschini L, Foglieni C, Dell'Antonio G, Caligaris-Cappio F, Ferrarini M, Ferrero $E$ (2010): Bortezomib induces autophagic death in proliferating human endothelial cells. Exp Cell Res 316(6), 1010-1018

Benyó Z, Gille A, Bennett CL, Clausen BE, Offermanns S (2006): Nicotinic AcidInduced Flushing Is Mediated by Activation of Epidermal Langerhans Cells. Mol Pharmacol $\underline{70}$ (6), 1844-1849

Berth-Jones J (2005): The use of ciclosporin in psoriasis. J Dermatolog Treat 16(5-6), 258-277

Bevilacqua MP, Pober JS, Mendrick DL, Cotran RS, Gombrone Jr MA (1987): Identification of an inducible endothelial-leukocyte adhesion molecule. Proc Natl Acad Sci U S A 84(24), 9238-9242

Bhushan M, Bleiker TO, Ballsdon AE, Allen MH, Sopwith M, Robinson MK, Clarke C, Weller RP, Graham-Brown RA, Keefe M (2002): Anti-E-selectin is ineffective in the treatment of psoriasis: a randomized trial. Br J Dermatol 146(5), 824-831

Bickel M (1993): The role of interleukin-8 in inflammation and mechanisms of regulation. J Periodontol 64 (5 Suppl), 456-460

Boehncke WH, Schön MP (2015): Psoriasis. Lancet 386(9997), 983-994

Bomprezzi R (2015): Dimethyl fumarate in the treatment of relapsing-remitting multiple sclerosis: an overview. Ther Adv Neurol Disord $\underline{8}(1), 20-30$ 
Borel JF, Feurer C, Gubler HU, Stähelin H (1976): Biological effects of cyclosporin A: a new antilymphocytic agent. Agents Actions $\underline{6}$ (4), 468-475

Bowcock AM (2005): The Genetics of Psoriasis and Autoimmunity. Annu Rev Genomics Hum Genet $\underline{6}(1), 93-122$

Bowcock AM, Krueger JG (2005): Getting under the skin: the immunogenetics of psoriasis. Nat Rev Immunol $\underline{5}(9), 699-711$

Breban M, Fernández-Sueiro JL, Richardson JA, Hadavand RR, Maika SD, Hammer RE, Taurog JD (1996): T cells, but not thymic exposure to HLA-B27, are required for the inflammatory disease of HLA-B27 transgenic rats. $J$ Immunol 15;156(2), 794-803

Breuer K, Gutzmer R, Völker B, Kapp A, Werfel T (2005): Therapy of noninfectious granulomatous skin diseases with fumaric acid esters. Br J Dermatol 152(6), 1290-1295

Bunting K, Rao S, Hardy K, Woltring D, Denyer GS, Wang J, Gerondakis S, Shannon MF (2007): Genome-wide analysis of gene expression in T cells to identify targets of the NF-kappa B transcription factor c-Rel. J Immunol 178(11), 70977109

Burke SJ, Lu D, Sparer TE, Masi T, Goff MR, Karlstad MD, Collier JJ (2014): NF-kB and STAT1 control CXCL1 and CXCL2 gene transcription. Am J Physiol Endocrinol Metab 306(2), 131-149

Cabrijan L, Batinac T, Lenkovic M, Gruber F (2009): The distinction between lesional and non-lesional skin in psoriasis vulgaris through expression of adhesion molecules ICAM-1 and VCAM-1. Med Hypotheses 72(3), 327-329

Chen D, Frezza M, Schmitt S, Kanwar J, Dou QP (2011): Bortezomib as the First Proteasome Inhibitor Anticancer Drug: Current Status and Future Perspectives. Curr Cancer Drug Targets 11(3), 239-253

Cheshire JL, Baldwin AS (1997): Synergistic activation of NF-kappaB by tumor necrosis factor alpha and gamma interferon via enhanced I kappaB alpha degradation and de novo I kappaBbeta degradation. Mol Cell Biol 17(11), 6746-6754

Christophers E (1996): The immunopathology of psoriasis. Int Arch Allergy Immunol $\underline{110}(3), 199-206$

Christophers E (2001): Psoriasis-epidemiology and clinical spectrum. Clin Exp Dermatol 26 (4), 314-320

Cooper KD, Voorhees JJ, Fisher GJ, Chan LS, Gupta AK, Baadsgaard O (1990): Effects of cyclosporine on immunologic mechanisms in psoriasis. J Am Acad Dermatol $\underline{23}(6), 1318-1328$ 
Cross SA, Cook DR, Chi AW, Vance PJ, Kolson LL, Wong BJ, Jordan-Sciutto KL, Kolson DL (2011): Dimethyl fumarate, an immune modulator and inducer of the antioxidant response, suppresses HIV replication and macrophagemediated neurotoxicity; a novel candidate for HIV-neuroprotection. J immunol $\underline{187}(10), 5015-5025$

Crow JM (2012): Psoriasis uncovered. Nature 492(7429), 50-51

de Jong R, Bezemer AC, Zomerdijk TP, van de Pouw-Kraan T, Ottenhoff TH, Nibbering PH (1996): Selective stimulation of T helper 2 cytokine responses by the anti-psoriasis agent monomethylfumarate. Eur J Immunol 26 (9), 20672074

Detmar M, Brown LF, Claffey KP, Yeo KT, Kocher O, Jackman RW, Berse B, Dvorak HF (1994): Overexpression of vascular permeability factor/vascular endothelial growth factor and its receptors in psoriasis. Journal Exp Med 180(3), 11411146

Dibbert S, Clement B, Skak-Nielsen T, Mrowietz U, Rostami-Yazdi M (2013): Detection of fumarate-glutathione adducts in the portal vein blood of rats: evidence for rapid dimethylfumarate metabolism. Arch Dermatol Res 305(5), $447-451$

Di Meglio P, Perera GK, Nestle FO (2011): The multitasking organ: recent insights into skin immune function. Immunity 35(6), 857-869

Dolcet X, Llobet D, Pallares J, Matias-Guiu X (2005): NF-kB in development and progression of human cancer. Virchows Arch $\underline{446}(5), 475-482$

Duffy S, So A, Murphy TH (1998): Activation of endogenous antioxidant defenses in neuronal cells prevents free radical-mediated damage. J Neurochem $\underline{71}(1)$, $69-77$

Dustin ML, Springer TA (1988): Lymphocyte function-associated antigen-1 (LFA-1) interaction with intercellular adhesion molecule-1 (ICAM-1) is one of at least three mechanisms for lymphocyte adhesion to cultured endothelial cells. $J$ Cell Biol 107(1), 321-331

Elias PM, Arbiser J, Brown BE, Rossiter H, Man MQ, Cerimele F, Crumrine D, Gunathilake R, Choi EH, Uchida Y (2008): Epidermal vascular endothelial growth factor production is required for permeability barrier homeostasis, dermal angiogenesis, and the development of epidermal hyperplasia: implications for the pathogenesis of psoriasis. Am J Pathol 173(3), 689-699

Ellrichmann G, Petrasch-Parwez E, Lee DH, Reick C, Arning L, Saft C, Gold R, Linker RA (2011): Efficacy of Fumaric Acid Esters in the R6/2 and YAC128 Models of Huntington's Disease. PLoS One $\underline{6}(1)$, e16172

Ettehadi P, Greaves MW, Wallach D, Aderka D, Camp RD (1994): Elevated tumour necrosis factor-alpha (TNF- $\alpha$ ) biological activity in psoriatic skin lesions. Clin Exp Immunol 96(1), 146-151 
Field-Smith A, Morgan GJ, Davies FE (2006): Bortezomib (Velcade ${ }^{\mathrm{TM}}$ ) in the treatment of Multiple Myeloma. Ther Clin Risk Manag 2(3), 271-279

Forkel S, Schön M, Hildmann A, Claßen A, John SM, Danker K, Schön MP (2014): Inositoylated platelet-activating factor (Ino-C2-PAF) modulates dynamic lymphocyte-endothelial cell interactions and alleviates psoriasis-like skin inflammation in two complementary mouse models. J Invest Dermatol 134(10), 2510-2520

Fox RJ, Miller DH, Phillips JT, Hutchinson M, Havrdova E, Kita M, Yang M, Raghupathi K, Novas M, Sweetser MT (2012): Placebo-controlled phase 3 study of oral BG-12 or glatiramer in multiple sclerosis. N Engl J Med 367(12), 1087-1097

Friedrich M, Phillip S, Rincic M, Mueller C, Soos N, Hoeflich C, Sabat R, Merk H, Sterry W, Mrowietz U (2005): Anti-L-selectin therapy is not effective in psoriasis : a randomized trial. Conference paper, 35th Annual Meeting of the European-Society-for-Dermatological-Research, Volume: 125

Frohman EM, Racke MK, Raine CS (2006): Multiple Sclerosis - The plaque and its pathogenesis. N Engl J Med 354(9), 942-955

Fuhlbrigge RC, Kieffer JD, Armerding D, Kupper TS (1997): Cutaneous lymphocyte antigen is a specialized form of PSGL-1 expressed on skin-homing T cells. Nature 389(6654), 978-981

García-Caballero M, Marí-Beffa M, Medina MÁ, Quesada AR (2011):

Dimethylfumarate inhibits angiogenesis in Vitro and In Vivo: A possible role for its antipsoriatic effect? J Invest Dermatol 131(6), 1347-1355

Gardembas-Pain M , Ifrah N, Foussard C (1990): Psoriasis after allogeneic bone marrow transplantation. Arch Dermatol $\underline{126}(11), 1523$

Gelfand JM, Neimann AL, Shin DB, Wang X, Margolis DJ, Troxel AB (2006): Risk of myocardial infarction in patients with psoriasis. JAMA 296(14), 1735-1741

Gelfand JM, Troxel AB, Lewis JD, Kurd SK, Shin DB, Wang X, Margolis DJ, Strom $\mathrm{BL}$ (2007): The risk of mortality in patients with psoriasis: results from a population-based study. Arch Dermatol 143(12), 1493-1499

Gerondakis S, Grossmann M, Nakamura Y, Pohl T, Grumont R (1999): Genetic approaches in mice to understand Rel/NF-kappaB and IkappaB function: transgenics and knockouts. Oncogene 18(49), 6888-6895

Ghosh S, May MJ, Kopp EB (1998): NF-kappa B and Rel proteins: evolutionarily conserved mediators of immune responses. Annu Rev Immunol $\underline{16}$, 225-260

Gill AJ, Kolson DL (2013): Dimethyl fumarate modulation of immune and antioxidant responses: application to HIV therapy. Crit Rev Immunol 33(4), 307-359 
Gillard GO, Collette B, Anderson J, Chao J, Scannevin RH, Huss DJ, Fontenot JD (2015): DMF, but not other fumarates, inhibits NF-kB activity in vitro in an Nrf2independent manner. J Neuroimmunol $\underline{283}, 74-85$

Gillitzer R, Ritter U, Spandau U, Goebeler M, Bröcker EB (1996): Differential Expression of GRO- $\alpha$ and IL-8 mRNA Psoriasis: A model for neutrophil migration and Accumulation In Vivo. J Invest Dermatol 107(5), 778-782

Gillitzer R, Wolff K, Tong D, Müller C, Yoshimura T, Hartmann AA, Stingl G, Berger R (1993): MCP-1 mRNA expression in basal keratinocytes of psoriatic lesions. $J$ Invest Dermatol 101(2), 127-131

Gladman D, Antoni C, Mease P, Clegg D, Nash P (2005): Psoriatic arthritis: epidemiology, clinical features, course, and outcome. Ann Rheum Dis 64(Suppl 2), 14-17

Gold R, Kappos L, Arnold DL, Bar-Or A, Giovannoni G, Selmaj K, Tornatore C, Sweetser MT, Yang M, Sheikh SI (2012): Placebo-controlled phase 3 study of oral BG-12 for relapsing multiple sclerosis. N Engl J Med 367(12), 1098-1107

Goldberg AL (2003): Protein degradation and protection against misfolded or damaged proteins. Nature $\underline{426}$ (6968), 895-899

Gottlieb AB, Grossman RM, Khandke L, Carter DM, Sehgal PB, Fu SM, GranelliPiperno A, Rivas M, Barazani L, Krueger JG (1992): Studies of the Effect of Cyclosporine in Psoriasis In Vivo: Combined effects on activated T Lymphocytes and epidermal regenerative maturation. J Invest Dermatol $\underline{98}(3)$, 302-309

Greten FR, Karin M (2004): The IKK/NF-kappaB activation pathway-a target for prevention and treatment of cancer. Cancer Lett 206(2), 193-199

Griffiths CE, Barker JN (2007): Pathogenesis and clinical features of psoriasis. Lancet 370(9583), 263-271

Grossmann M, Nakamura Y, Grumont R, Gerondakis S (1999): New insights into the roles of ReL/NF-kappa B transcription factors in immune function, hemopoiesis and human disease. Int J Biochem Cell Biol 31(10), 1209-1219

Groves RW, Allen MH, Barker JNWN, Haskard DO (1991): Endothelial leucocyte adhesion molecule-1 (ELAM-1) expression in cutaneous inflammation. $\mathrm{Br} \mathrm{J}$ Dermatol 124(2), 117-123

Groves RW, Allen MH, Ross EL, Barker JNWN, MacDonald DM (1995): Tumour necrosis factor alpha is pro-inflammatory in normal human skin and modulates cutaneous adhesion molecule expression. Br J Dermatol 132(3), 345-352

Gudjonsson JE, Karason A, Antonsdottir A, Runarsdottir EH, Hauksson VB, Upmanyu R, Gulcher J, Stefansson K, Valdimarsson H (2003): Psoriasis patients who are homozygous for the $\mathrm{HLA}-\mathrm{Cw}^{*} 0602$ allele have a 2.5 -fold increased risk of developing psoriasis compared with $\mathrm{Cw} 6$ heterozygotes. $\mathrm{Br} \mathrm{J}$ Dermatol 148(2), 233-235 
Hanson J, Gille A, Offermanns S (2012): Role of $\mathrm{HCA}_{2}$ (GPR109A) in nicotinic acid and fumaric acid ester-induced effects on the skin. Pharmacol Ther 136(1), 17

Hao Q, Wang L, Tang H (2009): Vascular endothelial growth factor induces protein kinase D-dependent production of proinflammatory cytokines in endothelial cells. Am J Physiol Cell Physiol 296(4), 821-827

Harden JL, Krueger JG, Bowcock AM (2015): The immunogenetics of Psoriasis: A comprehensive review. J Autoimmun. $\underline{64}$, 66-73

Hayden MS, Ghosh S (2004): Signaling to NF-KB. Genes Dev 18(18), 2195-2224

Heinemeyer W, Fischer M, Krimmer T, Stachon U, Wolf DH (1997): The active sites of the eukaryotic $20 \mathrm{~S}$ Proteasome and their Involvement in Subunit Precursor Processing. J Biol Chem 272(40), 25200-25209

Henseler T, Christophers E (1985): Psoriasis of early and late onset: characterization of two types of psoriasis vulgaris. J Am Acad Dermatol 13(3), 450-456

Hershko A, Ciechanover A. (1998): The Ubiquitin System. Annu Rev Biochem $\underline{67}(1)$, 425-479

Hoefnagel J, Thio HB, Willemze R, Bouwes Bavinck JN (2003): Long-term safety aspects of systemic therapy with fumaric acid esters in severe psoriasis. $\mathrm{Br} \mathrm{J}$ Dermatol 149(2), 363-369

Hoffmann A, Leung TH, Baltimore D (2003): Genetic analysis of NF-kappaB/Rel transcription factors defines functional specificities. EMBO J 22(20), 55305539

Höxtermann S, Nüchel C, Altmeyer P (1998): Fumaric acid esters suppress peripheral CD4- and CD8-positive lymphocytes in psoriasis. Dermatology (Basel, Switzerland) 196(2), 223-230

Hund AC, Lockmann A, Schön MP (2016): Mutually enhancing anti-inflammatory activities of dimethyl fumarate and NF-KB inhibitors - implications for dosesparing combination therapies. Exp Dermatol $\underline{25}(2), 124-30$

lademarco MF, McQuillan JJ, Rosen GD, Dean DC (1992): Characterization of the promoter for vascular cell adhesion molecule-1 (VCAM-1). J Biol Chem $\underline{267}(23), 16323-16329$

Ismail N, Collins P, Rogers S, Kirby B, Lally A (2014): Drug survival of fumaric acid esters for psoriasis: a retrospective study. Br J Dermatol 171(2), 397-402

Kaltschmidt B, Kaltschmidt C (2009): NF-kB in the Nervous System. Cold Spring Harb Perspect Biol 1(3), a001271

Kaltschmidt C, Kaltschmidt B, Neumann H, Wekerle H, Baeuerle PA (1994):

Constitutive NF-kappa B activity in neurons. Mol Cell Biol 14(6), 3981-3992 
Kappos L, Gold R, Miller DH, Macmanus DG, Havrdova E, Limmroth V, Polman CH, Schmierer K, Yousry TA, Yang M (2008): Efficacy and safety of oral fumarate in patients with relapsing-remitting multiple sclerosis: a multicentre, randomised, double-blind, placebo-controlled phase Ilb study. Lancet $\underline{372}(9648)$, 1463-1472

Karin M, Ben-Neriah Y (2000): Phosphorylation meets ubiquitination: the control of NF-[kappa]B activity. Annu Rev Immunol 18, 621-663

Kim I, Moon SO, Kim SH, Kim HJ, Koh YS, Koh GY (2001): Vascular Endothelial Growth Factor Expression of Intercellular Adhesion Molecule 1 (ICAM-1), Vascular Cell Adhesion Molecule 1 (VCAM-1), and E-selectin through Nuclear Factor-kB Activation in Endothelial Cells. J Biol Chem 276(10), 7614-7620

Kiriakidis S, Andreakos E, Monaco C, Foxwell B, Feldmann M, Paleolog E (2003): VEGF expression in human macrophages is NF-kappaB-dependent: studies using adenoviruses expressing the endogenous NF-kappaB inhibitor IkappaBalpha and a kinase-defective form of the lkappaB kinase 2. J Cell Sci $\underline{116}(\mathrm{Pt} 4), 665-674$

Klein CL, Köhler H, Bittinger F, Wagner M, Hermanns I, Grant K, Lewis JC, Kirkpatrick CJ (1994): Comparative studies on vascular endothelium in vitro. I. Cytokine effects on the expression of adhesion molecules by human umbilical vein, saphenous vein and femoral artery endothelial cells. Pathobiology 62(4), 199-208

Klein CL, Bittinger F, Köhler H, Wagner M, Otto M, Hermanns I, Kirkpatrick CJ (1995): Comparative studies on vascular endothelium in vitro. 3. Effects of cytokines on the expression of E-selectin, ICAM-1 and VCAM-1 by cultured human endothelial cells obtained from different passages. Pathobiology $\underline{63}(2)$, 83-92

Koizumi K, Tsutsumi Y, Yoshioka Y, Watanabe M, Okamoto T, Mukai Y, Nakagawa S, Mayumi T (2003): Anti-angiogenic effects of dimethyl sulfoxide on endothelial cells. Biol Pharm Bull 26(9), 1295-1298

Kouroukis TC, Baldassarre FG, Haynes AE, Imrie K, Reece DE, Cheung MC (2014): Bortezomib in multiple myeloma: systematic review and clinical considerations. Curr Oncol 21(4), e573-e603

Kumar A, Takada Y, Boriek AM, Aggarwal BB (2004): Nuclear factor-kappaB: its role in health and disease. J Mol Med $\underline{82}(7), 434-448$

Kunsch C, Rosen CA (1993): NF-kappa B subunit-specific regulation of the interleukin-8 promoter. Mol Cell Biol 13(10), 6137-6146

Lande R, Botti E, Jandus C, Dojcinovic D, Fanelli G, Conrad C, Chamilos G, Feldmeyer L, Marinari B, Chon S, Vence L, Riccieri V, Guillaume P, Navarini AA, Romero P, Costanzo A, Piccolella E, Gilliet M, Frasca L (2014): The antimicrobial peptide LL37 is a T-cell autoantigen in psoriasis. Nat Commun $\underline{3 ; 5}, 5621$ 
Langley RGB, Krueger GG, Griffiths CEM (2005): Psoriasis: epidemiology, clinical features, and quality of life. Ann Rheum Dis $\underline{64}$ (suppl 2), 18-23

Lawrence T, Gilroy DW, Colville-Nash PR, Willoughby DA (2001): Possible new role for NF-kappaB in the resolution of inflammation. Nat Med $\underline{7}(12), 1291-1297$

Layman DL (1987): Growth inhibitory effects of dimethyl sulfoxide and dimethyl sulfone on vascular smooth muscle and endothelial cells in vitro. In Vitro Cell Dev Biol 23(6), 422-428

Lew W, Bowcock AM, Krueger JG (2004): Psoriasis vulgaris: cutaneous lymphoid tissue supports T-cell activation and „Type 1“ inflammatory gene expression. Trends Immunol 25(6), 295-305

Lin SX, Lisi L, Dello Russo C, Polak PE, Sharp A, Weinberg G, Kalinin S, Feinstein DL (2011): The anti-inflammatory effects of dimethyl fumarate in astrocytes involve glutathione and haem oxygenase-1. ASN Neuro 3(2), 00055

Litjens $\mathrm{NH}$, van Strijen E, van Gulpen C, Mattie H, van Dissel JT, Thio HB, Nibbering $\mathrm{PH}$ (2004a): In vitro pharmacokinetics of anti-psoriatic fumaric acid esters. BMC Pharmacology $\underline{4}(1), 22$

Litjens NH, Burggraaf J, van Strijen E, Van Gulpen C, Mattie H, Schoermarker RC, van Dissel JT, Thio HB, Nibbering PH (2004b): Pharmacokinetics of oral fumarates in healthy subjects. Br J Clin Pharmacol 58(4), 429-432

Liu J, Marino MW, Wong G, Grail D, Dunn A, Bettadapura J, Slavin AJ, Old L, Bernard CC (1998): TNF is a potent anti-inflammatory cytokine in autoimmune-mediated demyelination. Nat Med $\underline{4}(1), 78-83$

Lizzul PF, Aphale A, Malaviya R, Sun Y, Masud S, Dombrovskiy V, Gottlieb AB (2005): Differential expression of phosphorylated NF-kappaB/RelA in normal and psoriatic epidermis and downregulation of NF-kappaB in response to treatment with etanercept. J Invest Dermatol 124(6), 1275-1283

Lockmann A, Schön MP (2013): Phenotypic and functional traits of peripheral blood mononuclear cells retained by controlled cryopreservation: implications for reliable sequential studies of dynamic interactions with endothelial cells. Exp Dermatol 22 (5), 358-359

Lockmann, A, Schön MP (2014): TNF a-induced leukocyte-endothelial cell interactions show marked interindividual differences independent of the clinical response to adalimumab. Exp Dermatol 23(2), 133-134

Loewe R, Pillinger M, de Martin R, Mrowietz U, Gröger M, Holnthoner W, Wolff K, Wiegrebe W, Jirovsky D, Petzelbauer P (2001): Dimethylfumarate inhibits tumor-necrosis-factor-induced CD62E expression in an NF-kappa Bdependent manner. J Invest Dermatol 117(6), 1363-1368 
Loewe R, Holnthoner W, Gröger M, Pillinger M, Gruber F, Mechtcheriakova D, Hofer E, Wolff K, Petzelbauer P (2002): Dimethylfumarate inhibits TNF-induced nuclear entry of NF-kappa B/p65 in human endothelial cells. J Immunol 168(9), 4781-4787

Loewe R, Valero T, Kremling S, Pratscher B, Kunstfeld R, Pehamberger H, Petzelbauer P (2006): Dimethylfumarate impairs Melanoma growth and metastasis. Cancer Res 66(24), 11888-11896

Lorch JH, Thomas TO, Schmoll HJ (2007): Bortezomib inhibits cell-cell adhesion and cell migration and enhances epidermal growth factor receptor inhibitor-induced cell death in squamous cell cancer. Cancer Res $\underline{67}(2), 727-734$

Lowes MA, Bowcock AM, Krueger JG (2007): Pathogenesis and therapy of psoriasis. Nature $\underline{445}(7130), 866-873$

Lowes MA, Suárez-Fariñas M, Krueger JG (2014): Immunology of psoriasis. Annu Rev Immunol 32, 227-255

Ludwig H, Khayat D, Giaccone G, Facon T (2005): Proteasome inhibition and its clinical prospects in the treatment of hematologic and solid malignancies. Cancer 104(9), 1794-1807

Mak RKH, Hundhausen C, Nestle FO (2009): Progress in understanding the immunopathogenesis of psoriasis. Actas Dermosifiliogr 100 (Suppl 2), 2-13

Makgoba MW, Sanders ME, Ginther Luce GE, Dustint ML, Springer TA, Clark EA, Mannoni P, Shaw S (1988): ICAM-1 a ligand for LFA-1-dependent adhesion of B, T and myeloid cells. Nature 331(6151), 86-88

Meili-Butz S, Niermann T, Fasler-Kan E, Barbosa V, Butz N, John D, Brink M, Buser PT, Zaugg CE (2008): Dimethyl fumarate, a small molecule drug for psoriasis, inhibits Nuclear Factor-kappaB and reduces myocardial infarct size in rats. Eur J Pharmacol $\underline{586}(1-3), 251-258$

Meissner M, Doll M, Hrgovic I, Reichenbach G, König V, Hailemariam-Jahn T, Gille J, Kaufmann R (2011): Suppression of VEGFR2 expression in human endothelial cells by dimethylfumarate treatment: evidence for anti-angiogenic action. J Invest Dermatol 131(6), 1356-1364

Menter A, Griffiths CEM (2007): Current and future management of psoriasis. Lancet $\underline{370}(9583), 272-284$

Micali G, Lacarrubba F, Musumeci ML, Massimino D, Nasca MR (2010): Cutaneous vascular patterns in psoriasis. Int J Dermatol $\underline{49}(3), 249-256$

Moharregh-Khiabani D, Linker RA, Gold R, Stangel M (2009): Fumaric Acid and its Esters: An Emerging Treatment for Multiple Sclerosis. Curr Neuropharmacol $\underline{7}(1), 60-64$ 
Moorchung N, Kulaar JS, Chatterjee M, Vasudevan B, Tripathi T, Dutta V (2014): Role of NF-KB in the pathogenesis of psoriasis elucidated by its staining in

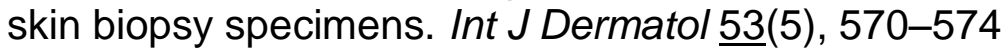

Morris A, Rogers M, Fischer G, Williams K (2001): Childhood psoriasis: a clinical review of 1262 cases. Pediatr Dermatolo 18(3), 188-198

Mrowietz U, Asadullah K (2005): Dimethylfumarate for psoriasis: more than a dietary curiosity. Trends Mol Med 11(1), 43-48.

Mrowietz U, Christophers E, Altmeyer P (1998): Treatment of psoriasis with fumaric acid esters: results of a prospective multicentre study. German Multicentre Study. Br J Dermatol 138(3), 456-460

Mrowietz U, Rostami-Yazdi M, Neureither M, Reich K (2009): 15 years of fumaderm: fumaric acid esters for the systemic treatment of moderately severe and severe psoriasis vulgaris. J Dtsch Dermatol Ges $\underline{7}$ (Suppl 2), 3-16

Murao K, Ohyama T, Imachi H, Ishida T, Cao WM, Namihira H, Sato M, Wong NC, Takahara J (2000): TNF- $\alpha$ Stimulation of MCP-1 Expression Is Mediated by the Akt/PKB Signal Transduction Pathway in Vascular Endothelial Cells. Biochem Biophys Res Comm 276(2), 791-796

Nair RP, Stuart PE, Nistor I, Hiremagalore R, Chia NV, Jenisch S, Weichenthal M, Abecasis GR, Lim HW, Christophers E (2006): Sequence and haplotype analysis supports HLA-C as the psoriasis susceptibility 1 Gene. Am J Hum Genet $\underline{78}(5), 827-851$

Nair RP, Duffin KC, Helms C, Ding J, Stuart PE, Goldgar D, Gudjonsson JE, Li Y, Tejasvi T, Feng BJ (2009): Genome-wide scan reveals association of psoriasis with IL-23 and NF-kappaB pathways. Nat Genet 41(2), 199-204

Naldi L, Parazzini F, Brevi A, Peserico A, Veller Fornasa C, Grosso G, Rossi E, Marinaro P, Polenghi MM, Finzi A (1992): Family history, smoking habits, alcohol consumption and risk of psoriasis. Br J Dermatol 127(3), 212-217

Naldi L, Peli L, Parazzini F (1999): Association of early-stage psoriasis with smoking and male alcohol consumption: Evidence from an italian case-control study. Arch Dermatol 135(12), 1479-1484

Naldi L, Chatenoud L, Linder D, Belloni Fortina A, Peserico A, Virgili AR, Bruni PL, Ingordo V, Lo Scocco G, Solaroli C (2005): Cigarette Smoking, Body Mass Index, and Stressful Life Events as Risk Factors for Psoriasis: Results from an Italian Case-Control Study. J Invest Dermatol 125(1), 61-67

Nast A, Boehncke WH, Mrowietz U, Ockenfels HM, Philipp S, Reich K, Rosenbach T, Sammain A, Schlaeger M, Sebastian M (2012a): German S3-guidelines on the treatment of psoriasis vulgaris (short version). Arch Dermatol Res 304(2), 87113 
Nast A, Boehncke WH, Mrowietz U, Ockenfels HM, Philipp S, Reich K, Rosenbach T, Sammain A, Schlaeger M, Sebastian M (2012b): S3 - Guidelines on the treatment of psoriasis vulgaris (English version). Update. JDDG: J Dtsch Dermatol Ges 10 (suppl 2), 1-95

Naujokat C, Hoffmann S (2002): Role and Function of the 26S Proteasome in

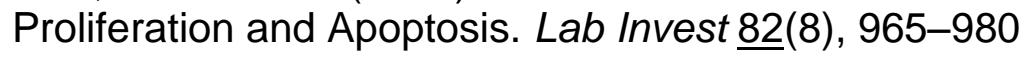

Navikas V, Link H (1996): Review: cytokines and the pathogenesis of multiple sclerosis. J Neurosci Res $\underline{45}$ (4), 322-333

Nestle FO, Turka LA, Nickoloff BJ (1994): Characterization of dermal dendritic cells in psoriasis. Autostimulation of T lymphocytes and induction of Th1 type cytokines. J Clin Invest 94(1), 202-209

Nestle FO, Kaplan DH, Barker J (2009): Psoriasis. N Engl J Med 361(5), 496-509

Nickoloff BJ, Karabin GD, Barker JN, Griffiths CE, Sarma V, Mitra RS, Elder JT, Kunkel SL, Dixit VM (1991): Cellular localization of interleukin-8 and its inducer, tumor necrosis factor-alpha in psoriasis. Am J Pathol 138(1), 129-140

Nickoloff BJ, Schröder JM, von den Driesch P, Raychaudhuri SP, Farber EM, Boehncke WH, Morhenn VB, Rosenberg EW, Schön MP, Holick MF (2000): Is psoriasis a T-cell disease? Exp Dermatol $\underline{9}$ (5), 359-375

Nieboer C, de Hoop D, van Loenen AC, Langendijk PN, van Dijk E (1989): Systemic therapy with fumaric acid derivates: new possibilities in the treatment of psoriasis. J Am Acad Dermatol 20(4), 601-608

Nieboer C, de Hoop D, Langendijk PN, van Loenen AC, Gubbels J (1990): Fumaric acid therapy in psoriasis: a double-blind comparison between fumaric acid compound therapy and monotherapy with dimethylfumaric acid ester. Dermatologica 181(1), 33-37

Nograles KE, Davidovici B, Krueger JG (2010): New insights in the immunologic basis of psoriasis. Semin Cutan Med Sur 29(1), 3-9

Nugteren-Huying WM, van der Schroeff JG, Hermans J, Suurmond D (1990): Fumaric acid therapy for psoriasis: a randomized, double-blind, placebocontrolled study. J Am Acad Dermatol 22(2 Pt 1), 311-312

Ockenfels HM, Schultewolter T, Ockenfels G, Funk R, Goos M (1998): The antipsoriatic agent dimethylfumarate immunomodulates $T$-cell cytokine secretion and inhibits cytokines of the psoriatic cytokine network. $\mathrm{Br} \mathrm{J}$ Dermatol 139(3), 390-395

O'Neill T, Silman AJ (1994): Psoriatic arthritis. Historical background and epidemiology. Baillière's Clin Rheumatol $\underline{8}(2), 245-261$ 
Oostingh GJ, Schlickum S, Friedl P, Schön MP (2007): Impaired induction of adhesion molecule expression in immortalized endothelial cells leads to functional defects in dynamic interactions with lymphocytes. J Invest Dermatol 127(9), 2253-2258

Osawa Y, Nagaki M, Banno Y, Brenner DA, Asano T, Nozawa Y, Moriwaki H, Nakashima S (2002): Tumor Necrosis Factor Alpha-Induced Interleukin-8 Production via NF-kB and Phosphatidylinositol 3-Kinase/Akt Pathways inhibits cell apoptosis in Human Hepatocytes. Infect Immun 70(11), 6294-6301

Owens R, Ball E, Ganesh R, Nesbitt A, Brown D, Gofton C, Stephens S, Chaplin L, Christofidou-Solomidou M, Blake S (1997): The in vivo and in vitro characterisation of an engineered human antibody to E-selectin. Immunotechnology $\underline{3}(2), 107-116$

Pahler JC, Krupnik Y, Keating M, Chandra J, Palladino M, McConkey D (2003): Effects of the proteasome inhibitor, bortezomib, on apoptosis in isolated lymphocytes obtained from patients with chronic lymphocytic leukemia. Clin Cancer Res $\underline{9}(12), 4570-4577$

Peng H, Guerau-de-Arellano M, Mehta VB, Yang Y, Huss DJ, Papenfuss TL, LovettRacke AE, Racke MK (2012): Dimethyl Fumarate Inhibits Dendritic Cell Maturation via Nuclear Factor kB (NF-kB) and Extracellular Signal-regulated Kinase 1 and 2 (ERK1/2) and Mitogen Stress-activated Kinase 1 (MSK1) Signaling. J Biol Chem 287(33), 28017-28026

Phillips JT, Fox RJ (2013): BG-12 in multiple sclerosis. Semin Neurol 33(1), 56-65

Piperdi B, Ling YH, Liebes L, Muggia F, Perez-Soler R (2011): Bortezomib: Understanding the Mechanism of Action. Mol Cancer Ther 10(11), 2029-2030

Piva R, Belardo G, Santoro MG (2006): NF-kB: A Stress-Regulated Switch for Cell Survival. Antioxid Redox Signal $\underline{8}(3-4)$, 478-486

Poikolainen K, Reunala T, Karvonen J (1994): Smoking, alcohol and life events related to psoriasis among women. Br J Dermatol 130(4), 473-477

Poulaki V, Mitsiades CS, Kotoula V, Negri J, McMillin D, Miller JW, Mitsiades N (2007): The proteasome inhibitor bortezomib induces apoptosis in human retinoblastoma cell lines in vitro. Invest Ophthalmol Vis Sci 48(10), 4706-4719

Raffler NA, Rivera-Nieves J, Ley K (2005): L-selectin in inflammation, infection and immunity. Drug Discov Today Ther Strateg 2(3), 213-220

Rayet B, Gélinas C (1999): Aberrant rel/nfkb genes and activity in human cancer. Oncogene 18(49), 6938-6947

Read MA, Whitley MZ, Williams AJ, Collins T (1994): NF-kappa B and I kappa B alpha: an inducible regulatory system in endothelial activation. $J$ Exp Med $\underline{179}(2), 503-512$ 
Reece D, Imrie K, Stevens A, Smith CA (2006): Bortezomib in multiple myeloma and lymphoma: a systematic review and clinical practice guideline. Curr Oncol $\underline{13}(5), 160-172$

Reich K, Mössner R, König IR, Westphal G, Ziegler A, Neumann C (2002): Promoter polymorphisms of the genes encoding tumor necrosis factor-alpha and interleukin-1 beta are associated with different subtypes of psoriasis characterized by early and late disease onset. J Invest Dermatol 118(1), 155163

Richards HL, Fortune DG, O'Sullivan TM, Main CJ, Griffiths CE (1999): Patients with psoriasis and their compliance with medication. J Am Acad Dermatol 41(4), $581-583$

Richards HL, Fortune DG, Griffiths CEM (2006): Adherence to treatment in patients with psoriasis. J Eur Acad Dermatol Venereol 20(4), 370-379

Roccaro AM, Hideshima T, Raje N, Kumar S, Ishitsuka K, Yasui H, Shiraishi N, Ribatti D, Nico B, Vacca A (2006): Bortezomib mediates Antiangiogenesis in Multiple Myeloma via direct and indirect effects on Endothelial Cells. Cancer Res 66(1), 184-191

Rostami-Yazdi M, Clement B, Schmidt TJ, Schinor D, Mrowietz U (2008): Detection of metabolites of Fumaric Acid Esters in human urine: Implications for their mode of action. J Invest Dermatol 129(1), 231-234

Rostami-Yazdi M, Clement B, Mrowietz U (2010): Pharmacokinetics of anti-psoriatic fumaric acid esters in psoriasis patients. Arch Dermatol Res 302(7), 531-538

Rubant SA, Ludwig RJ, Diehl S, Hardt K, Kaufmann R, Pfeilschifter JM, Boehncke WH (2008): Dimethylfumarate reduces leukocyte rolling in vivo through modulation of adhesion molecule expression. J Invest Dermatol 128(2), 326331

Scannevin RH, Chollate S, Jung MY, Shackett M, Patel H, Bista P, Zeng W, Ryan S, Yamamoto M, Lukashev M (2012): Fumarates promote cytoprotection of central nervous system cells against oxidative stress via the nuclear factor (erythroid-derived 2)-like 2 pathway. J Pharmacol Exp Ther 341(1), 274-284

Schindler U, Baichwal VR (1994): Three NF-kappa B binding sites in the human Eselectin gene required for maximal tumor necrosis factor alpha-induced expression. Mol Cell Biol 14(9), 5820-5831

Schmidt TJ, Muharrem AK, Mrowietz U(2007): Reactivity of dimethyl fumarate and methylhydrogen fumarate towards glutathione and $\mathrm{N}$-acetyl-L-cysteinepreparation of S-substituted thiosuccinic acid esters. Bioorg Med Chem 15(1), 333-342 
Schmitt-Egenolf M, Eiermann TH, Boehncke WH, Ständer M, Sterry W (1996):

Familial Juvenile Onset Psoriasis Is Associated with the Human Leukocyte Antigen (HLA) Class I side of the Extended Haplotype Cw6-B57-DRB1 ${ }^{*} 0701$ DQA1*0201-DQB1*0303: A Population- And Family-Based Study. J Invest Dermatol 106(4), 711-714

Schön MP (2005): Inhibitors of selectin functions in the treatment of inflammatory skin disorders. Ther Clinical Risk Manag 1(3), 201-208

Schön MP (2008): Animal models of psoriasis: A critical appraisal. Exp Dermatol 17(8), 703-12

Schön MP, Ruzicka T (2001): Psoriasis: the plot thickens . . Nat Immunol $\underline{2}(2), 91-$ 91

Schön MP, Boehncke WH (2005): Psoriasis. N Engl J Med 352(18), 1899-1912

Schön MP, Detmar M, Parker CM (1997): Murine psoriasis-like disorder induced by naive CD4+ T cells. Nat Med $\underline{3}(2), 183-8$

Schön MP, Zollner TM, Boehncke WH (2003): The molecular basis of lymphocyte recruitment to the skin: clues for pathogenesis and selective therapies of inflammatory disorders. J Invest Dermatol 121(5), 951-962

Schön M, Wienrich BG, Kneitz S, Sennefelder H, Amschler K, Vöhringer V, Weber O, Stiewe T, Ziegelbauer K, Schön MP (2008): KINK-1, a novel small-molecule inhibitor of IKKbeta, and the susceptibility of melanoma cells to antitumoral treatment. J Natl Cancer Inst 100(12), 862-875

Seidel P, Roth M (2013): Anti-inflammatory dimethylfumarate: a potential new therapy for asthma? Mediators Inflamm Volume 2013, Article ID 875403 online

Seidel P, Merfort I, Hughes JM, Oliver BG, Tamm M, Roth M (2009):

Dimethylfumarate inhibits NF-kappaB function at multiple levels to limit airway smooth muscle cell cytokine secretion. Am J Physiol Lung Cell Mol Physiol $\underline{297}(2), 326-339$

Sen R, Baltimore D (1986): Multiple nuclear factors interact with the immunoglobulin enhancer sequences. Cell $\underline{46}(5), 705-716$

Shibata A, Nagaya T, Imai T, Funahashi H, Nakao A, Seo H (2002): Inhibition of NFkappaB activity decreases the VEGF mRNA expression in MDA-MB-231 breast cancer cells. Breast Cancer Res Treat 73(3), 237-243

Shieh JM, Tsai YJ, Tsou CJ, Wu WB (2014): CXCL1 Regulation in Human Pulmonary Epithelial Cells by Tumor Necrosis Factor. Cell Physiol Biochem 34(4), 1373-1384

Shimizu Y, Newman W, Gopal TV, Horgan KJ, Graber N, Beall LD, van Seventer GA, Shaw S (1991): Four molecular pathways of T cell adhesion to endothelial cells: roles of LFA-1, VCAM-1, and ELAM-1 and changes in pathway hierarchy under different activation conditions. J Cell Biol 113(5), 1203-1212 
Siebenlist U, Franzoso G, Brown K (1994): Structure, regulation and function of NFkappa B. Annu Rev Cell Biol 10, 405-455

Slavin A, Kelly-Modis L, Labadia M, Ryan K, Brown ML (2010): Pathogenic mechanisms and experimental models of multiple sclerosis. Autoimmunity $\underline{43}(7), 504-513$

Sommer DM, Jenisch S, Suchan M, Christophers E, Weichenthal M (2006): Increased prevalence of the metabolic syndrome in patients with moderate to severe psoriasis. Arch Dermatol Res 298(7), 321-328

Steinman L (2001): Multiple sclerosis: a two-stage disease. Nat Immunol $\underline{2}(9), 762-$ 764

Sticherling M, Sautier W, Schröder JM, Christophers E (1999): Interleukin-8 plays its role at local level in psoriasis vulgaris. Acta Derm Venereol $\underline{79}(1), 4-8$

Stoof TJ, Flier J, Sampat S, Nieboer C, Tensen CP, Boorsma DM (2001): The antipsoriatic drug dimethylfumarate strongly suppresses chemokine production in human keratinocytes and peripheral blood mononuclear cells. $\mathrm{Br} J$ Dermatol $\underline{144}(6), 1114-1120$

Suárez-Fariñas M, Li K, Fuentes-Duculan J, Hayden K, Brodmerkel C, Krueger JG (2012): Expanding the psoriasis disease profile: interrogation of the skin and serum of patients with moderate-to-severe psoriasis. J Invest Dermatol 132(11), 2552-2564

Szepietowski J, Wasik F, Bielicka E, Nockowski P, Noworolska A (1999): Soluble Eselectin serum levels correlate with disease activity in psoriatic patients. Clin Exp Dermatol 24(1), 33-36

Tamura D, Arao T, Tanaka K, Kaneda H, Matsumoto K, Kudo K, Aomatsu K, Fujita Y, Watanabe T, Saijo N (2010): Bortezomib potentially inhibits cellular growth of vascular endothelial cells through suppression of G2/M transition. Cancer Sci 101(6), 1403-1408

Tedder TF, Penta AC, Levine HB, Freedman AS (1990): Expression of the human leukocyte adhesion molecule, LAM1. Identity with the TQ1 and Leu-8 differentiation antigens. J Immunol 144(2), 532-540

Tedder TF, Steeber DA, Chen A, Engel P (1995): The selectins: vascular adhesion molecules. FASEB J $\underline{9}(10), 866-873$

Telfer NR, Chalmers RJ, Whale K, Colman G (1992): The role of streptococcal infection in the initiation of guttate psoriasis. Arch Dermatol 128(1), 39-42

Thorp KM, Southern C, Bird IN, Matthews N (1992): Tumour necrosis factor induction of ELAM-1 and ICAM-1 on human umbilical vein endothelial cells--analysis of tumour necrosis factor-receptor interactions. Cytokine 4(4), 313-319 
Tong Q, Zheng L, Lin L, Bo L, Wang D, Huang C, Li D (2006): VEGF is upregulated by hypoxia-induced mitogenic factor via the PI-3K/Akt-NF-KB signaling pathway. Respir Res $\underline{7}(1), 37$

Treumer F, Zhu K, Gläser R, Mrowietz U (2003): Dimethylfumarate Is a Potent Inducer of Apoptosis in Human T Cells. J Invest Dermatol 121(6), 1383-1388

Tsang YT, Neelamegham S, Hu Y, Berg EL, Burns AR, Smith CW, Simon SI (1997): Synergy between L-selectin signaling and chemotactic activation during neutrophil adhesion and transmigration. J Immunol 159(9), 4566-4577

Tsianakas A, Herzog S, Landmann A, Patsinakidis N, Perusquía Ortiz AM, Bonsmann G, Luger TA, Kuhn A (2014): Successful treatment of discoid lupus erythematosus with fumaric acid esters. J Am Acad Dermatol 71(1), 15-17

Tu L, Chen A, Delahunty MD, Moore KL, Watson SR, McEver RP, Tedder TF (1996): L-selectin binds to P-selectin glycoprotein ligand-1 on leukocytes: interactions between the lectin, epidermal growth factor, and consensus repeat domains of the selectins determine ligand binding specificity J Immunol 157(9), 39954004

Ueda A, Okuda K, Ohno S, Shirai A, Igarashi T, Matsunaga K, Fukushima J, Kawamoto S, Ishigatsubo Y, Okubo T (1994): NF-kappa B and Sp1 regulate transcription of the human monocyte chemoattractant protein-1 gene. $J$ Immunol 153(5), 2052-2063

Vandermeeren M, Janssens S, Borgers M, Geysen J (1997): Dimethylfumarate is an inhibitor of cytokine-induced E-selectin, VCAM-1, and ICAM-1 expression in human endothelial cells. Biochem Biophys Res Commun 234(1), 19-23

Vandermeeren M, Janssens S, Wouters H, Borghmans I, Borgers M, Beyaert R, Geysen J (2001): Dimethylfumarate is an inhibitor of cytokine-induced nuclear translocation of NF-kappa B1, but not RelA in normal human dermal fibroblast cells. J Investig Dermatol 116(1), 124-130

Venten I, Hess N, Hirschmüller A, Altmeyer P, Brockmeyer N (2006): Treatment of therapy-resistant Alopecia areata with fumaric acid esters. Eur $\mathrm{J}$ Med Res 11(7), 300

Wallbrecht K, Drick N, Hund AC, Schön MP (2011): Downregulation of endothelial adhesion molecules by dimethylfumarate, but not monomethylfumarate, and impairment of dynamic lymphocyte-endothelial cell interactions. Exp Dermatol 20(12), 980-985

Wang L, Yang L, Gao L, Gao TW, Li W, Liu YF (2008): A functional promoter polymorphism in monocyte chemoattractant protein-1 is associated with psoriasis. Int J Immunogenet 35(1), 45-49

Weinstein GD, McCullough JL, Ross P (1984): Cell proliferation in normal epidermis. J Invest Dermatol 82(6), 623-628 
Werdenberg D, Joshi R, Wolffram S, Merkle HP, Langguth P (2003) Presystemic metabolism and intestinal absorption of antipsoriatic fumaric acid esters. Biopharm Drug Dispos 24(6), 259-273

Wollina U (2011): Fumaric acid esters in dermatology. Indian Dermatol Online J $\underline{2}(2)$, $111-119$

Yamazoe Y, Tsubaki M, Matsuoka H, Satou T, Itoh T, Kusunoki T, Kidera Y, Tanimori Y, Shoji K, Nakamura H, Ogaki M (2009): Dimethylfumarate inhibits tumor cell invasion and metastasis by suppressing the expression and activities of matrix metalloproteinases in melanoma cells. Cell Biol Int $\underline{33}$ (10), 1087-1094

Yates VM, Watkinson G, Kelman A (1982): Further evidence for an association between psoriasis, Crohn's disease and ulcerative colitis. Br J Dermatol 106(3), 323-330

Zachariae H (2012): Prevalence of Joint Disease in Patients with Psoriasis. Am J Clin Dermatol 4 (7), 441-447

Zaghloul SS, Goodfield MJD (2004): Objective assessment of compliance with psoriasis treatment. Arch Dermatol 140(4), 408-414

Zhu K, Mrowietz U (2001): Inhibition of Dendritic Cell Differentiation by Fumaric Acid Esters. J Investig Dermatol 116(2), 203-208

Zollner TM, Podda M, Pien C, Elliott PJ, Kaufmann R, Boehncke WH (2002):

Proteasome inhibition reduces superantigen-mediated $T$ cell activation and the severity of psoriasis in a SCID-hu model. J Clin Invest 109(5), 671-9 
Ergebnisse dieser Arbeit wurden bereits in folgenden Publikationen veröffentlicht:

Hund AC, Lockmann A, Schön MP (2016): Mutually enhancing anti-inflammatory activities of dimethyl fumarate and NF-KB inhibitors - implications for dose-sparing combination therapies. Exp Dermatol 25(2), 124-30

(Die Verwendung von Abbildung 6, 17, 19, 20, 21, 22 und 23 erfolgte mit freundlicher Genehmigung des Verlags John Wiley \& Sons A/S.)

Mrowietz $\mathrm{U}$, Altmeyer $\mathrm{P}$, Augustin $\mathrm{M}$, Boehncke $\mathrm{WH}$, Bonnekoh B, Frambach $\mathrm{Y}$, Gambichler T, Ghoreschi K, Hertl M, Hund AC, Jacobi A, Kuhn A, Ludwig RJ, Luger T, Martin SF, Merk H, Norgauer J, Reich K, Rostami-Yazdi M, Sabat R, Schäkel K, Scharffetter-Kochanek K, Schön MP, Scola N, Sticherling M, Thaci D, WilsmannTheis D, Viehweg A, Wozel G, Zouboulis CC, Neureither M (2012): New insights into fumaric acid esters (Fumaderm $\AA$ ):results of the 2nd Expert Workshops. J Dtsch Dermatol Ges 10 (Suppl 8), 1-15 


\section{Veröffentlichte Arbeiten:}

Wallbrecht K, Drick N, Hund AC, Schön MP (2011): Downregulation of endothelial adhesion molecules by dimethylfumarate, but not monomethylfumarate, and impairment of dynamic lymphocyte-endothelial cell interactions. Exp Dermatol $\underline{20}(12)$, 980-985

Mrowietz $\mathrm{U}$, Altmeyer $\mathrm{P}$, Augustin $\mathrm{M}$, Boehncke $\mathrm{WH}$, Bonnekoh B, Frambach $\mathrm{Y}$, Gambichler T, Ghoreschi K, Hertl M, Hund AC, Jacobi A, Kuhn A, Ludwig RJ, Luger T, Martin SF, Merk H, Norgauer J, Reich K, Rostami-Yazdi M, Sabat R, Schäkel K, Scharffetter-Kochanek K, Schön MP, Scola N, Sticherling M, Thaci D, WilsmannTheis D, Viehweg A, Wozel G, Zouboulis CC, Neureither M (2012): New insights into fumaric acid esters (Fumaderm $\AA$ ):results of the 2nd Expert Workshops. J Dtsch Dermatol Ges $\underline{10}$ (Suppl 8), 1-15

Sadeghi H, Lockmann A, Hund AC, Samavedam UK, Pipi E, Vafia K, Hauenschild E, Kalies K, Pas HH, Jonkman MF, Iwata H, Recke A, Schön MP, Zillikens D, Schmidt E, Ludwig RJ (2015): Caspase-1-independent IL-1 release mediates blister formation in autoantibody-induced tissue injury through modulation of endothelial adhesion molecules. J Immunol 15;194(8), 3656-63

Hund AC, Lockmann A, Schön MP (2016): Mutually enhancing anti-inflammatory activities of dimethyl fumarate and NF-KB inhibitors - implications for dose-sparing combination therapies. Exp Dermatol $\underline{25}(2), 124-130$ 


\section{Danksagung}

Abschließend möchte ich mich bei den Menschen bedanken, die zum erfolgreichen Abschluss dieser Arbeit beigetragen haben.

Mein besonderer Dank gilt Herrn Prof. Dr. med. M. P. Schön, ohne dessen Ideen, Ratschläge und natürlich auch den Materialien im Labor diese Arbeit nicht zustande gekommen wäre. Vielen Dank vor allem für Ihre freundliche und motivierende Art. Ebenfalls danken möchte ich Frau Dr. med. A. Lockmann für die Einarbeitung an der Bench, die vielen fachlichen Diskussionen sowie all die schönen Stunden die wir nicht nur im Labor miteinander verbracht haben und verbringen.

Vielen Dank vor allem auch an Dr. rer. nat. V. Lorenz, Dr. rer. nat. N. Pletz und Dr. med. K. Amschler für ihre hilfreichen Tipps und Anleitungen. Ebenso ein großes Dankeschön an K. Zachmann, A. Bennemann und B. Messerschmidt, die das Labor am Laufen halten.

Insgesamt danke ich der gesamten Arbeitsgruppe Schön für den freundlichen Empfang und die gemeinsamen Jahre, die ich trotz aller Rückschläge, nicht missen möchte. 